\title{
Contractile Performance and Energy Utilization of Skeletal Muscle; Creatine Kinase and Acto-myosin ATPase
}

\author{
by \\ Jason Alexander Melnyk \\ Dissertation submitted to the faculty of the Virginia Polytechnic Institute and State \\ University in partial fulfillment of the requirements for the degree of

\section{Doctor of Philosophy} \\ In
}

\section{The Department of Human Nutrition, Foods \& Exercise}

Committee:

Jay H. Williams, Chair

Kevin P. Davy

David M. Moore

William E. Newton

Janet W. Rankin

January 23, 2008

Blacksburg, VA

Keywords: contractile performance, muscle energetics 


\begin{abstract}
Creatine kinase $(\mathrm{CK})$ primarily serves as an energy buffer assisting in regulating ATP homeostasis through synthesis of ATP from ADP and phosphocreatine (PCr). This enzyme is bound in the sarcomere near sites of ATP consumption via acto-myosin ATPase (A-M.ATPase) and research in cardiac muscle has found that $\mathrm{PCr}$ can alter contractile performance (maximal isometric force and $\mathrm{Ca}^{2+}$ sensitivity). Based on this evidence, CK and A-M.ATPase may be coupled in skeletal muscle. Therefore the purpose of this investigation was to determine the influence of the CK system on contractile performance and energy utilization in skeletal muscle.

When skinned fibers (membrane removed) were provided a limited supply of [ATP] $(0.1 \mathrm{mM})$, this resulted in increased $\mathrm{Ca}^{2+}$ sensitivity. The addition of PCr to low ATP solutions restored $\mathrm{Ca}^{2+}$ sensitivity and allowed normal isometric force generation across a range of $\left[\mathrm{Ca}^{2+}\right]$ via ATP synthesis by $\mathrm{CK}$. This was also possible with only $\mathrm{CK}$ reaction substrates (ADP, PCr) in the absence of ATP. Based on these findings, endogenous $\mathrm{CK}$ activity in glycerol skinned skeletal muscle fibers is sufficient to permit normal function of the contractile apparatus.

Energy utilization was studied by indirect assessment of ADP production. Decreased net ADP production as measured by NADH fluorescence revealed endogenous CK was able to convert ADP produced by A-M.ATPase to ATP in skeletal muscle across a range of both $\left[\mathrm{Ca}^{2+}\right]$ and $[\mathrm{ATP}]$. This was confirmed directly via high-performance liquid chromatography measurements of ATP and ADP by showing that skinned skeletal muscle bundles have sufficient endogenous $\mathrm{CK}$ activity to produce ATP from substrates (ADP, PCr) and the ability to maintain low [ADP] in the presence of PCr.
\end{abstract}

This study adds to the evidence for specific compartmentation of CK near sites of ATP utilization and contributes to the body of knowledge on contractile performance in skinned skeletal muscle fibers. By showing how changing demands on skeletal muscle (through increased $\mathrm{Ca}^{2+}$ ) alters force production and $\mathrm{Ca}^{2+}$ sensitivity, these findings lend support for the importance of endogenous CK as a pathway of ATP regeneration in skeletal muscle. 


\section{DEDICATION}

I dedicate this work to my fiancé Julia Engstrom. Her patience and understanding, love and support were a tremendous influence in completing this work. I would also like to dedicate this to my parents, Stephen \& Susan Melnyk for providing me the opportunity to pursue my dreams. 


\section{ACKNOWLEDGEMENTS}

This work would not have been possible without the assistance from my advisor and mentor, Jay Williams. I would also like to thank the gracious assistance from my committee members for providing insightful questions and valuable feedback on the revisions of this document.

There were also numerous others who assisted me in completing this work. Laboratory assistance with HPLC was kindly provided by Janet Rinehart. I am extremely grateful for chemical supplies provided by Carolyn Smith and Dr. Kathy Reynolds. This work would also not have been possible if not for the kind assistance of Dr. Hongwei Si and Dr. Dongmin Liu as well as the technicians at the Laboratory Animal Resources, especially Dave Gemmell.

Lastly, I would like to thank the entire HNFE Department, especially Sherry Saville and Sherry Terry as well as my fellow graduate students, Mary Pat Meany, Beth Abbey, Kevin Voelker, Jeremy Akers and Nick Evans. 


\section{TABLE OF CONTENTS}

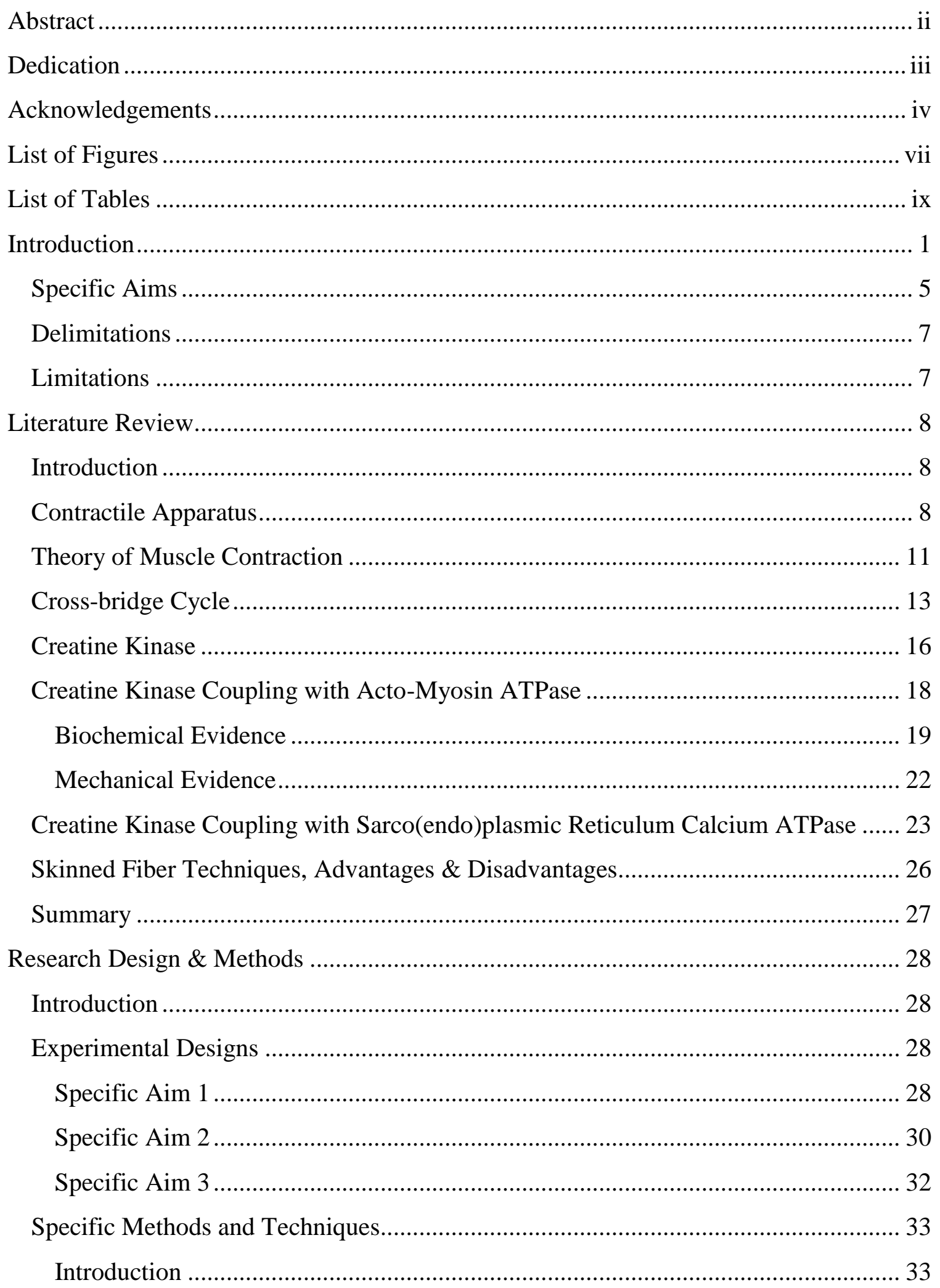




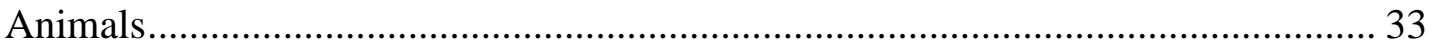

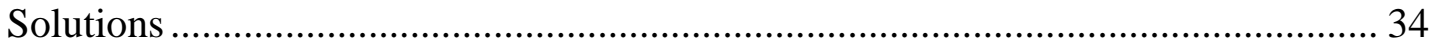

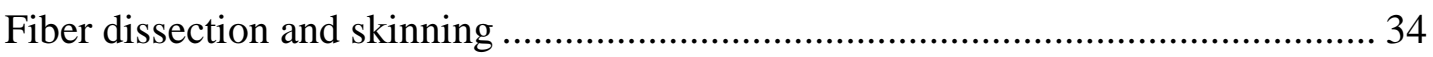

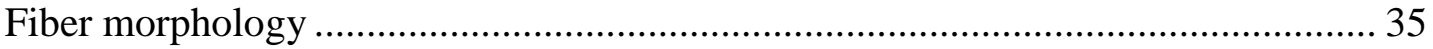

Force and rate of change in ADP measurements .................................................. 35

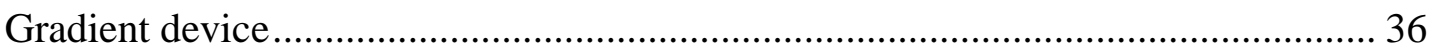

High-Performance Liquid Chromatography (HPLC) …........................................ 37

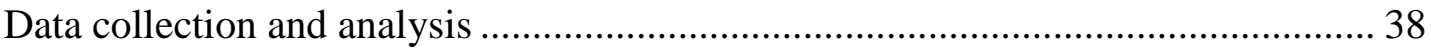

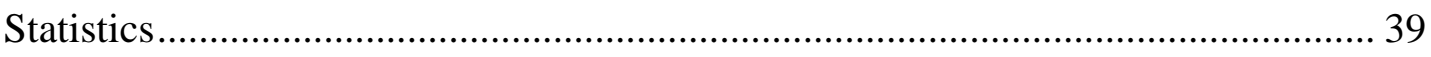

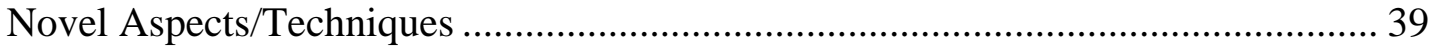

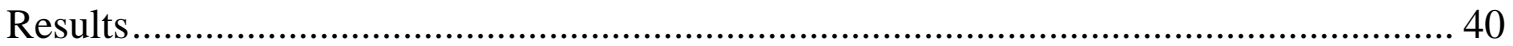

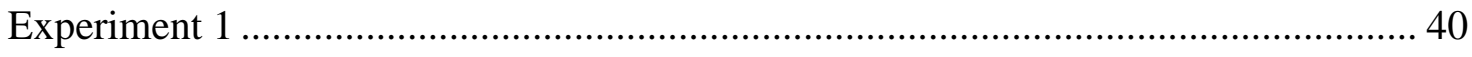

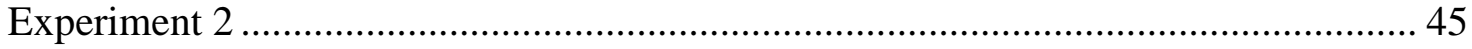

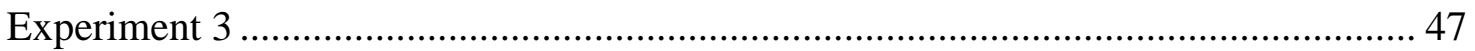

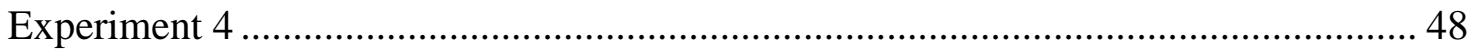

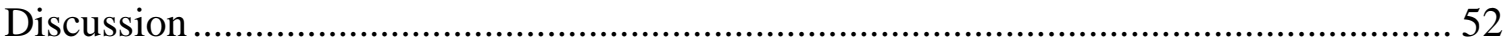

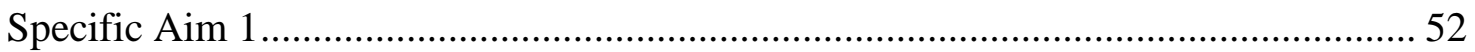

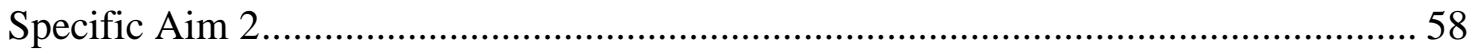

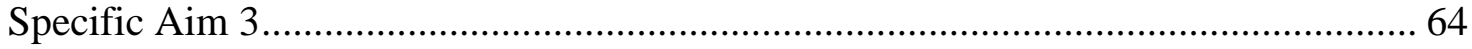

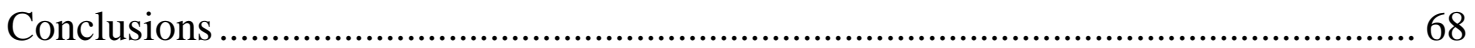

Recommendations for Future Research ...................................................... 70

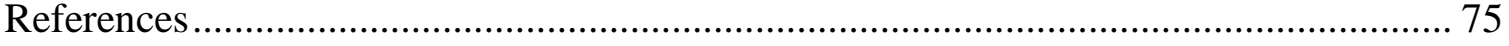

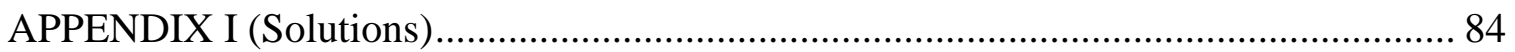

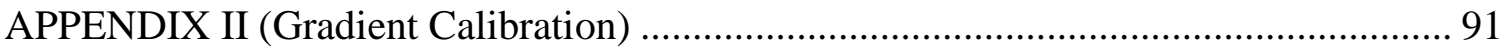

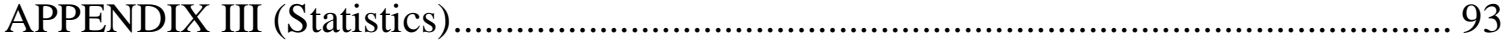

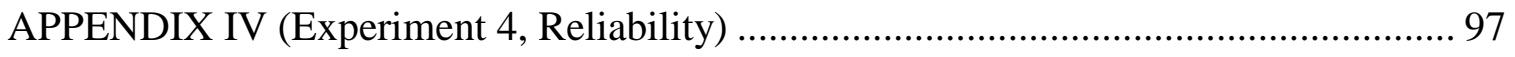

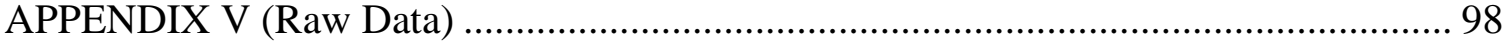




\section{List of Figures}

Figure $\quad \underline{\text { Caption }} \quad \underline{\text { Page }}$

Figure 1. The relationship between force and free $\left[\mathrm{Ca}^{2+}\right]$. Relative force is calculated as $\mathrm{F} / \mathrm{F}_{\max }$. 2

Figure 2. Proposed functional coupling between CK and A-M.ATPase. 3

Figure 3. Picture of a myofibril, one sarcomere, and the proteins myosin and actin.

Figure 4. Schematic of the biochemical cross-bridge cycle and mechanical events as described by Lymn \& Taylor (1971).

Figure 5. Six-state model depicting strong and weak binding states of $\mathrm{A}=$ Actin and $\mathrm{M}=$ Myosin. Adapted from Stein, 1995.

Figure 6. Two pathways for ADP. Pathway 1, ADP is recycled and converted to ATP by CK. Pathway 2, ADP is converted to pyruvate by pyruvate kinase (PK) and then converted to lactate by lactate dehydrogenase (LDH) resulting in a decrease in $\mathrm{NADH}$. If pathway 1 occurs, there will be a smaller decline in NADH.

Figure 7. Effects of Metabolites at Low [ATP] on EDL Fibers. 42

Figure 8. Effects of Metabolites on EDL Fibers at High and Low [ATP] 42

Figure 9. Effects of Metabolites on EDL and Soleus Fibers 43

Figure 10. Differences Between $\mathrm{pCa}_{50}$ Values of the 2 ATP Condition Versus All Others. Values are differences between $\mathrm{pCa}_{50}$ of the 2 ATP condition minus $\mathrm{pCa}_{50}$ of condition listed on the $\mathrm{x}$-axis. Low $=0.1 \mathrm{mM}$ ATP and high $=2 \mathrm{mM}$ ATP.

Figure 11. Raw tracings of NADH fluorescence decay at different $\left[\mathrm{Ca}^{2+}\right]$ without (-) and with (+) PCr at $2 \mathrm{mM}$ ATP.

Figure 12. Change in NADH slope fluorescence decay at high and low $\mathrm{Ca}^{2+}$ in EDL and soleus muscle fibers. Values are slope in $\mu \mathrm{M} / \mathrm{sec}$. Low [ATP] indicates an [ATP] of $0.1 \mathrm{mM}$ whereas high indicates $2 \mathrm{mM}$. (-) Without PCr, (+) With PCr (10 mM concentration).

Figure 13. Slope change across an ATP gradient at high $\left[\mathrm{Ca}^{2+}\right]$. Values are slope in $\mu \mathrm{M} / \mathrm{sec}$. Lines labeled $+\mathrm{PCr}$ contain $10 \mathrm{mM}$ of $\mathrm{PCr}$.

Figure 14. Force change across an ATP gradient at high $\left[\mathrm{Ca}^{2+}\right]$.

Figure 15. Effects of ATP and ADP on gapp. WB = weak binding state, SB $=$ strong binding state. 
Figure 16. Schematic of the Güth Muscle Research System.

Figure 17. Cross bridge cycle and creatine kinase in skeletal muscle adapted from Ventura-Clapier et al. 1994. A=Actin. M=Myosin. $\mathrm{CK}=$ Creatine Kinase. $\mathrm{Cr}=$ Creatine. $\mathrm{PCr}=\mathrm{Phosphocreatine.} \mathrm{A} \mathrm{"."}$ denotes a bound state. Bold indicates cross-bridge in strongly bound state. Italics indicates weakly bound state.

Figure 18. Calibration results. Measured and calculated $\mathrm{pCa}$ values vs. pump step (top). Measured pCa vs. calculated pCa (bottom). 


\section{List of Tables}

Table

$\underline{\text { Page }}$

Table 1. Concentrations (in $\mathrm{mM}$ ) of solutions for experiment 1

Table 2. Concentrations (in $\mathrm{mM}$ ) of solutions for experiment 2

Table 3. Concentrations (in $\mathrm{mM}$ ) of solutions for experiment 4 in high ( $\mathrm{pCa}$ 4.0) and low ( $\mathrm{pCa} 9.0) \mathrm{Ca}^{2+}$

Table 4. Contractile performance characteristics of skinned skeletal muscle fibers of the Rat

Table 5. Metabolite values at high and low $\left[\mathrm{Ca}^{2+}\right]$

Table 6. Metabolite values in rat EDL and soleus bundles 50

Table 7. Net rate change and metabolite values for the three conditions 50

Table 8. Metabolite values in high and low $\left[\mathrm{Ca}^{2+}\right]$ of rat EDL and soleus bundles

Table 9. Experimental solutions, 2.0 mM ATP 84

Table 10. Experimental solutions, 0.1 mM ATP 85

Table 11. Experimental solutions, $2.0 \mathrm{mM}$ ATP and $10.0 \mathrm{mM} \mathrm{PCr} 86$

Table 12. Experimental solutions, $0.1 \mathrm{mM}$ ATP and $10.0 \mathrm{mM} \mathrm{PCr} 87$

Table 13. Experimental solutions, $2.0 \mathrm{mM}$ ATP, $10.0 \mathrm{mM}$ PCr, and $2.0 \mathrm{mM}$ ADP

Table 14. Experimental solutions, $0.1 \mathrm{mM} \mathrm{ATP}, 10.0 \mathrm{mM} \mathrm{PCr}$, and $2.0 \mathrm{mM}$ ADP

Table 15. Experimental solutions, $10.0 \mathrm{mM} \mathrm{PCr}$, and 2.0 mM ADP

Table 16. Analysis of variance results. Comparison of $\mathrm{F}_{\max }$ between conditions for EDL fibers

Table 17. Analysis of variance results. Comparison of $\mathrm{pCa}_{50}$ between conditions for EDL fibers

Table 18. Analysis of variance results. Comparison of $n_{\mathrm{H}}$ between conditions for EDL fibers

Table 19. Analysis of variance results. Comparison of $\mathrm{F}_{\max }$ between conditions for soleus fibers

Table 20. Analysis of variance results. Comparison of $\mathrm{pCa}_{50}$ between conditions for soleus fibers 
Table 21. Analysis of variance results. Comparison of $n_{\mathrm{H}}$ between conditions for soleus fibers

Table 22. Type 3 Tests of Fixed Effects for [ATP] and [ADP], experiment 495

Table 23. Type 3 Tests of Fixed Effects for net rate change of ATP, experiment 4

Table 24. Type 3 Tests of Fixed Effects for net rate change of ADP, experiment 4

96

Table 25. Repeated measurements of [ATP] and [ADP] with HPLC

97 


\section{INTRODUCTION}

Skeletal muscle is a filamentous system comprising of fascicles, muscle fibers, myofibrils, and myofilaments. Myofibrils are a string of sarcomeres arranged in series with the sarcomere being the functional unit of contraction. Within a sarcomere, there are two interdigitating thick and thin myofilaments which are comprised of the proteins actin and myosin (Brooks, 2005). When actin comes in contact with calcium $\left(\mathrm{Ca}^{2+}\right)$, strong acto-myosin interaction occurs and results in force generation. This cyclic interaction of actin and myosin is termed cross-bridge (XB) cycling (Huxley, 1969).

During repeated cyclic interactions of the $\mathrm{XB}$ cycle, skeletal muscle contractions may be impaired due to diminished nervous system stimulation (central fatigue) or changes within the muscle cells (peripheral fatigue) (Cooke, 2007). Peripheral fatigue has been proposed to be caused by a decrease in available $\mathrm{Ca}^{2+}$, changes in metabolites concentrations (ATP, ADP, PCr, Pi), or functional and structural changes in the contractile apparatus. In order to study these contractile characteristics, muscle fibers are chemically skinned (membrane is removed) such that the physiological environment surrounding the fiber can be manipulated. By exposing a skinned fiber to solutions of increasing $\left[\mathrm{Ca}^{2+}\right]$, a relationship between force and $\left[\mathrm{Ca}^{2+}\right]$ can be constructed (Figure 1), which provides information on contractile performance. Contractile performance is indicated by three variables: maximal isometric force $\left(\mathrm{F}_{\max }\right)$, calcium sensitivity $\left(\left[\mathrm{Ca}^{2+}\right]\right.$ 50) or the free $\left[\mathrm{Ca}^{2+}\right]$ at which half of $\mathrm{F}_{\max }$ is generated, and the slope of the line known as the Hill coefficient $\left(n_{\mathrm{H}}\right)$. 


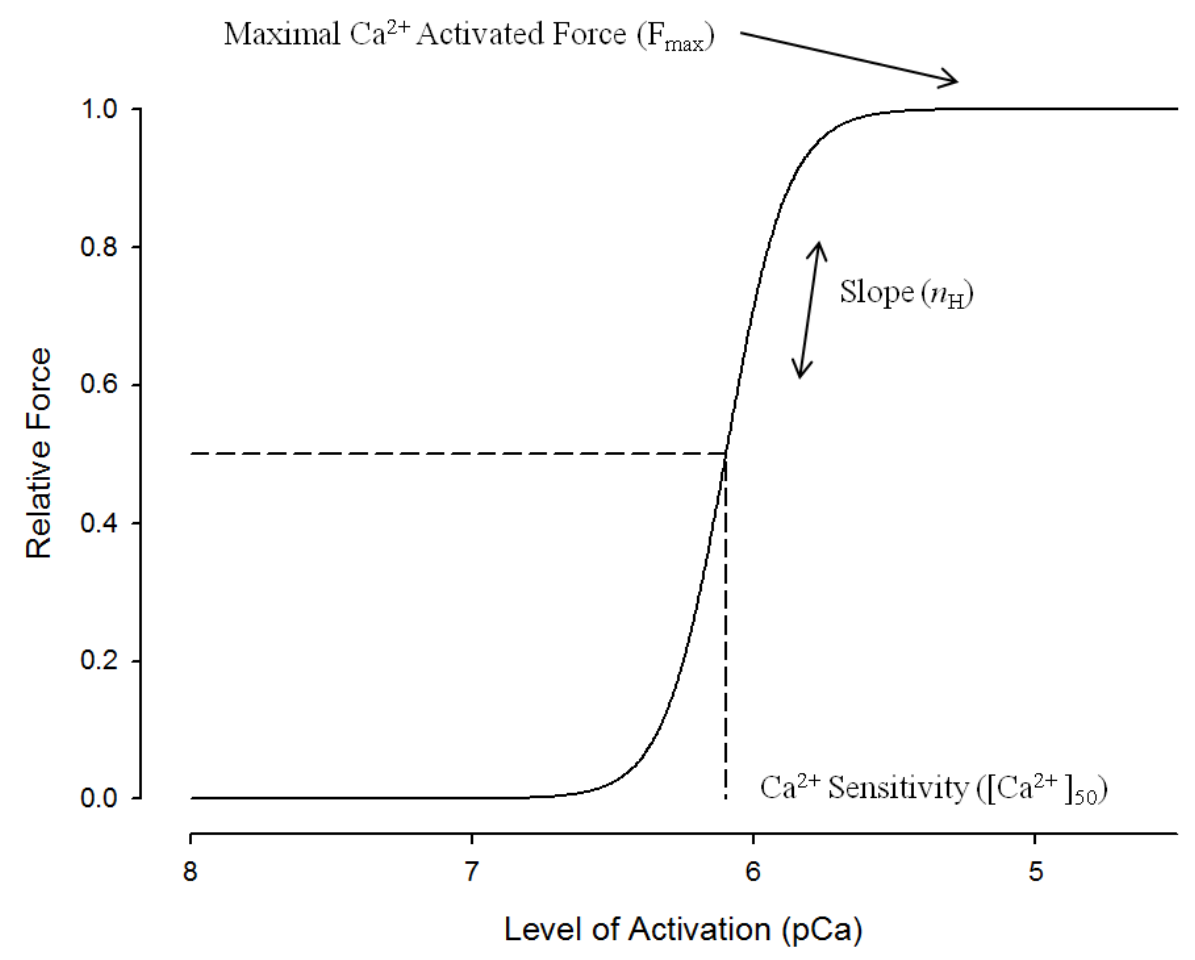

Figure 1. The relationship between force and free $\left[\mathrm{Ca}^{2+}\right]$. Relative force is calculated as $\mathrm{F} / \mathrm{F}_{\text {max }}$.

The energy required for force generation during XB cycling is provided by ATP which is hydrolyzed by acto-myosin ATPase (A·M·ATPase):

$$
\mathrm{ATP} \leftrightarrow \mathrm{ADP}+\mathrm{Pi}
$$

A second enzyme, creatine kinase (CK) plays a role in providing ATP to ATPases by catalyzing the following reaction:

$$
\mathrm{PCr}+\mathrm{ADP}+\mathrm{H}^{+} \leftrightarrow \mathrm{ATP}+\mathrm{Cr}
$$

The CK enzyme has four isoenzymes, MM-CK (skeletal muscle), BB-CK (brain), and two Mi-CK (mitochondrial) forms. The location of MM-CK has been identified on the M-line of the sarcomere (Turner et al., 1973; Wallimann et al., 1978). Due to this location, it has been suggested that $\mathrm{CK}$ and $\mathrm{A} \cdot \mathrm{M} \cdot \mathrm{ATPase}$ are functionally coupled both in skeletal (Savabi et al., 1983; Wallimann et al., 1984; Khan et al., 1989; Gregor et al., 2003) and cardiac muscle (Bessman et al., 1980; Ventura-Clapier et al., 1987; Krause \& 
Jacobus, 1992; Ventura-Clapier et al., 1994). It has also been shown that in the presence of $\mathrm{CK}$ substrates, MM-CK binds more tightly to the M-line as measured via the the Fluorescence Lost in Photobleaching technique (Zurmanova et al., 2007) suggesting that CK plays an important role in resynthesizing ATP near sites of ATP utilization in skeletal muscle.

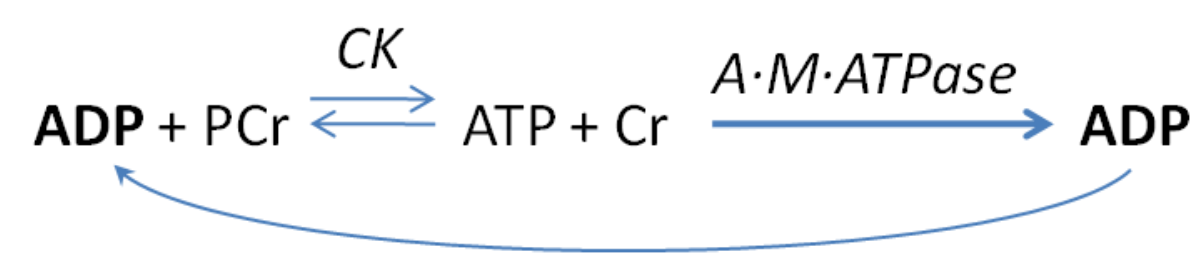

Figure 2. Proposed functional coupling between $\mathrm{CK}$ and $\mathrm{A} \cdot \mathrm{M} \cdot \mathrm{ATPase}$.

Research in cardiac myofibrils has revealed that A·M·ATPase used ATP generated from the CK system (Bessman et al., 1980) and that endogenous CK lowered the $\mathrm{K}_{\mathrm{mATP}}$ for A·M·ATPase whereas other ATP regenerating systems did not (Krause \& Jacobus, 1992). When chemically skinned rat cardiac muscle was exposed to ATP and $\mathrm{PCr}$ in solution, removal of $\mathrm{PCr}$ caused an increase in $\mathrm{F}_{\max }$ and $\left[\mathrm{Ca}^{2+}\right]_{50}$ whereas $n_{\mathrm{H}}$ decreased (Ventura-Clapier et al., 1987). This was also true when the muscle was exposed to $10 \mathrm{mM}$ ADP and $3 \mathrm{mM}$ ATP. It is known increased ADP causes an increase in $F_{\max }$ and decreases $\left[\mathrm{Ca}^{2+}\right]_{50}$ due to ADP inhibiting the dissociation of ADP from the actomyosin-ADP complex (Cooke \& Pate, 1985). Thus, XBs are attached in a strongly bound state for a longer period of time which increases the tension generated per XB (see fig. 5) (Macdonald \& Stephenson, 2006).

Whereas research into the functional coupling of myofibrillar CK and A·M.ATPase in cardiac myocytes is adequate (review, Ventura-Clapier et al., 1994), insight on the link between these two enzymes in skeletal muscle is limited (Savabi et al., 
1983; Wallimann et al., 1984; Khan et al., 1989; Gregor et al., 2003). Savabi et al. (1983) showed faster and stronger contractions in glycerinated rabbit psoas fiber bundles with ADP and PCr than ATP alone and attributed this to the close proximity of $\mathrm{CK}$ to the A.M.ATPase site. This was further demonstrated in chicken pectoralis skeletal muscle that MM-CK was sufficient to regenerate ATP hydrolyzed by A-M.ATPase and that ATP regeneration potential was abolished when anti-MM-CK antibodies were used (Wallimann et al., 1984). More recently, Gregor et al. (2003) quantified substrate channeling between MM-CK and A-M.ATPase by comparing ATP production and $\mathrm{PCr}$ consumption at varying $\mathrm{pH}$ levels (6-7.25) in rat myofibrils. The authors concluded that $40-50 \%$ of ATP produced by the CK reaction was channeled to A·M·ATPase (Gregor et al., 1999; Gregor et al., 2003).

Despite evidence proposing a coupling between $\mathrm{CK}$ and $\mathrm{A} \cdot \mathrm{M} \cdot \mathrm{ATPase}$ (Wallimann et al., 1992; Ventura-Clapier et al., 1994; Wallimann et al., 1998) some contrary evidence has been presented in ${ }^{31} \mathrm{P}-\mathrm{NMR}$ experiments, in which $\mathrm{CK}$ flux measurements in skeletal muscle at varying workloads indicated that CK flux did not change despite increased A·M·ATPase activity (McFarland et al., 1994; Wiseman \& Kushmerick, 1995). These papers concluded that CK compartmentalization provides negligible benefits with respect to overall cellular bioenergetics due to $\mathrm{CK}$ and its substrates behaving as a homogenous solution as supported by thermodynamics (Wallimann et al., 1998). This reasoning may be unfounded due to limitations detecting flux of bound CK and possibly PCr and/or ATP by NMR and has been questioned by Wallimann (1996). Another author has suggested that the enzymes are not coupled because of their distance (>10 nm) and they propose that consumption of substrates by 
the enzymes is done at rates higher than their diffusion rates, thus no functional coupling is necessary (Arrio-Dupont et al., 1992).

While distance between $\mathrm{CK}$ and A.M.ATPase may be an issue, as described above, there is support for a link between A·M·ATPase and CK in cardiac and skeletal muscle. However our understanding of contractile performance is limited to cardiac tissue only. Therefore the purpose of this work was to assess contractile characteristics of skinned skeletal muscle fibers and determine if CK can alter these properties.

Furthermore, direct and indirect assessment of [ADP] may show how the CK system influences contractile performance in skinned skeletal muscle fibers. By exposing skinned fibers to a $\mathrm{Ca}^{2+}$ gradient as well as an energy gradient of [ATP], further insight will be gained on how changing energy demands influences functional coupling between $\mathrm{CK}$ and A.M.ATPase. Direct assessment of metabolite changes at high and low $\left[\mathrm{Ca}^{2+}\right]$ will also probe the question of whether or not the location of CK is specific to the M-line for regeneration of ATP to be preferentially used by A·M·ATPase.

\section{SPECIFIC AIMS}

\section{Overall Objective}

The overall objective of this study was to determine the role of the CK system of skeletal muscle on contractile performance and energy utilization.

\section{Aim 1}

If $\mathrm{CK}$ is present in the sarcomere, the $\mathrm{CK}$ system will utilize ADP and $\mathrm{PCr}$ to regenerate ATP. The enzymes ability to regenerate ATP may alter contractile performance $\left(\mathrm{F}_{\max },\left[\mathrm{Ca}^{2+}\right]_{50}, n_{\mathrm{H}}\right)$ in skeletal muscle. Therefore, the purpose of Aim 1 was 
to compare the effects of exogenous ATP and endogenously generated ATP on contractile performance.

Aim 2

Confirmation was required in order to determine if $\mathrm{A} \cdot \mathrm{M} \cdot \mathrm{ATPase}$ uses exogenous ATP, endogenously generated ATP by the CK system, or both. This can be determined by monitoring the rate of change in ADP production during skeletal muscle contraction (see Figure 6). By monitoring the change in NADH fluorescence, an indirect assessment of ADP utilization can be evaluated. A direct analysis of changes in concentrations of ATP and ADP over time through high-performance liquid chromatography would also indicate if A·M·ATPase used endogenously generated ATP. Therefore, the purpose of Aim 2 was to determine if the contractile apparatus uses endogenous ATP generated from the CK system, exogenously supplied ATP, or both.

Aim 3

Differences exist between fast and slow skeletal muscle. In terms of contractile performance and energetics, slow skeletal muscle has a lower $\left[\mathrm{Ca}^{2+}\right]_{50}$ than fast skeletal muscle indicating greater $\mathrm{Ca}^{2+}$ sensitivity (Metzger \& Moss, 1990). Specific enzyme activity of $\mathrm{CK}(\mu \mathrm{mol} \mathrm{PCr} / \mathrm{min} / \mathrm{mg})$ and $\mathrm{A} \cdot \mathrm{M} \cdot \mathrm{ATPase}(\mu \mathrm{mol} \mathrm{ATP} / \mathrm{min} / \mathrm{mg})$ have been shown to be higher in fast skeletal muscle compared to slow (Wallimann et al., 1984). If ATPase activity is lower in slow skeletal muscle, the consumption of ATP will also be lower. Thus contractile performance, energy requirements, and source of ATP (endogenous or exogenous) may differ between these two fiber types. Therefore, the purpose of Aim 3 was to determine if exogenous ATP and endogenously generated 
ATP differentially affect contractile performance and energy utilization in fast and slow skeletal muscle.

\section{Delimitations}

1. The investigation will be delimited to skeletal muscle fibers of rat extensor digitorum longus and soleus muscles.

2. Measurement conditions will be delimited to imidazole propionate buffered experimental solutions maintained at $20^{\circ} \mathrm{C}, \mathrm{pH} 7.0$, and $0.18 \mathrm{M}$ ionic strength and a skinned fiber free of membranes as compared to intact fibers.

\section{Limitations}

1. Due to methodological considerations, sarcomere length will not be controlled.

2. It will be assumed that a change in $[\mathrm{NADH}]$ accurately reflects a change in ADP utilization.

3. It will be assumed that fibers taken from EDL muscles are fast-twitch whereas soleus fibers are slow-twitch.

4. Skeletal muscle tissues taken from rats were assumed to be healthy and free of disease. 


\section{LITERATURE REVIEW}

\section{Introduction}

Since the 1940s, much biochemical and physiological research has been performed to understand skeletal muscle structure and function. The structure of skeletal muscle is related to its primary function, contraction. Contraction is initiated by an action

potential causing a release of $\mathrm{Ca}^{2+}$ from the SR. Increased $\mathrm{Ca}^{2+}$ allows for cyclic interaction to occur between actin and myosin. During actomyosin XB cycling, chemical energy (ATP) is converted to mechanical energy via A·M·ATPase. The kinetics of the XB cycle can be altered by many factors, including metabolite concentrations (ATP, ADP, PCr, Pi) and activity of A·M·ATPase. Maintenance of a steady [ATP] is crucial for continued functioning of the XB cycle. One method by which the cell controls ATP homeostasis is the CK reaction. This literature review will discuss an overview of skeletal muscle structure, contraction, and the role of $\mathrm{CK}$ as a source of energy and its link to skeletal muscle contraction with A·M·ATPase.

\section{Contractile Apparatus}

Skeletal muscle cells are highly specialized based on their primary function, to produce movement. These highly specialized cells form structures and have been categorized in order of size starting with whole muscle, muscle fascicles, muscle fibers, myofibrils, and myofilaments. A single muscle fiber $(\sim 100 \mu \mathrm{m}$ diameter $)$ can contain many hundreds of myofibrils (1 $\mu$ m diameter) arranged in parallel (Brooks, 2005). Myofibrils consist of a mosaic pattern and contain the basic functional unit of contraction, the sarcomere. Sarcomeres are arranged in series and consist of numerous contractile, structural and regulatory proteins. 
There are two filaments, thick and thin, which interdigitate to form a hexagonal lattice that gives sarcomeres a striated appearance when viewed longitudinally. When observed under a microscope, the myofibril shows very distinct regions. Those containing thick filaments are known as the A-band (anisotropic), due to its dark appearance because of the overlap of actin and myosin. However within the A-band is the H-zone (helle, German for light) where there is no actin-myosin overlap. Actin filaments are located in the I-band (isotropic) and the dark line that intersects the I-band is the Zband (zwitter, German for between) from a longitudinal perspective.

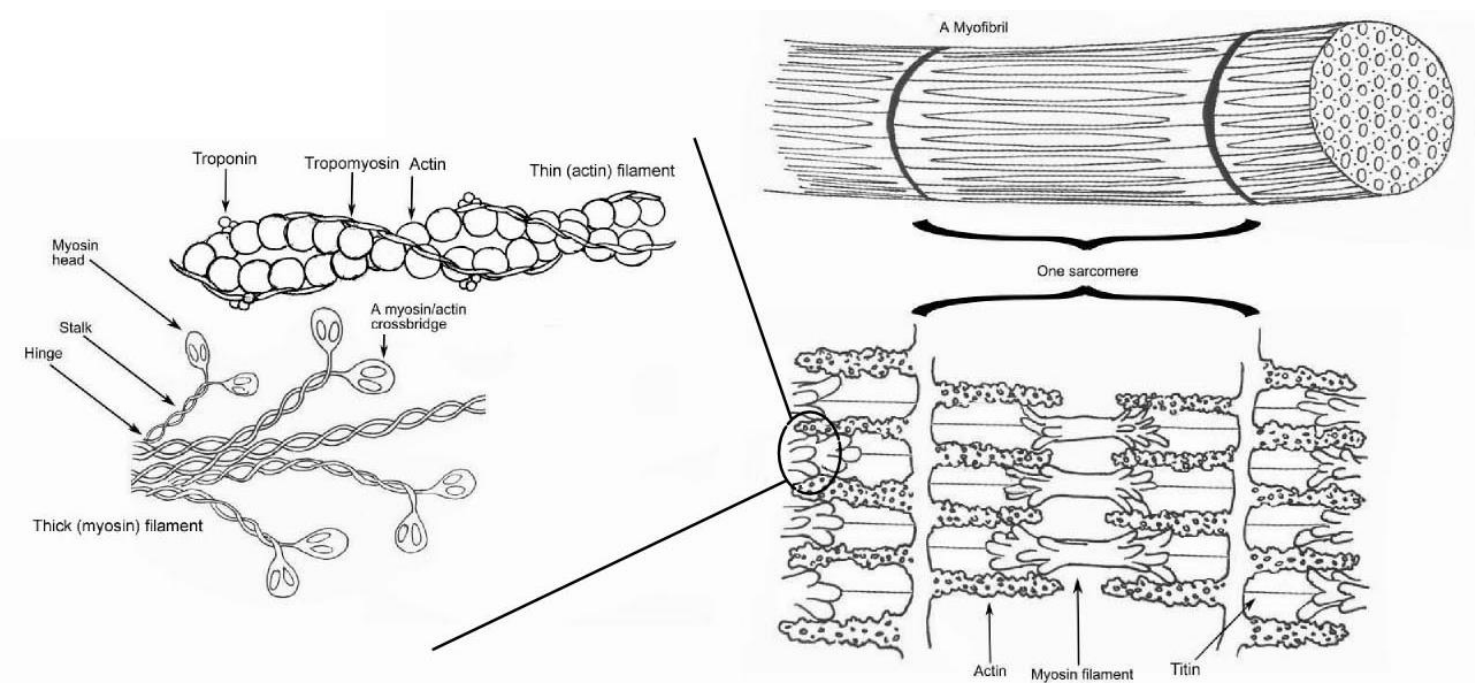

Figure 3. Picture of a myofibril, one sarcomere, and the proteins myosin and actin.

Incidentally one sarcomere is defined as the region between Z-bands. Within the A-band is a dense zone known as the M-line which contains structural proteins to keep the sarcomere in proper orientation during lengthening and shortening contractions.

Located throughout the M-line and sarcomere are other structural proteins that assist in anchoring the myofilaments. Some of the essential proteins include myosinbinding protein-c (holds the tails of myosin in correct spatial agreement); titin (links the end of the thick filaments to the Z-line); M-line protein (myomesin; keeps the thick and 
thin filaments in their correct spatial arrangement); $\alpha$-actinin (attaches actin filaments together at the Z-line); and desmin (links Z-lines of adjacent myofibrils together) (Brooks, 2005). These proteins comprise only a small portion of the total myofibrillar protein content because the proteins, myosin and actin comprise approximately one-half and one-fifth of total myofibrillar protein content respectively (Brooks, 2005).

The thick filament is composed of myosin-binding protein-c and myosin, one of the most studied eukaryotic molecular motor proteins (Warrick \& Spudich, 1987). Isolated myosin can be cleaved by trypsin into two components, light meromyosin (LMM) and heavy meromyosin (HMM). The tail portion of the molecule (LMM) consists of two heavy chains whereas HMM consists of two heavy and four light chains isoforms (Staron \& Johnson, 1993). Further proteolytic cleavage by papain splits HMM into two globular heads (HMM-S1) and a flexible neck (HMM-S2) that project from the LMM backbone. Each globular heads contains an A-M.ATPase enzyme and an actin-binding site. Based on the myosin heavy chain composition, the fiber type (i.e., slow; I, fast; IIa, IId, IIx) can be determined and categorized by its properties (i.e., ATPase activity) (Pette \& Staron, 2000). Lastly, when myosin proteins polymerize to form the thick filament, they arrange anti-parallel or tail-to-tail. Relative to molecules on either side, one rotates $60^{\circ}$ such that the filament has a feathered appearance with heads projecting from the myosin backbone with a distinct middle region void of any myosin heads (H-zone).

Although the myosin molecules generate tension, it is the actin filament that regulates force in mammals (Ohtsuki, 1999). The thin filament is composed of actin, tropomyosin, and troponin. In vitro, actin exists in globular form (G-actin), but in the presence of magnesium ions and ATP, it polymerizes to form a fibrous chain (F-actin) 
with bound ADP (Martonosi et al., 1960). Due to the interconnections of F-actin in a $\alpha$ helical arrangement, a long groove is formed along the filament, into which the regulatory protein tropomyosin fits (Ebashi, 1963; Ebashi \& Ebashi, 1964). A second protein, troponin, is also located periodically along tropomyosin and is composed of three sub-units. Troponin- $\mathrm{T}\left(\mathrm{T}_{\mathrm{n}} \mathrm{T}\right.$, tropomyosin-binding subunit) binds to tropomyosin in order to prevent it from moving off actin. Troponin- $\mathrm{C}\left(\mathrm{T}_{\mathrm{n}} \mathrm{C}\right.$, for calcium) binds $\mathrm{Ca}^{2+}$ and Troponin-I ( $T_{n} I$, for inhibitory) binds to $T_{n} C, T_{n} T$, and actin in a calcium-dependent manner (Greaser \& Gergely, 1971).

Based on studies in the 1970s (Gillis \& O'Brien, 1975), the steric block model was proposed and still appears in many textbooks. It states that when intracellular $\mathrm{Ca}^{2+}$ levels are low, there is a strong affinity of $\mathrm{T}_{\mathrm{n}} \mathrm{I}$ for $\mathrm{T}_{\mathrm{n}} \mathrm{C}$ and troponin sits over the myosinbinding site on tropomyosin. When intracellular calcium levels rise, four $\mathrm{Ca}^{2+}$ ions bind to $\mathrm{T}_{\mathrm{n}} \mathrm{C}$ and shifts all three subunits of troponin to move tropomyosin azimuthally. This movement exposes the myosin-binding sites on actin and allows the $\mathrm{S} 1$ head of myosin to bind to actin creating the XB attachment (Brooks, 2005). However, other investigators have shown actin and myosin binding in the presence of very low $\left[\mathrm{Ca}^{2+}\right]$ levels (Brenner et al., 1982). Thus, it has been proposed that the troponin complex does not prevent binding but rather inhibits the rate-limiting step of Pi release in the XB cycle (Chalovich \& Eisenberg, 1982).

\section{Theory of Muscle Contraction}

Analysis of the sarcomere revealed a striation pattern in skeletal muscle. The alternating light and dark regions were identified as thick filaments (A-band) and thin filaments (I-band) occurring approximately every $2-3 \mu \mathrm{m}$ from Z-line to Z-line. The thick 
filaments were measured at $1.6 \mu \mathrm{m}$ in the A-band and the thin filaments were measured at $1 \mu \mathrm{m}$ from the Z-line to the H-zone (Huxley, 1953). Under contraction, both thick and thin filaments maintained their approximate lengths as the sarcomeres shortened under ATP-induced contraction. Confirmation of sarcomere shortening was seen with light contrast (Huxley \& Hanson, 1954) and interference microscopy (Huxley \& Niedergerke, 1954) that revealed the A-band maintained its length whereas the I-band shortened. The observations of these two papers established the basis for the sliding filament theory which was later proposed by Huxley (1957). This theory stated that the sliding of actin past myosin was driven by XB formation and powered by ATP hydrolysis.

Research by Huxley and others relied on physical changes observed during contraction, direct visual evidence that could explain movement in these regions was not discovered until 1965. Reedy et al. (1965) provided direct evidence that the myosin head (S1) projected at an angle of $90^{\circ}$ from the thick filament when the muscle was at rest, but in a rigor state (no ATP present) the myosin head was tilted at an angle of $45^{\circ}$. This evidence was used in proposing the swinging cross bridge model that myosin heads change their orientation during the XB cycle (Huxley, 1969). 


\section{Cross-bridge Cycle}

The XB cycle is a multi-step process that involves the heavy meromyosin (HMM) components that project from the thick filament backbone ( $\mathrm{S} 1$ and $\mathrm{S} 2$, the myosin head and neck). HMM-S1 attaches to an actin monomer and the neck (HMM-S2) ratchets forcing the thin filaments to slide toward the $\mathrm{M}$ line, thus causing a small amount of sarcomere shortening. This process occurs many times along the length of a muscle resulting in a large overall movement, due to shortening of each sarcomere arranged in series (Brooks, 2005).

Early work elucidating the XB cycle examined the interaction of actin and myosin with soluble fragments of actin and HMM (Eisenberg \& Moos, 1968). The primary findings were that actomyosin ATPase activity is greater when actin and S1 are bound and that in the presence of ATP, actin and S1 are dissociated $~ 100$ times more than in the absence of ATP. Further work by Eisenberg and colleagues concluded that motion in muscle occurs by repeated cycles of actin-myosin rigor links dissociated by ATP followed by hydrolysis of ATP (Eisenberg et al., 1968). Based on these studies, Taylor and colleagues propose a four-state model of the XB cycle based on two key findings: (i) hydrolysis of ATP occurred in the detached state when myosin was not bound to actin and (ii) each myosin molecule hydrolyzed 1 ATP per myosin head per XB cycle (Lymn $\&$ Taylor, 1971). In addition, they suggested that the rate-limiting step of this model was the dissociation of the hydrolysis products (ADP, Pi) from AM (Lymn \& Taylor, 1971). 


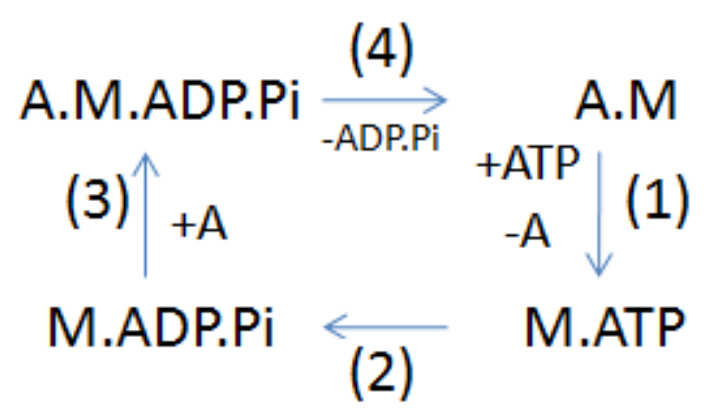

Figure 4. Schematic of the biochemical cross-bridge cycle and mechanical events as described by Lymn \& Taylor (1971).

The basic four-step model of the XB cycle can be described as follows: (1) The acto-myosin XB dissociates when ATP binds to the S1 head of myosin; (2) A.M.ATPase hydrolyzes the ATP into an intermediate state of ADP-Pi and the S1 head moves into position to rebind to actin; (3) Myosin head binds to actin with its hydrolysis products (ADP-Pi); (4) The XB generates force (power stroke) and actin displaces the reaction products from the XB (Figure 4) (Lymn \& Taylor, 1971).

Further work by Eisenberg et al. (1972) documented an additional step after M.ATP underwent hydrolysis. This was identified as the refractory state (M.ADP.Pi) where upon detachment of S1 from actin and after hydrolysis of ATP and the Pi burst (removal of ADP, Pi from myosin), the M.ADP.Pi underwent a transition from refractory to a nonrefractory state that limited the rate of rebinding of S1 to actin. Stein et al. (1979) further expanded this study by demonstrating that hydrolysis of ATP can occur without myosin disassociating from actin. Rather, the binding between $\mathrm{S} 1$ and actin in the steady state was due to a rapid equilibrium occurring between M.ATP and AM.ATP. The data also suggested that M.ATP and M.ADP.Pi have the same binding constant to actin and are in rapid equilibrium with AM.ATP and AM.ADP.Pi, respectively. Based on their 
findings, a kinetic model was proposed wherein actin and myosin undergo a transition between a weak binding state and a strong binding state (Stein et al., 1979).

The weak binding state is a group of configurations that do not produce or contribute to force generation. There are four states of weak binding that are all in rapid equilibrium with each other (Figure 5). These include myosin bound to ATP or its hydrolysis products (ADP-Pi) in rapid equilibrium with binding to actin. Binding of $\mathrm{Ca}^{2+}$ to troponin-C causes an increase in the affinity of actin to myosin and the kinetics of ATP hydrolysis is increased thus releasing phosphate from the myosin head. Phosphate release causes transition into the force-generating or strong-binding states. Here the myosin head is shifted from $90^{\circ}$ to $45^{\circ}$ causing the myosin and actin filaments to slide past one another. Upon release of ADP, actin and myosin are in a strongly bound rigor state and will remain until a new ATP is bound to the myosin head. However the ATP molecule does not need to be hydrolyzed to produce relaxation. This cycle will be repeated until $\mathrm{Ca}^{2+}$ is sequestered to the SR by means of calcium pumps. 


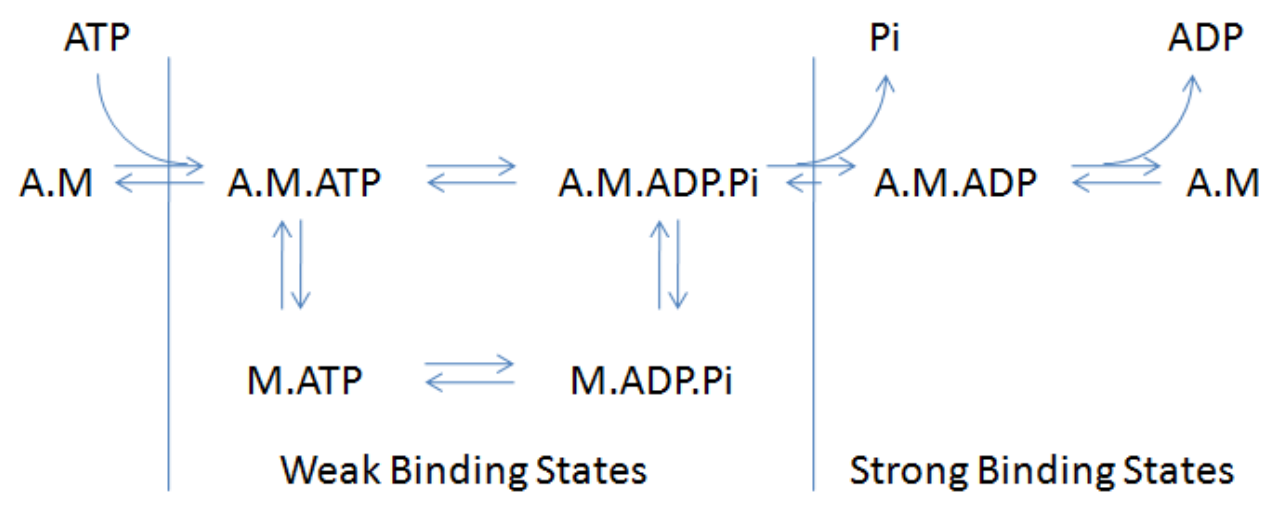

Figure 5. Six-state model depicting strong and weak binding states of $A=A c t i n$ and M=Myosin. Adapted from Stein, 1995.

Much of our understanding of skeletal muscle contraction was elucidated based on biochemical research from the 1940s to the 1970s (Szent-Gyorgyi, 2004). Skeletal muscle movement was identified as the interaction between actin and myosin which led to the sliding filament theory. Further knowledge of the role of ATP as an energy source and its interactions with $\mathrm{XBs}$ provided a detailed analysis of the $\mathrm{XB}$ cycle as we know it today.

\section{Creatine Kinase}

Cellular metabolism requires an input of energy that is provided in the form of ATP. In living cells, transport, production, conversion, and utilization of energy can occur via metabolic pathways involving tightly regulated enzyme-catalyzed reactions. These reactions are tightly regulated by factors such as changes in substrate concentrations, specific regulatory molecules, post-translational modification, or by subcellular compartmentation (Wallimann et al., 1992). One such enzyme that is a key regulator of cellular energetics is $\mathrm{CK}$. This enzyme has a number of isoenzymes which are compartmentalized at sites of energy production and utilization. A key component of this enzyme system is phosphocreatine (PCr). 
In 1927, PCr was discovered in skeletal muscle (Eggleton \& Eggleton, 1928). Later, when CK (E.C. 2.7.3.2) was identified, it was elucidated that CK catalyzes the reversible reaction of the transfer of a $\gamma$-phosphate group of ATP to the guanidino group of creatine (Cr) (Wyss \& Kaddurah-Daouk, 2000; McLeish \& Kenyon, 2005).

Specifically, CK catalyzes the reaction: $\mathrm{PCr}+\mathrm{ADP}+\mathrm{H}^{+} \leftrightarrow \mathrm{ATP}+\mathrm{Cr}$. This reaction is important because ATP is the universal energy currency. In skeletal muscle, the rate of ATP hydrolysis is $10 \mu \mathrm{mol} / \mathrm{g} / \mathrm{s}$, and ATP content in muscle is $4-7 \mu \mathrm{mol} / \mathrm{g}$, which would sustain a muscle contraction for less than a second in the absence of ADP rephosphorylation (Hancock et al., 2006). One method of ADP rephosphorylation is the $\mathrm{CK} / \mathrm{PCr}$ system. This system is important because increasing the [ATP] to meet the demand would not be feasible due to the influence of ATP, ADP, and the ATP/ADP ratio (Cooke \& Pate, 1985) as key regulators in metabolic reactions (From et al., 1990).

CK exists in four forms and each form is named for its tissue location and amino acid sequence. Two forms are found in cytosol: MM-CK (skeletal muscle) and BB-CK (brain); and two mitochondrial forms: ubiquitous $\left(\mathrm{Mi}_{u}-\mathrm{CK}\right)$ and sarcomeric $\left(\mathrm{Mi}_{s}-\mathrm{CK}\right)$ (Jacobs et al., 1964). All of these isoenzymes catalyze the same reaction and are kinetically similar (McLeish \& Kenyon, 2005).

Concentrations of PCr differ based on location and fiber type. In resting fasttwitch skeletal muscle, $[\mathrm{PCr}]$ stores are high ranging from $20-40 \mathrm{mM}$, whereas in heart, brain, kidney, and smooth muscle, [PCr] may be in the range of 5-10 $\mathrm{mM}$ (Iyengar, 1984). During contraction, the demand for ATP is high yet it is maintained at a near constant level despite a high turnover rate (Myburgh, 2004). The CK reaction is one mechanism that matches the ATP demand with supply. Thus a primary function of this 
system is to maintain ATP homeostasis (Wallimann et al., 1992). For example, in rat cardiac muscle, the maximal rate of ATP synthesis by the CK-catalyzed reaction (30 $\mu \mathrm{mol} / \mathrm{g} / \mathrm{s})$ is much higher than the maximal rate of ATP synthesis by oxidative phosphorylation $(2.5 \mu \mathrm{mol} / \mathrm{g} / \mathrm{s})$ or by de novo pathways $(0.39 \mu \mathrm{mol} / \mathrm{g} / \mathrm{s})($ Bittl $\&$ Ingwall, 1985; Ingwall et al., 1990). However the CK/PCr system is only able to maintain ATP homeostasis for 30 seconds in periods of intense muscular activities before other systems must be utilized (e.g. glucose non-oxidative and oxidative metabolism) to generate ATP (Brooks, 2005).

Besides the $\mathrm{Cr} / \mathrm{PCr}$ system serving as an energy buffer, it is also thought to function as an energy shuttle with PCr being the carrier (Bessman \& Geiger, 1981). Here PCr acts by connecting sites of ATP production (e.g. mitochondria) with sites of ATP utilization (e.g. various ATPases such as A·M·ATPase). Other functions of the $\mathrm{Cr} / \mathrm{PCr}$ system include keeping intracellular [free ADP] low, consumption of $\mathrm{H}^{+}$ions, and lastly, to provide local ATP/ADP ratios at sites where CK is functionally coupled to ATPases or ATP consuming processes (Wallimann et al., 1992).

\section{Creatine Kinase Coupling with Acto-Myosin ATPase}

Experiments in heart and skeletal muscle have revealed a functional coupling of $\mathrm{A} \cdot \mathrm{M} \cdot \mathrm{ATPase}$ and $\mathrm{CK}$. This means that ATP and ADP are rapidly turning over in the CK and ATPase reactions at rates higher than their diffusion rates resulting in maintained high ATP/ADP ratios in the sarcomere (Ventura-Clapier et al., 1994). This is possible due to MM-CK in cardiac and skeletal muscle being located on the M-line of the sarcomere (Wallimann \& Eppenberger, 1985). This was shown by repeatedly washing chicken pectoralis major muscle under physiological ionic strength and $\mathrm{pH}$ conditions 
(0.1 $\mathrm{M} \mathrm{KCl}, \mathrm{pH} 7.0)$. The activity of $\mathrm{CK}$ that was retained accounted for a minimum of $5 \%$ of the total CK present in skeletal muscle (Wallimann et al., 1984). All other CK (mitochondrial) was washed away. The remaining MM-CK was then immunofluorescently stained with anti-MM-CK antibodies which localized the myofibrilbound MM-CK in the middle of the A-band on the M-line. Further repeated washing of myofibrils in a low ionic-strength buffer removed the electron-opaque M-band structure due to removal of the fluorescently labeled MM-CK on the M-line in skeletal muscle (Turner et al., 1973).

\section{Biochemical Evidence}

Biochemical evidence for this coupling was first demonstrated by Yagi \& Mase (1962) using isolated myosin and CK from rabbit skeletal muscle. The experiments demonstrated that myosin and CK formed a complex. Michaelis-Menten kinetics revealed the $\mathrm{K}_{\mathrm{m}}$ of A·M.ATPase for ATP was 1 to 2 orders of magnitude lower with CK present than when compared to A·M·ATPase alone. This result suggested that when ATP is supplied to $\mathrm{A} \cdot \mathrm{M} \cdot \mathrm{ATPase}$ from the $\mathrm{CK}$ reaction, the product (ADP) is rephosphorylated by the CK system and returns to the ATPase active site as a substrate. Thus, the substrate concentration at the active site would be much higher than the mean concentration in the reaction solution (Yagi \& Mase, 1962).

Kinetic similarities of mitochondrial CK with myofibrillar CK from rat heart were identified by Saks et al. (1976). These two enzymes were shown to have a much higher affinity for ADP and PCr than ATP and Cr. There was a six-fold difference in the $\mathrm{K}_{\mathrm{mATP}}$ in the $\mathrm{CK}$ reaction $(0.95 \mathrm{mM})$ compared to the $\mathrm{K}_{\mathrm{mATP}}$ in the $\mathrm{A} \cdot \mathrm{M} \cdot \mathrm{ATPase}$ reaction $(0.16$ 
$\mathrm{mM}$ ) suggesting that ATP formed from CK will be rapidly redistributed to myosin to start a new cycle. The $\mathrm{K}_{\mathrm{mATP}}$ for A-M.ATPase was close to the $\mathrm{K}_{\mathrm{mADP}}$ in the CK reaction (0.9 $\mathrm{mM}$ vs $0.8 \mathrm{mM}$, respectively) signifying functional coupling between the two enzymes (Saks et al., 1976). Further evidence was generated by studying the activity of A·M.ATPase and CK with ${ }^{32} \mathrm{P} \gamma$-labeled ATP (Bessman et al., 1980). Count values of labeled Pi after one minute were 10,470/nmol for ATP only and 7,847/nmol for ATP with added PCr. Labeled Pi was much higher when PCr was not in solution indicating that with added PCr, less labeled Pi formed due to A.M.ATPase using endogenously generated ATP from CK.

Production of ADP in the A.M.ATPase reaction was studied under various enzyme systems that produce ATP, including exogenous pyruvate kinase (PK) and phosphoenolpyruvate which competes with the CK reaction for ADP (Saks et al., 1984). Yet when the ratio of PK/CK was 100, it was not enough to prevent Cr formation. This suggests that ADP has preferential access to the CK reaction as opposed to PK (Saks et al., 1984) and CKs ability to synthesize ATP was dependent on the [PCr]. Reported $\mathrm{K}_{\mathrm{mADP}}$ values for PK and CK are approximately $0.1 \mathrm{mM}$ (Arrio-Dupont et al., 1992; Krause \& Jacobus, 1992). Because the CK reaction consumes protons when producing ATP, functional coupling of CK and A.M.ATPase has been demonstrated through use of a pH-stat assay system that monitored total consumption of protons from the CK reaction in chicken pectoralis myofibrils (Wallimann et al., 1984). It was shown that CK bound to the M-line of the sarcomeres was sufficient to regenerate all ATP hydrolyzed by $\mathrm{A} \cdot \mathrm{M} \cdot \mathrm{ATPase}$. Use of proton consumption as a method for determining ADP utilization by $\mathrm{CK}$ also revealed that despite proton production by the $\mathrm{A} \cdot \mathrm{M} \cdot \mathrm{ATPase}$ reaction, there 
was local alkalinization in myofibrils due to proton consumption by the CK reaction. Optimum activity of $\mathrm{CK}$ occurred at $\mathrm{pH} 6.5-6.6$ versus $7.5-7.8$ for $\mathrm{A} \cdot \mathrm{M} \cdot \mathrm{ATPase}$ in fast fibers of chicken pectoralis muscle. It would seem that lowering the $\mathrm{pH}$ by 0.5 units during muscle contraction in vivo further stimulates the $\mathrm{CK}$ reaction to regenerate ATP (Wallimann et al., 1984). This also lends evidence to the role the $\mathrm{PCr} / \mathrm{Cr}$ shuttle plays in proton transport where sites of proton production (ATPases) can be transferred to sites of utilization (oxidative phosphorylation in mitochondria) (Wallimann et al., 1992; VenturaClapier et al., 1994).

Krause \& Jacobus (1992) provided similar rationale for the dynamic role of PCr to transport phosphates from sites of production to sites of utilization in heart muscle. The authors were able to demonstrate in rabbit heart myofibrils that A·M.ATPase has a greater affinity for ATP produced by the CK reaction as compared to basal ATP or other regenerating systems by showing that the $\mathrm{K}_{\mathrm{m}}$ of ATP was the lowest in the endogenous CK system $(0.14 \mathrm{mM})$ versus either exogenous $\mathrm{CK}(0.56 \mathrm{mM})$ or no regenerating system (ATP only, $0.8 \mathrm{mM})$. They also showed that the activity of CK $(0.63 \pm 0.08 \mathrm{IU} / \mathrm{mg}$ protein) was five-fold greater than A·M·ATPase $(0.12 \pm 0.01 \mathrm{IU} / \mathrm{mg}$ protein $)$ indicating the CK system has the potential to generate ATP much faster than ATP consumption by A·M·ATPase (Krause \& Jacobus, 1992). However there is one piece of contradicting evidence that the binding of $\mathrm{CK}$ to the M-line in cardiac myofibrils is not sufficient to satisfy the kinetic properties of A·M·ATPase (Dowell \& Fu, 1992).

The functional coupling of $\mathrm{CK}$ and $\mathrm{A} \cdot \mathrm{M} \cdot \mathrm{ATPase}$ has been described as occurring within a cellular compartment (e.g., at the M-line and myosin head within the myofibrils), meaning the product of the CK reaction (ATP) is channeled to the ATPase 
site and does not diffuse out of the cellular compartment (Arrio-Dupont, 1988). This is thought to occur because the consumption of intermediates by the enzymes occurs at rates higher than their diffusion rates. By co-immobilizing $\mathrm{CK}$ and myosin on an artificial membrane, investigators mimicked the position of $\mathrm{CK}$ on the M-line of myofilaments (Arrio-Dupont et al., 1992). Again the ADP produced by A·M·ATPase did not diffuse into the bulk solution and was recycled to ATP by CK.

Gregor and colleagues (Gregor et al., 1999; Gregor et al., 2003) provided evidence for substrate channeling showing that $40-50 \%$ of ATP produced by the CK reaction was channeled to $\mathrm{A} \cdot \mathrm{M} \cdot \mathrm{ATPase}$. The influence of $\mathrm{pH}(6-7.25)$ was also examined on $\mathrm{PCr}$ consumed by the $\mathrm{CK}$ reaction versus the ATP produced by the $\mathrm{CK}$ reaction (Gregor et al., 2003). The CK reaction was more efficient in a slightly acidic environment ( $\mathrm{pH}$ 6.95) which corresponds to $\mathrm{pH}$ levels (6.7) occurring during muscle contraction (Sullivan et al., 1994).

\section{Mechanical Evidence}

The next question is what is the role of $\mathrm{CK}$ and $\mathrm{A} \cdot \mathrm{M} \cdot \mathrm{ATPase}$ coupling relative to contractile performance and $\mathrm{XB}$ cycling? One of the first studies that showed the importance of the CK/PCr system on contraction was done by Perry (1954) where it was shown that ADP bound to actin was not used by A-M.ATPase, thus added ADP with PCr was needed to generate contraction. In rabbit myofibrils in solution, a faster, stronger contraction and a more complete relaxation occurred with the addition of $4 \mu \mathrm{M}$ ADP and $10 \mathrm{mM}$ PCr as compared to $10 \mathrm{mM}$ ATP (Savabi et al., 1983). This study also used no added $\mathrm{CK}$ as the myofibrils had sufficient $\mathrm{CK}$ activity (1.8 $\mu$ moles/min/mg protein). 
Apart from studying contractile properties in solution, skinned fiber studies have been done to assess maximal $\mathrm{Ca}^{2+}$-activated force and $\mathrm{Ca}^{2+}$ sensitivity (Ventura-Clapier et al., 1987). It was found that tension increased as $\mathrm{PCr}$ was reduced $(12 \mathrm{mM}$ to $0 \mathrm{mM})$ in a solution of high $\left[\mathrm{Ca}^{2+}\right](\mathrm{pCa} 4.5)$ and $3.16 \mathrm{mM}$ ATP. Skinned cardiac muscle fibers were also exposed to gradients of $\mathrm{Ca}^{2+}$ under varying conditions of ATP, ADP, and PCr. In comparison to $\mathrm{Ca}^{2+}$ solutions containing $\mathrm{PCr}$ and ATP, removal of $\mathrm{PCr}$ resulted in increased $\mathrm{F}_{\max }$ and $\left[\mathrm{Ca}^{2+}\right]_{50}$ and decreased $n_{\mathrm{H}}$. This was also true when ATP was replaced with ADP and PCr (Ventura-Clapier et al., 1987).

The influence of ADP on XB cycling is not entirely known. Many authors have proposed that increased [ADP] slows XB detachment (Cooke \& Pate, 1985; Hoar et al., 1987; Macdonald \& Stephenson, 2006) which is similar to situations where PCr is unavailable and thus the system cannot maintain low [ADP] (Ventura-Clapier et al., 1987; Godt \& Nosek, 1989).

\section{Creatine Kinase Coupling with Sarco(endo)plasmic Reticulum Calcium ATPase}

CK has also been shown to be attached to highly purified sarcoplasmic reticulum (SR) membranes from skeletal muscle (Rossi et al., 1990). The SR is composed of two continuous, heterogeneous compartments, the longitudinal SR (LSR) which surrounds the myofibrils and the terminal cisternae (TC) that are associated with the transverse $\mathrm{T}$ tubule membrane (Rossi et al., 1990). In the same manner that CK and A.M.ATPase are functionally coupled, evidence also shows a coupling between CK and sarco(endo)plasmic reticulum $\mathrm{Ca}^{2+}$ ATPase (SERCA) (Korge et al., 1993). The primary role of SERCA is to maintain $\mathrm{Ca}^{2+}$ homeostasis, enabling muscle to relax. The $\mathrm{Ca}^{2+}$ pump requires a considerable amount of ATP and is located uniformly throughout the SR with 
the exception of the junctional face of the TC membrane (Franzini-Armstrong, 1980; Jorgensen et al., 1982). It is thought that CK is able to provide ATP by converting ADP produced from SERCA to ATP whereas other benefits of this coupling are similar to A-M.ATPase and include: reduced diffusion distance for ATP compared to other sources and maintenance of ATP/ADP ratios (Korge et al., 1993).

Rossi et al. (1990) investigated the involvement of CK in ATP-dependent $\mathrm{Ca}^{2+}$ sequestration by SR vesicles and found that MM-CK is bound to the SR membrane both in situ and on isolated SR vesicles. The effects of $\mathrm{CK}$ on $\mathrm{SR} \mathrm{Ca}^{2+}$ loading was investigated by measuring the $\mathrm{Ca}^{2+}$-loading rate in four SR fractions which displayed $\mathrm{CK}$ activity ranging from 0.7 to $1.4 \mathrm{IU} / \mathrm{mg}$ protein. These fractions contained LSR with some transverse tubules and plasma membrane, LSR, LSR with some TC contaminants, and TC with some LSR. The $\mathrm{Ca}^{2+}$-loading rate was measured in the presence of $1 \mathrm{mM}$ ADP and $10 \mathrm{mM} \mathrm{PCr}$ and with $\left(1.4 \mu \mathrm{mol} \mathrm{Ca}{ }^{2+} / \mathrm{mg}\right.$ protein/min) and without $\left(0.4 \mu \mathrm{mol} \mathrm{Ca}^{2+} / \mathrm{mg}\right.$ protein/min) exogenously added CK as compared to control (1mM ATP, $1.7 \mu \mathrm{mol}$ $\mathrm{Ca}^{2+} / \mathrm{mg}$ protein/min) in the SR fraction containing LSR only. In the SR fraction containing LSR with some TC contaminants, SR-bound CK supported $40 \%$ of the maximal $\mathrm{Ca}^{2+}$ uptake rate as compared to $24 \%$ in the LSR only fraction. The LSR only fraction contained the highest relative amount of SERCA, due to the longitudinal SR tubules present.

While Rossi et al. (1990) provided evidence for a link between CK and SERCA, Korge et al. (1993) added two important findings by showing that CK-produced ATP is preferentially used for $\mathrm{Ca}^{2+}$ transport and SERCA produced ADP is preferentially available to $\mathrm{CK}$. When the $\mathrm{Ca}^{2+}$-uptake rate was measured with $5 \mathrm{mM} \mathrm{PCr}$ and $0.1 \mathrm{mM}$ 
ADP, the rate was $\sim 60 \%$ of the uptake rate observed when stimulated by $1 \mathrm{mM}$ ATP (0.61 versus $1.02 \mu \mathrm{mol} / \mathrm{mg} / \mathrm{min}$ ). The ability of CK to utilize SERCA-produced ADP was confirmed by addition of PCr to the reaction mixture whereby the decreased [ADP] removed inhibition on $\mathrm{Ca}^{2+}$ uptake during SERCA activity. Also when the $\mathrm{CK}$ inhibitor Dnp-F was added, the effects of PCr were fully reversed.

An added benefit of the CK system is the use of PCr at sites of ATP utilization where PCr is consumed (ATPases) and sites of ATP production (mitochondria) where PCr is produced. SERCA can be supplied with ATP either through exogenous ATP, the CK reaction, or mitochondrial ATP regeneration. Kaasik et al. (2001) studied $\mathrm{Ca}^{2+}$ release after inducing $\mathrm{Ca}^{2+}$ loading under conditions of varying ATP sources. It was shown that mitochondrially produced energy can support the $\mathrm{SR} \mathrm{Ca}^{2+}$ load as effectively as the $\mathrm{CK} / \mathrm{PCr}$ system. However in order to determine which system of ATP regeneration dominates, $\mathrm{Cr}$ formation and ADP-dependent oxygen consumption were monitored under the same conditions tested for $\mathrm{SR} \mathrm{Ca}^{2+}$ loading. It was estimated that under conditions of $\mathrm{Cr}$ formation $(53 \mathrm{nmol} \mathrm{Cr} / \mathrm{min} / \mathrm{mg}$ dry weight) and oxygen consumption (5.3 nmol $\mathrm{O}_{2} / \mathrm{min} / \mathrm{mg}$ dry weight), $\geq 65 \%$ of ATP consumed came from the CK reaction and $\leq 35 \%$ from mitochondria assuming a one-to-one ATP production per $\mathrm{Cr}$ and an ADP/Oxygen ratio of $\leq 3$. Upon blocking the $\mathrm{CK}$ reaction, mitochondrial ATP production increased by $80 \%\left(9.7 \mathrm{nmol} \mathrm{O}_{2} / \mathrm{min} / \mathrm{mg}\right.$ dry weight), whereas inhibition of mitochondria resulted in a $40 \%$ increase in $\mathrm{Cr}$ production ( $77 \mathrm{nmol} / \mathrm{min} / \mathrm{mg}$ dry weight) (Kaasik et al., 2001).

Other studies have come to similar conclusions linking CK bound to SR in local regeneration of ATP and its importance in calcium pump function (Korge et al., 1993; Korge \& Campbell, 1994; Minajeva et al., 1996; Williams et al., 2008). For example, 
$\mathrm{Ca}^{2+}$ uptake by the SR was improved in the presence of PCr with either ATP or ADP as compared to $\mathrm{Ca}^{2+}$ loading in the ATP only condition (Minajeva et al., 1996). Also, addition of PK plus PEP ATP-regenerating system to the previously described conditions did not significantly increase $\mathrm{Ca}^{2+}$ loading (Minajeva et al., 1996). Similar results were found by Korge et al. (1993) whereby $\mathrm{Ca}^{2+}$ uptake increased in parallel with an increase in [PCr]. It was also shown that ADP production by SERCA significantly declined when $\mathrm{PCr}$ was added to the reaction mixture. Similar findings were presented by Williams et al. (2008) in which adenosine metabolites (ATP, ADP, and PCr) were determined by HPLC. When SERCA was stimulated with maximal $\mathrm{Ca}^{2+}(5 \mu \mathrm{M})$ in the presence of ATP and $\mathrm{PCr},[\mathrm{ATP}]$ was maintained near initial values as $[\mathrm{PCr}]$ declined and ADP accumulation was minimal (Williams et al., 2008).

CK plays an important role in regulating ATP/ADP ratio, keeping [ADP] low and providing ATP for the purposes of SERCA activity and $\mathrm{Ca}^{2+}$ uptake. The ability of CK to provide ATP to SERCA is an effective method to meet the high energy demands of the cell in order to produce relaxation by resquestering $\mathrm{Ca}^{2+}$ into the SR.

\section{Skinned Fiber Techniques, Advantages \& Disadvantages}

One of the primary features of examining skinned skeletal muscle fibers is their ability to maintain their primary function of force generation. This is a process whereby force can be generated by the conversion of chemical energy (ATP) to mechanical work. In intact skeletal muscle, complications arise due to the presence of the sarcoplasmic reticulum, mitochondria, and enzymes that can affect energy metabolism of the cell. By skinning fibers, these functional components are destroyed and the solution exposed to the skinned fibers can be manipulated and controlled while maintaining function of the 
contractile apparatus. One noticeable difference that does occur is the diameter of skinned muscle fibers is increased compared to intact fibers. There may be an increase of up to $28 \%$ in relaxed skinned fiber lattice spacing between thick filaments (Godt \& Maughan, 1981). Other disadvantages of skinned fibers are that soluble enzymes which may have important effects on muscle function may be lost. Also, some metabolites that may not be present in solution may play a role that is not yet understood.

Prior to investigations in skinned skeletal muscle fibers, proteins such as myosin and actin were placed in solution which required lowering the ionic strength of these solutions below physiological values (Eisenberg \& Moos, 1968; White \& Taylor, 1976). Now with current techniques, because the solution can be altered to suit the hypotheses tested by the researcher, ionic strength can be controlled and manipulated to values more suited to physiological conditions.

\section{Summary}

Research into the biochemical and mechanical steps of skeletal muscle contraction have yielded amazing discoveries. Since the discovery of CK and PCr, many hypotheses have been proposed for the role of the CK reaction for both ATP and PCr synthesis. Evidence has been presented demonstrating either functional coupling between $\mathrm{CK}$ and $\mathrm{A} \cdot \mathrm{M} \cdot \mathrm{ATPase}$ or a channeling of substrates and products between the two enzymes.

The cell's ability to maintain ATP homeostasis is critical for cellular function. The location of $\mathrm{CK}$ in relation to A.M.ATPase on myosin heads plays a role in energy utilization and may influence contractile performance. 


\section{RESEARCH DESIGN \& METHODS}

\section{Introduction}

The overall objective of this study was to determine the role of the CK system of skeletal muscle on contractile performance and energy utilization. This was done through the use of a skinned-fiber system whereby the extracellular environment could be controlled by varying metabolites in solution while monitoring changes in $\mathrm{F}_{\max }$ across a range of $\left[\mathrm{Ca}^{2+}\right]$. This system also allowed for the detection of NADH fluorescence to indirectly monitor the pathway of ADP production by A-M.ATPase. Furthermore, adenosine metabolites were also measured through HPLC in order to determine specific changes in concentrations. The procedures performed in this project were approved by the IACUC at Virginia Tech.

\section{Experimental Designs}

\section{Specific Aim 1}

The purpose of Aim 1 was to compare the effects of exogenous ATP and endogenously generated ATP on contractile performance. If $\mathrm{CK}$ is connected to the myofibrillar proteins, ATP production will occur and allow normal functioning of the contractile apparatus. The ability to resynthesize ATP and its effects on XB kinetics, $\mathrm{F}_{\max }$, and/or $\left[\mathrm{Ca}^{2+}\right]_{50}$ was studied.

Experiment 1. The purpose of the first experiment was to determine the effects of the CK-regenerating system on contractile performance. Single skinned skeletal muscle fibers were exposed to solutions containing high ATP, low ATP, or no ATP in the presence of PCr and ADP. Solutions were formulated according to Table 1. Skeletal 
muscle fibers of the rat were dissected from whole extensor digitorum longus muscle and chemically skinned with glycerol. Isometric force was measured across a physiological range of $\mathrm{Ca}^{2+}$ and normalized by cross-sectional area and reported in $\mathrm{N} / \mathrm{cm}^{2}$. The primary outcome variables were $\mathrm{F}_{\max },\left[\mathrm{Ca}^{2+}\right]_{50}$, and $n_{\mathrm{H}}$.

In order to determine the influence of the CK system on contractile performance, three general conditions were chosen. High ATP conditions 1 through 3 provided the system with adequate ATP to function regardless of additional substrates (ADP , PCr) that activate CK. Low ATP conditions stressed the system such that CK must be utilized in order for the fiber to function (conditions $4 \& 5$ ). Conditions 2 and 5 most closely resembled in vivo conditions whereas condition 7 contained ADP and PCr which checks the effectiveness of $\mathrm{CK}$ to meet the requirements of A·M·ATPase. These seven conditions assessed how the CK system influences contractile performance.

Table 1. Concentrations (in $\mathrm{mM}$ ) of solutions for experiment 1.

\begin{tabular}{lcccc} 
& Condition & {$[\mathrm{ATP}]$} & {$[\mathrm{PCr}]$} & {$[\mathrm{ADP}]$} \\
\hline High ATP & 1 & 2.0 & 10.0 & 2.0 \\
& 2 & 2.0 & 10.0 & - \\
& 3 & 2.0 & - & - \\
\hline Low ATP & 4 & 0.1 & 10.0 & 2.0 \\
& 5 & 0.1 & 10.0 & - \\
& 6 & 0.1 & - & - \\
\hline No ATP & 7 & - & 10.0 & 2.0 \\
\hline
\end{tabular}

Please note that throughout the results and discussion section, 0.1 ATP condition is referring to $0.1 \mathrm{mM}$ ATP. Similarly the 2 ATP condition is referring to $2 \mathrm{mM}$ ATP condition. 


\section{Specific Aim 2}

The second aim of this proposal was to determine if the contractile apparatus uses endogenous ATP generated from the CK system, exogenously supplied ATP, or both. This was done first using an indirect method by monitoring the change in fluorescence of NADH. It was assumed that if ADP accumulates and proceeds through to form lactate (Figure 6), A·M·ATPase is using exogenous ATP. No change in NADH fluorescence indicates that ADP is not accumulating, therefore, it is being rephosphorylated to ATP by the CK system. The second assessment of metabolites was performed more directly by measuring changes in concentration of ATP and ADP over time with high-performance liquid chromatography.

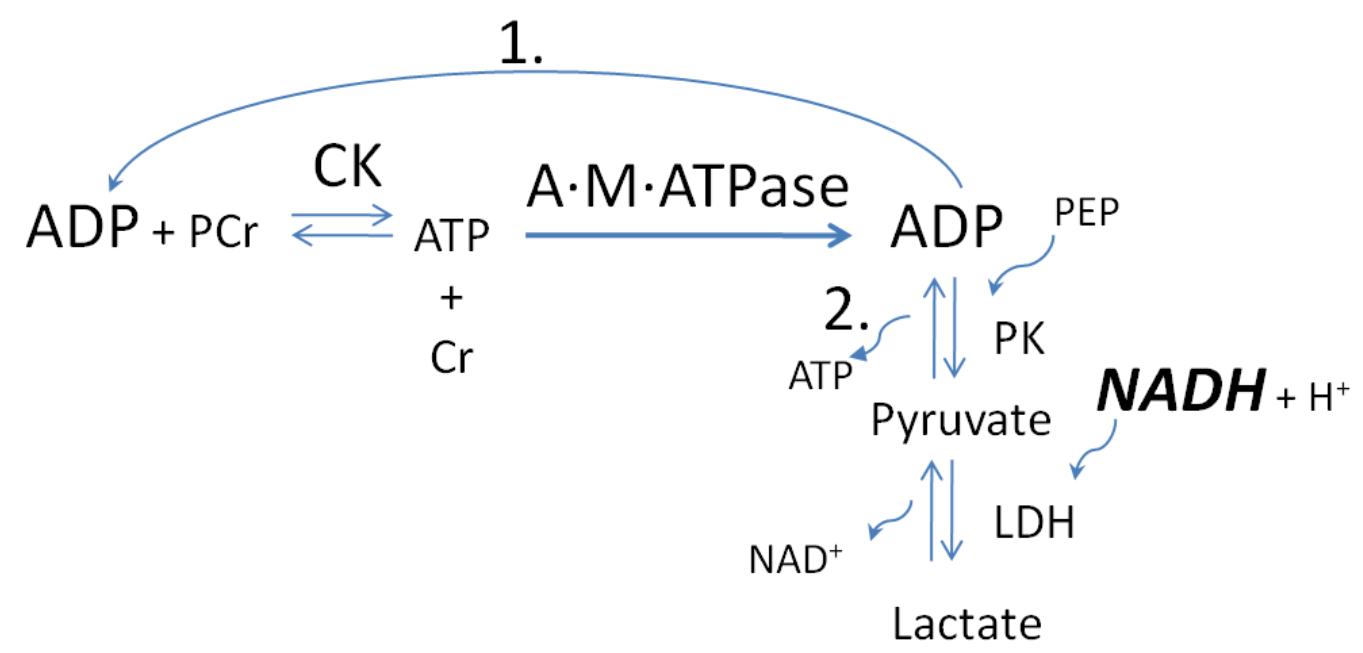

Figure 6. Two pathways for ADP utilization. Pathway 1, ADP is recycled and converted to ATP by CK. Pathway 2, ADP is converted to pyruvate by pyruvate kinase (PK) and then converted to lactate by lactate dehydrogenase $(\mathrm{LDH})$ resulting in a decrease in [NADH]. If pathway 1 occurs, this will affect the decline in [NADH].

Experiment 2. The purpose of the second experiment was to indirectly examine the production of ADP during $\mathrm{Ca}^{2+}$ activation with and without the CK-based ATPregenerating system. Single skinned skeletal muscle fibers were exposed to solutions 
containing ATP or ATP and PCr (Table 2) across a physiological range of $\left[\mathrm{Ca}^{2+}\right]$ which provided a gradient of increased energy utilization. Skeletal muscle fibers of the rat were dissected from whole extensor digitorum longus muscle and chemically skinned with glycerol. The net rate of change in [ADP] was measured across a physiological range of $\mathrm{Ca}^{2+}$ and normalized by muscle fiber volume and reported in $\mu \mathrm{M} / \mathrm{sec}$.

Table 2. Concentrations (in $\mathrm{mM}$ ) of solutions for experiment 2.

\begin{tabular}{ccc} 
Condition & [ATP] & {$[\mathrm{PCr}]$} \\
\hline 1 & 0.1 & - \\
2 & 2.0 & - \\
3 & 0.1 & 10.0 \\
4 & 2.0 & 10.0 \\
\hline
\end{tabular}

By monitoring the change in NADH absorbance, the utilization of the intermediate substrate ADP was indirectly determined. In this experiment, the contractile apparatus was stressed at low $(0.1 \mathrm{mM})$ and high $(2 \mathrm{mM})$ ATP in order to determine how the $\mathrm{CK}$ system functions across a $\left[\mathrm{Ca}^{2+}\right]$ gradient (pCa 9.0 to 4.0 ) which simulates changing demands in energy consumption. Also, because A-M.ATPase activity is influenced by [ATP], control conditions $1 \& 2$ were done in order to understand the changes related to $\mathrm{PCr}$ conditions $3 \& 4$.

Experiment 3. The purpose of the third experiment was to measure the accumulation of ADP at high $\left[\mathrm{Ca}^{2+}\right]$ (pCa 4.0) with a gradient of [ATP] (0 $\mathrm{mM}$ to $\left.2 \mathrm{mM}\right)$ with and without PCr. Whereas in experiment 1 and 2, the gradient was in the $\left[\mathrm{Ca}^{2+}\right]$, the system was altered to deliver an incremental gradient in [ATP]. As [ATP] increases, this will affect the net rate of change in $[\mathrm{ADP}]$ due to $[\mathrm{ATP}]$ influencing A.M.ATPase activity. 
While this experiment maintained a constant high $\left[\mathrm{Ca}^{2+}\right]$, an $[\mathrm{ATP}]$ gradient allowed the ability to examine ADP production in a different manner. Changing the [ATP] showed how exogenous ATP influences ADP production and how the CK system changes based on the system's requirements for ATP.

Experiment 4. The purpose of the fourth experiment was to directly measure the amount of metabolites present in high ( $\mathrm{pCa} 4.0)$ and low ( $\mathrm{pCa} 9.0)\left[\mathrm{Ca}^{2+}\right]$ solutions after 30 minutes in three conditions (Table 3 ). The primary outcome variables were [ATP] and [ADP]. Skeletal muscle bundles were placed in test tubes with activating or relaxing solution and the addition of ATP or ADP plus PCr began the reaction. The reaction was stopped with addition of $0.6 \mathrm{~N}$ perchloric acid and the concentrations of ATP and ADP were measured in solution with high-performance liquid chromatography (Williams et al., 2008).

Table 3. Concentrations (in $\mathrm{mM}$ ) of solutions for experiment 4 using either high ( $\mathrm{pCa}$ 4.0) or low (pCa 9.0) $\mathrm{Ca}^{2+}$.

\begin{tabular}{cccc} 
Condition & {$[\mathrm{ATP}]$} & {$[\mathrm{PCr}]$} & {$[\mathrm{ADP}]$} \\
\hline 1 & 5.0 & - & - \\
2 & 5.0 & 10.0 & - \\
3 & - & 10.0 & 2.0 \\
\hline
\end{tabular}

\section{Specific Aim 3}

The third aim of this proposal was to determine how exogenous ATP and endogenously generated ATP affect contractile performance and energy utilization between fast and slow skeletal muscle. A.M.ATPase activity differs between these two fiber types and this influences the rate at which chemical energy (ATP) is converted into mechanical energy (XB cycling) (Bottinelli et al., 1994). Therefore because of this 
difference in ATPase activity, it can be assumed that the influence of the CK system may differ between fast and slow skeletal muscle on contractile performance and energy use.

Experiments 1-4 were conducted with soleus (slow twitch) muscle of the rat and were performed concurrently with EDL (fast twitch) muscle experiments. Please refer to Specific Aims 1 and 2 for detailed information.

\section{Specific Methods and Techniques}

\section{Introduction}

The main apparatus used for this investigation is the Güth Muscle Research System (Güth \& Wojciechowski, 1986). This system allows the measurement of isometric force and fluorescence of compounds in skinned skeletal muscle fibers $(\sim 100$ $\mu \mathrm{m}$ diameter, $1-2 \mathrm{~mm}$ length). One of the key features of this system is the ability to change the intracellular environment (solutions) while monitoring contractile apparatus function and energy utilization. Also a key feature of the system is the ability to deliver incremental changes in $\left[\mathrm{Ca}^{2+}\right]$ or $[$ ATP $]$ or any other variable through use of a twochamber delivery system.

\section{Animals}

There were a total of 10 Harlan Sprague-Dawley rats (6 male, 4 female) used for all experiments. Although the number of animals used was small, both EDL and soleus muscles were removed from each leg of the animal. Therefore each animal provided a potential sample of size of hundreds of single muscle fibers that were used in this study. For total number of fibers used in each experiment, please refer to tables in the results section. 


\section{Solutions}

For most experiments, two stock solutions were prepared that differed in freecalcium concentration (relaxing and activating). They contained $85 \mathrm{mM} \mathrm{K}^{+}$and $\mathrm{Na}^{+}, 1$ $\mathrm{mM} \mathrm{Mg}{ }^{2+}, 7 \mathrm{mM}$ glycol-bis(2-aminoethylether)-N,N,N',N'-tetraacetic acid, and propionate. Ionic strength of all solutions was adjusted to $0.18 \mathrm{M}$ and a $\mathrm{pH}$ of 7.0 with imidazole propionate (see appendix I). Concentrations of $\mathrm{Ca}^{2+}$ were $10^{-9} \mathrm{M}$ or a pCa (-log $\left.\left[\mathrm{Ca}^{2+}\right]\right)$ of 9.0 for relaxing conditions whereas the activating solution contained added $\mathrm{Ca}^{2+}$ to meet a concentration of $10^{-4} \mathrm{M}(\mathrm{pCa} 4.0)$. Solutions were refrigerated and used within 5 days. On experimental days $\sim 20 \mathrm{ml}$ of each solution were placed on ice and the following chemicals were added: ATP (varying), ADP (varying), and PCr (varying). For experiments involving the use of NADH fluorescence, the following chemicals were added in addition to those already mentioned: $0.4 \mathrm{mM}$ NADH, $1 \mathrm{mM}$ phosphoenol pyruvate (PEP), $0.1 \mathrm{mM} \mathrm{P} \mathrm{P}^{1}, \mathrm{P}^{5}$-di(adenosine-5')pentaphosphate $\left(\mathrm{AP}_{5} \mathrm{~A}\right), 10 \mathrm{U} / \mathrm{ml}$ of pyruvate kinase $(\mathrm{PK})$ and lactate dehydrogenase $(\mathrm{LDH})$. Ionic strength and $\mathrm{pH}$ were adjusted using a computer algorithm supplied by Dr. W. G. Kerrick and known binding constants.

\section{Fiber dissection and skinning}

Skeletal muscles were harvested from adult Sprague Dawley rats (approximately 250-300 g). Following exposure to $\mathrm{CO}_{2}$, soleus and EDL muscles of both limbs were harvested and placed in cold relaxing solution (pCa 9.0) with 50\% glycerol and $2 \mathrm{mM}$ ATP for 20 minutes. Muscle bundles were then dissected free and tied to glass capillaries. Bundles were stored in the glycerol and relaxing solution mixture with added ATP at $-20^{\circ} \mathrm{C}$ for at least 24 hours. Previous investigators have demonstrated that storage of 
skinned muscle fibers for periods of 1-2 months did not significantly alter contractile performance or enzymatic properties.

On experimental days, stored muscle bundles were placed in ice-cold relaxing solution $\left(\sim-16{ }^{\circ} \mathrm{C}\right)$ and single fibers were dissected under a video microscope. Fiber segments (1-2 mm) were mounted between a pair of micro-tweezers in the Güth Muscle Research System (Güth \& Wojciechowski, 1986). One set of tweezers was attached to a photodiode force transducer and the other pair was attached to a motorized length controller. The fiber was enclosed in a quartz capillary tube with a cross-sectional area of $1 \mathrm{~mm}^{2}$ and $1 \mathrm{~cm}$ in length. Fiber length was determined by setting an initial slack length (point at which increasing fiber length produces detectable force) and then setting the fibers resting length at $110 \%$ of slack length.

\section{Fiber morphology}

After the fiber was mounted, it was briefly exposed to air and visualized with a video microscope. Images were taken and stored on a computer for fiber morphology analysis. Fibers were measured by assessing the largest and smallest diameter and averaging the two values. Cross-sectional area was computed by assuming a cylindrical fiber shape.

\section{Force and rate of change in ADP measurements}

Force-Ca ${ }^{2+}$ relationships were determined by exposing the skinned fiber initially to a low level of $\left[\mathrm{Ca}^{2+}\right]\left(10^{-9} \mathrm{M}\right)$. The $\left[\mathrm{Ca}^{2+}\right]$ was then increased every 20 seconds via a peristaltic pump system which mixed the relaxing and activating solution $\left(10^{-4} \mathrm{M}\right)$ while monitoring isometric force output and change in NADH fluorescence. Specifically, the 
calcium gradient was created by perfusing solutions into the cuvette in $58 \mu$ increments every 20 seconds (see gradient device below). This exposed the skinned fiber to 30-60 increments of $\left[\mathrm{Ca}^{2+}\right]$ (pCa range of $\left.9.0-4.0\right)$ and allowed enough time at each increment for isometric force to plateau (see Appendix II).

In experiments involving NADH fluorescence measurements, the cuvette was illuminated with a high pressure xenon lamp with light filtered at $340 \mathrm{~nm}$. A microscope photometer, with a $470 \mathrm{~nm}$ interference filter detected NADH fluorescence.

The net rate of change in $[\mathrm{ADP}]$ was determined simultaneously during force measurements by NADH fluorescence. This was accomplished by using a coupled pyruvate kinase (PK) lactate dehydrogenase (LDH) system (Güth \& Wojciechowski, 1986). Specifically, this system regenerates ATP from ADP and PEP by PK. This reaction is coupled to the oxidation of $\mathrm{NADH}$ (fluorescent) to $\mathrm{NAD}^{+}$(non-fluorescent) and the conversion of pyruvate to lactate by LDH (see Figure 6). One mole of ADP, PEP, and NADH is consumed to produce one mole of ATP, lactate, and NAD ${ }^{+}$. The rate of decline in NADH fluorescence was equated to the net rate of change in [ADP]. During each 20-second increment, the decline in fluorescence was determined over the last 15 seconds.

\section{Gradient device}

The gradient device consists of an upper chamber and a lower mixing chamber. Before each experiment, the lower chamber was filled with relaxing solution and perfused through the tubing by use of a peristaltic pump until the cuvette is filled. At the start of the experiment, the upper chamber was filled with $2.5 \mathrm{ml}$ of activating solution 
(pCa 4.0). Both relaxing and activating solutions contained varying amounts of ATP, ADP, and PCr depending on the condition.

Upon initiating the experiment, each step pulled $58 \mu \mathrm{l}$ of activating solution from the upper chamber into the lower mixing chamber and also delivered $58 \mu 1$ of solution through the tubing system into the cuvette. The amount of solution delivered with each step and the volume of the tubing was periodically calculated. Calculations for $\left[\mathrm{Ca}^{2+}\right]$ were determined by a program provided by Dr. Konrad Güth utilizing tubing volume, volume delivered per step, and $\left[\mathrm{Ca}^{2+}\right]$ of the relaxing and activating solutions. Also free

$\left[\mathrm{Ca}^{2+}\right]$ was measured with the fluorescent indicator $\mathrm{Ca}^{2+}$ Green-2 (480 nm excitation, 515 emission) (see Appendix II).

\section{High-Performance Liquid Chromatography (HPLC)}

Changes in $[\mathrm{ATP}]$ and $[\mathrm{ADP}]$ were determined during stimulation of A·M·ATPase. Skeletal muscle fiber bundles were exposed to all treatment conditions in both high and low $\mathrm{Ca}^{2+}$ solutions. Treatment conditions were randomized. Analysis of repeated measurements on the same bundles revealed a coefficient of variation of $6 \%$ for [ATP] and $22 \%$ for [ADP] (Appendix IV).

Skeletal muscle fiber bundles were placed into activating solution or relaxing solution and the reaction was initiated by adding varying amounts of ATP, ADP, and PCr. The reactions proceeded for 30 minutes at $36^{\circ} \mathrm{C}$. After 30 minutes, ice-cold $0.6 \mathrm{~N}$ perchloric acid was added to stop the reaction. After 10 minutes, $\mathrm{KOH}$ was added to return the $\mathrm{pH}$ of the solution to initial values $(\mathrm{pH}$ 7.0). The samples were then centrifuged $\left(12,000 \mathrm{RPM}\right.$ at $\left.4^{\circ} \mathrm{C}\right)$ and the supernatant was collected and stored for analysis of ATP and ADP. Analysis of the solutions for metabolites was carried out with HPLC using the 
approach of Williams et al. (2008). The skeletal muscle bundles were stored in a 50:50 glyercol and relaxing solution mixture with $5 \mathrm{mM}$ ATP. Weights of the fiber bundles were assessed after washing briefly in relaxing solution to remove glycerol.

ATP and ADP were detected using a Waters HPLC system with a diode array detector. Separation was done on a Supelchem C18 3- $\mu$ m reversed-phase column (0.46 x $15 \mathrm{~cm}$ ) with an injection volume of $20 \mu 1$. The mobile phase consisted of a gradient with two buffers. Buffer A contained $0.1 \mathrm{M} \mathrm{KH}_{2} \mathrm{PO}_{4}, 5 \mathrm{mM}$ tetrabutylammonium hydrogen sulfate (TBAHS), and 2.5\% (v/v) acetonitrile ( $\mathrm{pH}$ 6.0). Buffer B contained $0.1 \mathrm{M}$ $\mathrm{KH}_{2} \mathrm{PO}_{4}, 5 \mathrm{mM}$ TBAHS, and 25\% (v/v) acetonitrile (pH 5.5). The column was eluted for 3 min with buffer A (100\%), 2 min with buffers A (89\%) and B (11\%), and 25 min with $100 \%$ buffer B. The column was reequilibrated for 20 min with $100 \%$ buffer A. Flow was maintained at $0.8 \mathrm{ml} / \mathrm{min}$, and separations were done at room temperature. ADP and ATP were detected at $260 \mathrm{~nm}$. Standard curves were prepared by using known amounts of ATP and ADP in solution using the extraction procedure described above.

\section{Data collection and analysis}

Isometric force and NADH fluorescence data were collected via computer during each step and analyzed offline. Curves were generated for isometric force based on a modified Hill equation:

$$
\mathrm{F} / \mathrm{F}_{\max }=\left[\mathrm{Ca}^{2+}\right]^{\mathrm{N}} *\left(\left[\mathrm{Ca}^{2+}\right]_{50}{ }^{\mathrm{N}}+\left[\mathrm{Ca}^{2+}\right]^{\mathrm{N}}\right)^{-1}
$$

where $\mathrm{N}$ is the slope of the line and $\left[\mathrm{Ca}^{2+}\right]_{50}$ represents the $\left[\mathrm{Ca}^{2+}\right]$ required to elicit $50 \%$ of maximal isometric force $\left(\mathrm{F}_{\max }\right)$. 


\section{Statistics}

One-way analysis of variance was used to assess differences between conditions and muscle type for experiments one and two with multiple pairwise comparisons assessed with Tukey's HSD. A multi-way analysis of variance, 3 X 2 X 2 (condition X muscle type $\mathrm{X}$ solution) was used to test for significant interactions in experiment four. The level of significance was set at an alpha of 0.05 .

\section{Novel Aspects/Techniques}

It is noteworthy that the techniques in this dissertation attempted to determine the energy source (exogenous or endogenous ATP) for A-M.ATPase and pathways of substrates using novel methods. This is primarily because it is difficult to monitor changes in $[\mathrm{ATP}]$ or $[\mathrm{ADP}]$ in real time during active skeletal muscle contraction. Therefore methods have been developed to measure ADP production indirectly in real time and directly after allowing a muscle to contract for a set time period (specific aim 2).

One such method is presented in experiment 3 , where [ATP] is continually changed in solutions with and without $\mathrm{PCr}$ to determine how $\mathrm{CK}$ compensates over a range of $[\mathrm{ATP}]$. Second, determination of metabolite concentrations (ATP, ADP) through HPLC is novel in that the method proposed here has been developed and modified from a

previously published protocol that assessed metabolites in myocardial tissue (Bernocchi et al., 1994). 


\section{RESULTS}

\section{Experiment 1}

Mean values of $\mathrm{F}_{\max }, \mathrm{pCa}_{50}$, and $n_{\mathrm{H}}$ in rat $\mathrm{EDL}$ and soleus skeletal muscle fibers

are presented in Table 4. There were no significant differences for $F_{\max }$ across conditions for soleus fibers. However in $\mathrm{EDL}$ fibers, $\mathrm{ADP}+\mathrm{PCr}$ had significantly greater $\mathrm{F}_{\max }$ than 0.1 ATP. Values for $n_{\mathrm{H}}$ were not significantly different between conditions for EDL fibers, but in soleus fibers $n_{\mathrm{H}}$ was significantly smaller in 0.1 ATP compared to 0.1 ATP+PCr and 2 ATP.

Table 4. Contractile performance characteristics of skinned skeletal muscle fibers of the Rat

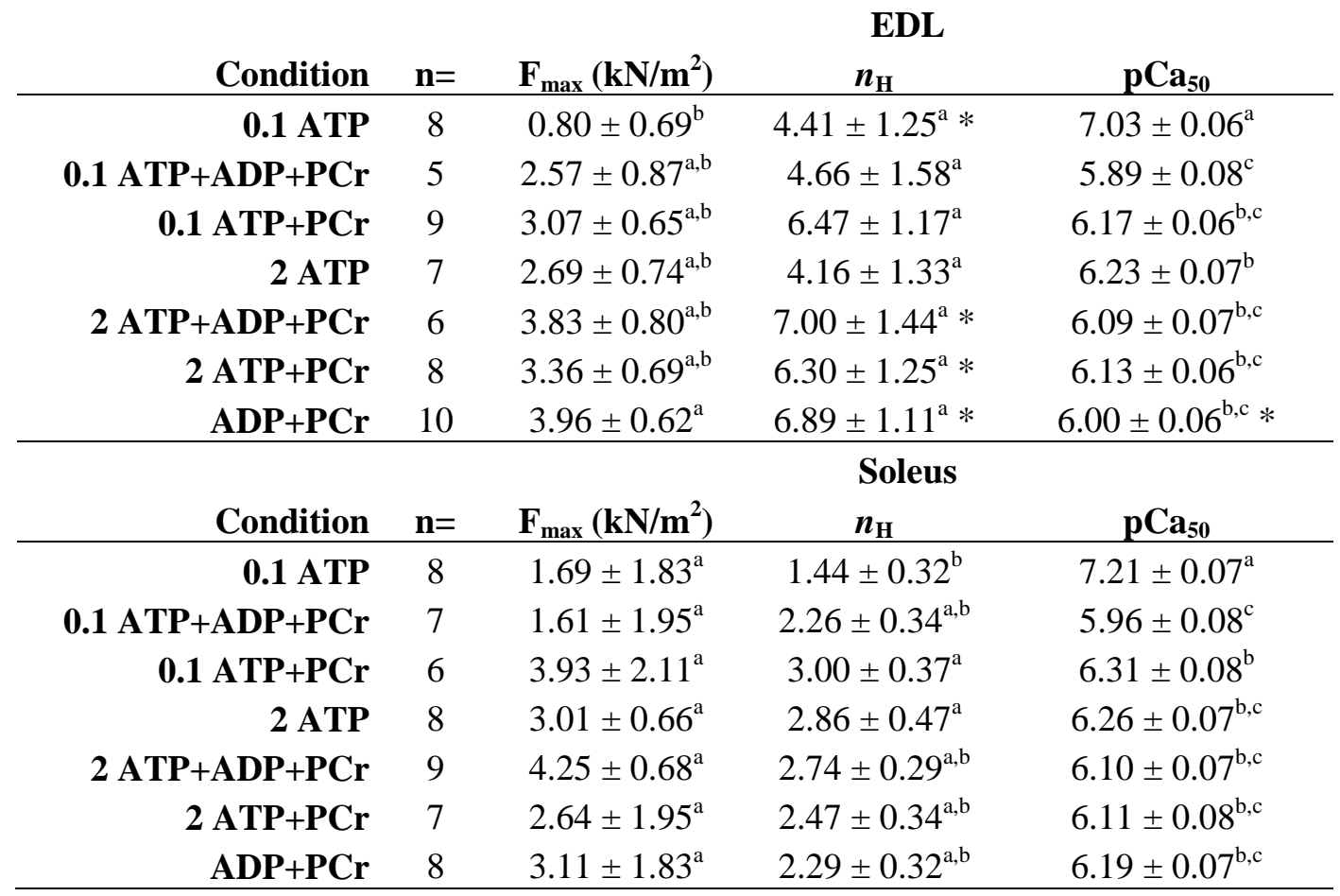

Values are mean \pm SE. Conditions with identical letters are not significantly different from one another. * Significantly different than soleus. Concentrations of metabolites are $2 \mathrm{mM}$ for ADP and $10 \mathrm{mM}$ for PCr. [ATP] is 0.1 or $2 \mathrm{mM}$ where indicated. 
Values reported for $\mathrm{pCa}_{50}$ are calculated by taking $-\log \left[\mathrm{Ca}^{2+}\right]$ at which $50 \%$ of $\mathrm{F}_{\max }$ is achieved. There are many variables which can alter $\mathrm{pCa}_{50}$ values, which include changes in sarcomere length, temperature, the rate at which XBs transition between strong and weak binding states, as well as changes in [ATP] and [ADP]. The effects of 0.1 ATP with and without ADP and $\mathrm{PCr}$ on $\mathrm{pCa}_{50}$ are presented graphically in Figure 7 and force-pCa curves were constructed with mean $\mathrm{pCa}_{50}$ and $n_{\mathrm{H}}$ values from Table 4 . The control condition used for comparison was 2 ATP. Deviations from this condition were found by reducing [ATP] to $0.1 \mathrm{mM}$ as this condition was significantly more sensitive to $\mathrm{Ca}^{2+}\left(\mathrm{pCa}_{50}, 7.03\right)$ as indicated by the leftward shift in the curve (Figure 7). Addition of PCr either with or without ADP removed this effect as the fibers were able to regenerate ATP presumably at concentrations near $2 \mathrm{mM}$ based on $\mathrm{pCa}_{50}$ values decreasing to values similar to the 2 ATP condition.

Interestingly, in high ATP conditions, $\mathrm{pCa}_{50}$ values did not differ when the endogenous CK system was activated with addition of PCr with or without ADP (Figure 8). Whereas in 0.1 ATP conditions, activation of CK caused a rightward shift in EDL and soleus, activation of CK in high ATP conditions caused only a slight rightward shift $\left(\mathrm{pCa}_{50}, 6.23\right.$ to 6.1$)$. 


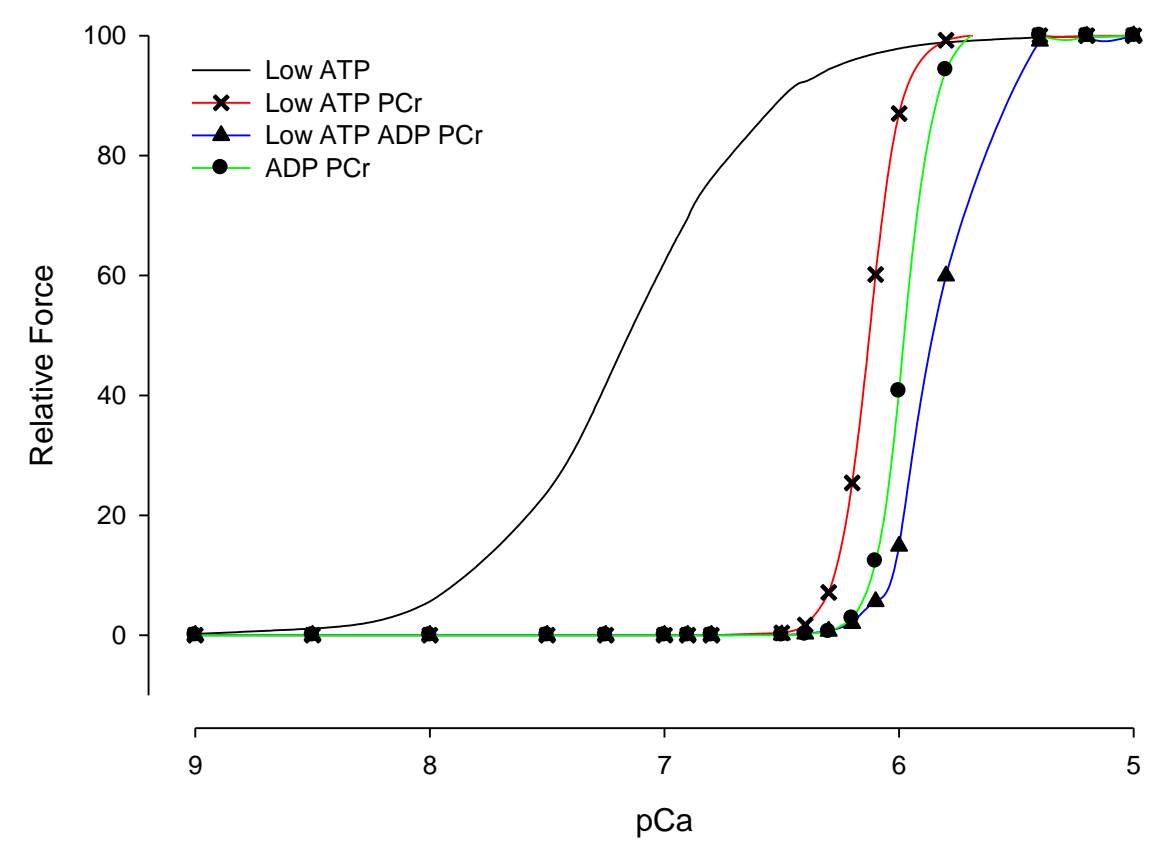

Figure 7. Effects of Metabolites at Low [ATP] on EDL Fibers. Curves constructed based on the equation, $\mathrm{F} / \mathrm{F}_{\max }=\left[\mathrm{Ca}^{2+}\right]^{\mathrm{n}} *\left(\left[\mathrm{Ca}^{2+}\right]_{50}{ }^{\mathrm{n}}+\left[\mathrm{Ca}^{2+}\right]^{\mathrm{n}}\right)^{-1}$ based on $\mathrm{pCa} 50$ and $n_{\mathrm{H}}$ values from Table 4. Low ATP $=0.1 \mathrm{mM}$ ATP.

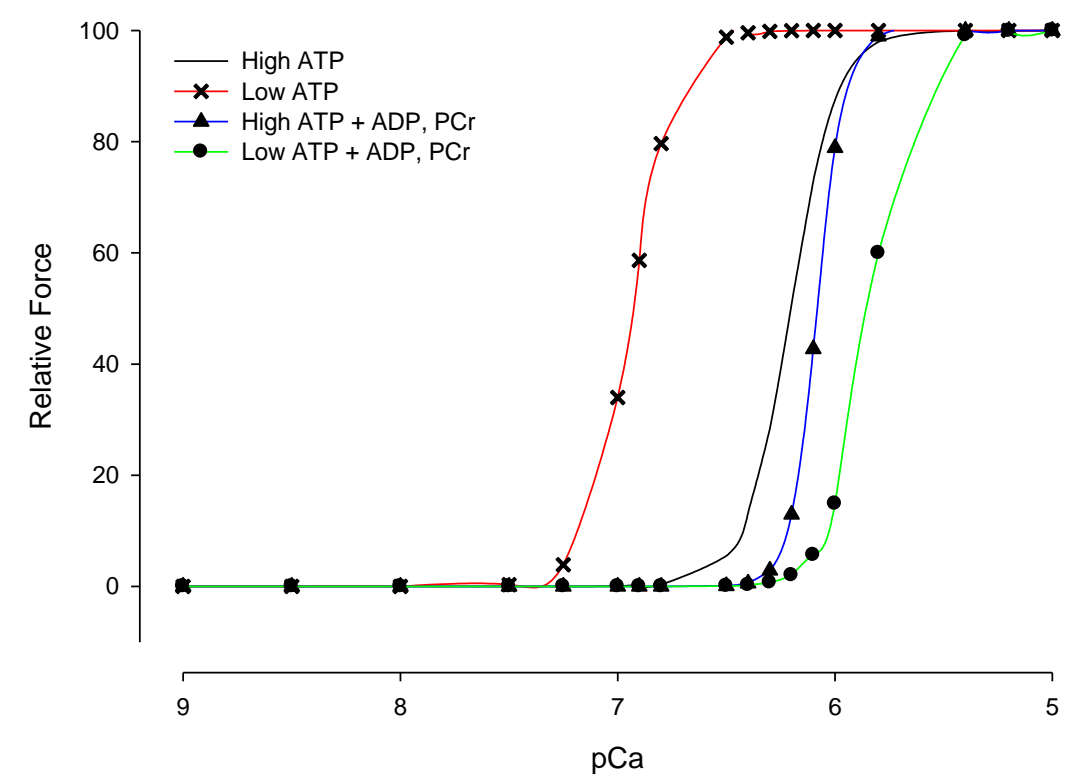

Figure 8. Effects of Metabolites on EDL Fibers at High and Low [ATP]. Curves constructed based on the equation, $\mathrm{F} / \mathrm{F}_{\max }=\left[\mathrm{Ca}^{2+}\right]^{\mathrm{n}} *\left(\left[\mathrm{Ca}^{2+}\right]_{50}{ }^{\mathrm{n}}+\left[\mathrm{Ca}^{2+}\right]^{\mathrm{n}}\right)^{-1}$ based on $\mathrm{pCa}_{50}$ and $n_{\mathrm{H}}$ values from Table 4 . High ATP $=2 \mathrm{mM}$ ATP. Low ATP $=0.1 \mathrm{mM}$ ATP. 
Comparisons between EDL and soleus muscles indicated no significant differences in $\mathrm{F}_{\max }$. Fibers from EDL muscle had significantly larger $n_{\mathrm{H}}$ values in all conditions but $2 \mathrm{ATP}, 0.1 \mathrm{ATP}+\mathrm{PCr}$, and $0.1 \mathrm{ATP}+\mathrm{ADP}+\mathrm{PCr}$ when compared to soleus fibers. The effect of a larger $n_{\mathrm{H}}$ value is indicative of reaching $\mathrm{F}_{\max }$ more quickly as can be seen in Figure 9. Figure 9 also depicts differences between fast and slow twitch fibers for $\mathrm{pCa}_{50}$ as these were higher in soleus than EDL for all conditions except $2 \mathrm{ATP}+\mathrm{PCr}$, however only the ADP+PCr condition was significantly different. Slow twitch fibers of the soleus muscle are more $\mathrm{Ca}^{2+}$ sensitive meaning they are producing greater relative force at a given $\left[\mathrm{Ca}^{2+}\right]$ than EDL fibers.

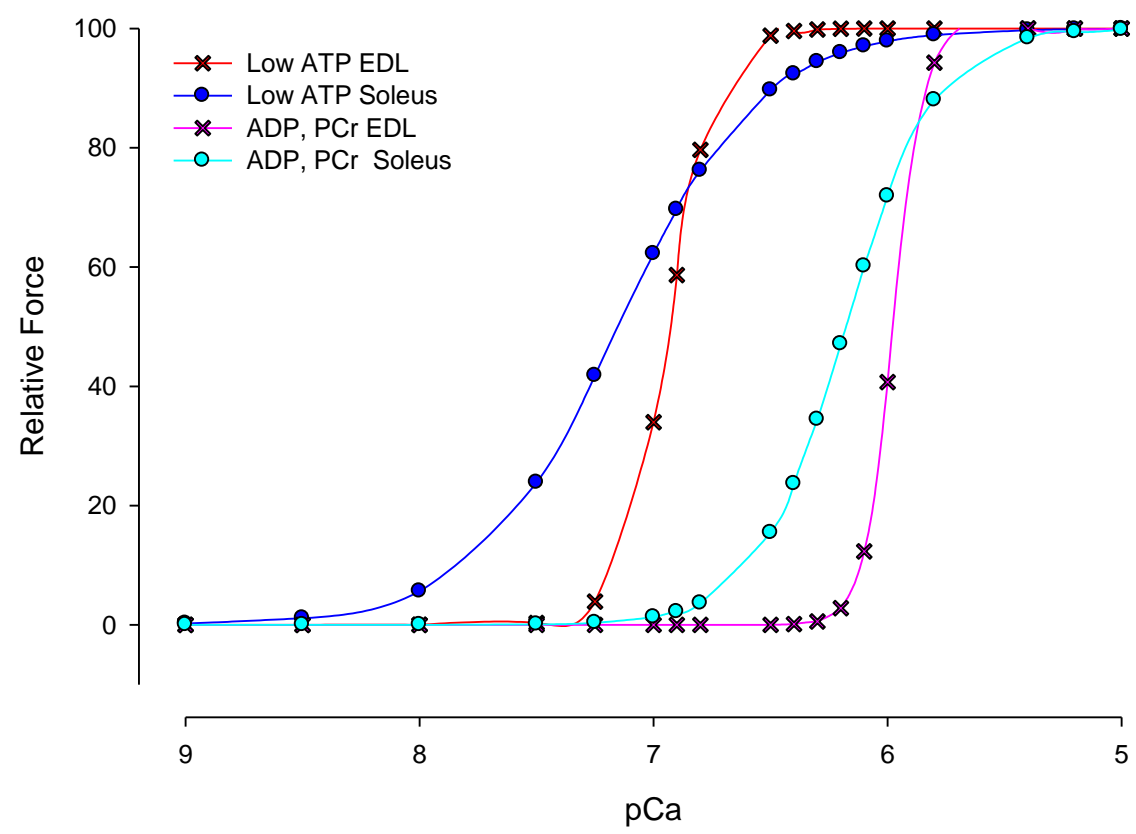

Figure 9. Effects of Metabolites on EDL and Soleus Fibers. Curves constructed based on the equation, $\mathrm{F} / \mathrm{F}_{\max }=\left[\mathrm{Ca}^{2+}\right]^{\mathrm{n}} *\left(\left[\mathrm{Ca}^{2+}\right]_{50}{ }^{\mathrm{n}}+\left[\mathrm{Ca}^{2+}\right]^{\mathrm{n}}\right)^{-1}$ based on $\mathrm{pCa}_{50}$ and $n_{\mathrm{H}}$ values from Table 4. Low ATP indicates $0.1 \mathrm{mM}$ ATP condition. 
Changes from the normal condition (2 ATP) are depicted graphically in Figure 10 to provide better visualization of the change in $\mathrm{Ca}^{2+}$ sensitivity as well as differences between EDL and soleus fibers. The $\mathrm{pCa}_{50}$ values are represented as a difference between

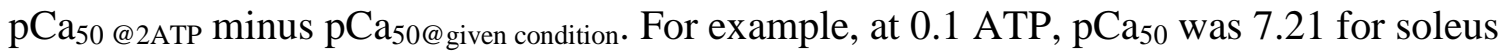
whereas at 2 ATP $\mathrm{pCa}_{50}$ was 6.26, equating to a difference value of 0.95 . Positive values are indicative of increased $\mathrm{Ca}^{2+}$ sensitivity whereas negative values indicate reduced $\mathrm{Ca}^{2+}$ sensitivity as compared to the 2 ATP control condition.

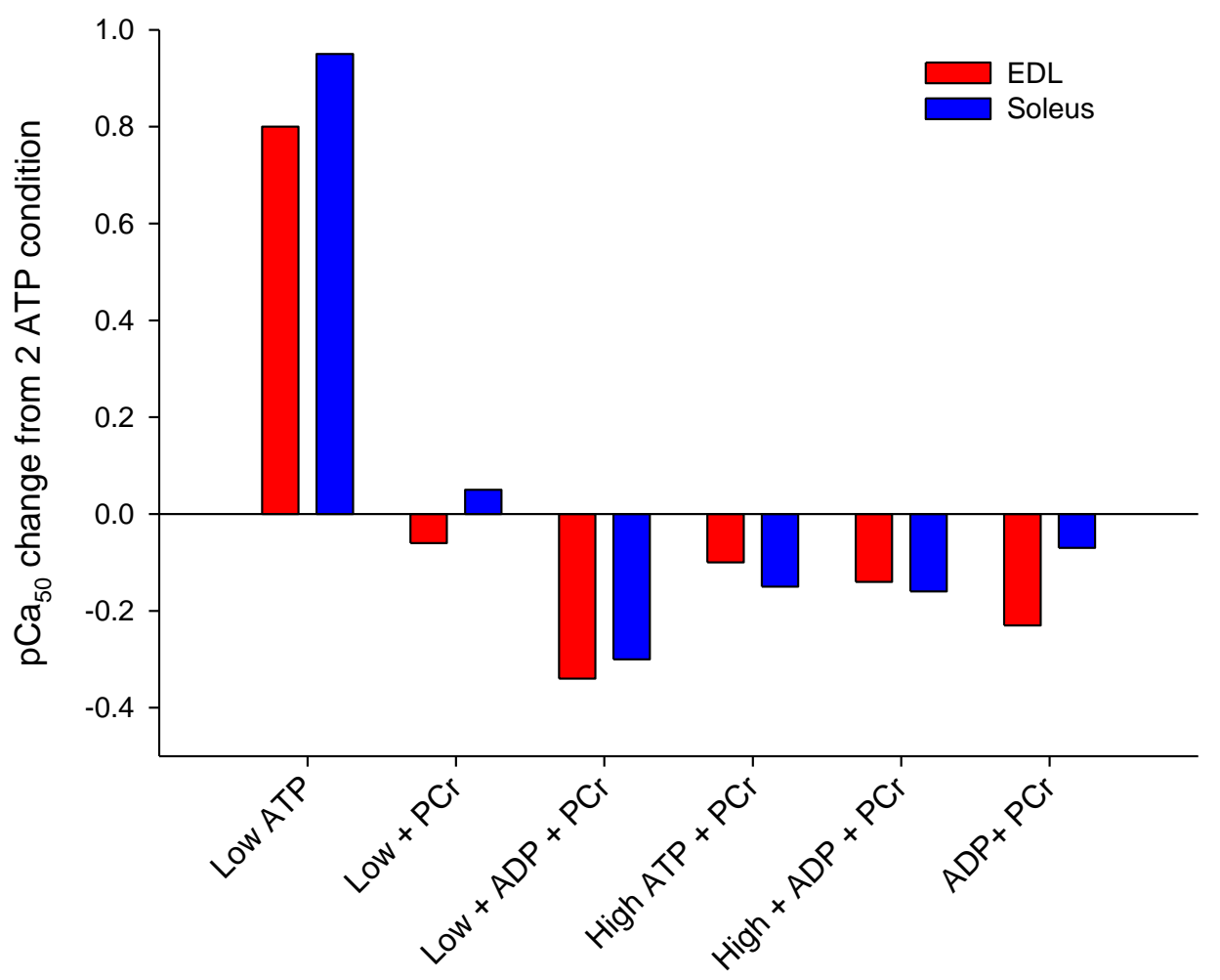

Figure 10. Differences Between $\mathrm{pCa}_{50}$ Values of the 2 ATP Condition Versus All Others. Values are differences between $\mathrm{pCa}_{50}$ of the 2 ATP condition minus $\mathrm{pCa}_{50}$ of condition listed on the $\mathrm{x}$-axis. Low $=0.1 \mathrm{mM}$ ATP and high $=2 \mathrm{mM}$ ATP. 
As previously reported, the 0.1 ATP condition had significantly higher $\mathrm{pCa}_{50}$ values compared to all other conditions as evidenced by the large change values reported in Figure 10. Comparisons between EDL and soleus for $\mathrm{pCa}_{50}$ revealed a significant difference between the ADP+PCr condition. Although the ADP+PCr condition did not differ from the normal 2 ATP condition in both EDL and soleus fibers, the soleus fibers were significantly more sensitive to $\mathrm{Ca}^{2+}$ than EDL fibers for the $\mathrm{ADP}+\mathrm{PCr}$ condition $(6.19 \pm 0.07$ vs. $6.00 \pm 0.06, \mathrm{P}<0.05)$.

\section{Experiment 2}

Raw fluorescence decay of NADH is presented in Figure 11 showing that with increasing $\left[\mathrm{Ca}^{2+}\right]$, the rate of decay also increases. Decay rates were computed from the slope of the line in $\mu \mathrm{M} / \mathrm{sec}$ normalized by fiber volume and are indicative of a net rate of change in $[\mathrm{ADP}]$. Slope values are presented in Figure 12 for EDL and soleus fibers in high and low [ATP] with and without $\mathrm{PCr}$ at high and low $\mathrm{Ca}^{2+}$ (pCa 5.4 and 9.0). At high [ATP], addition of PCr in solution caused a significant decline in slope values at both low and high $\left[\mathrm{Ca}^{2+}\right]$ in EDL and soleus fibers. The same pattern occurred in low [ATP] conditions but results were not statistically significant.

Comparisons between EDL and soleus fibers revealed lower slope values for soleus compared to EDL at all conditions with the exception of $2 \mathrm{ATP}+\mathrm{PCr}$ at $\mathrm{pCa} 9.0$ ( $7 \pm 3$ vs. $13 \pm 3 \mu \mathrm{M} / \mathrm{sec}, \mathrm{P}>0.05$ ) and none were statistically significant. The only exception was at pCa 5.4 for $2 \mathrm{ATP}+\mathrm{PCr}$ where mean slope for soleus was significantly lower than EDL (52 \pm 10 vs. $21 \pm 3 \mu \mathrm{M} / \mathrm{sec}, \mathrm{P}<0.05)$. 


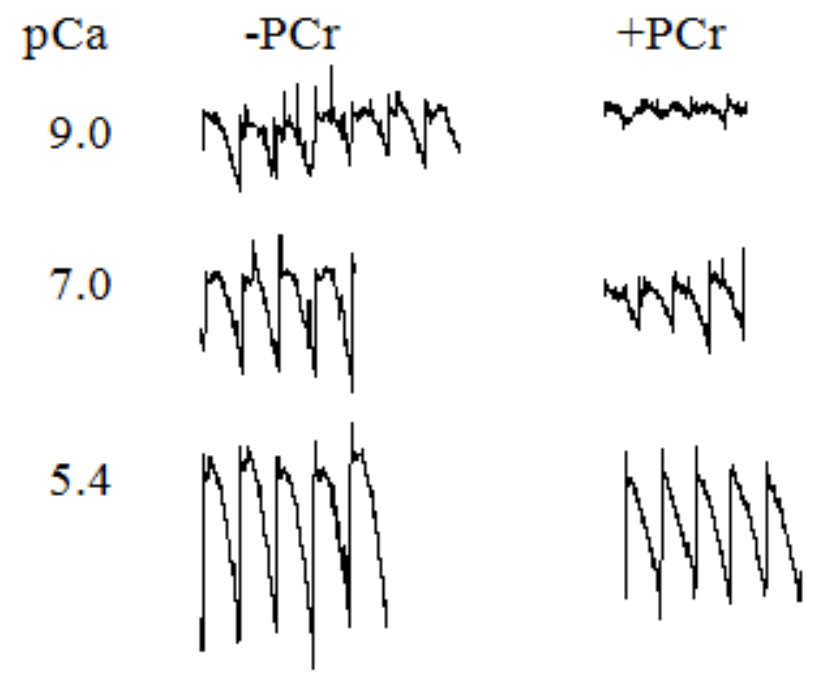

Figure 11. Raw tracings of NADH fluorescence decay at different $\left[\mathrm{Ca}^{2+}\right]$ without (-) and with (+) $10 \mathrm{mM}$ PCr at $2 \mathrm{mM}$ ATP.

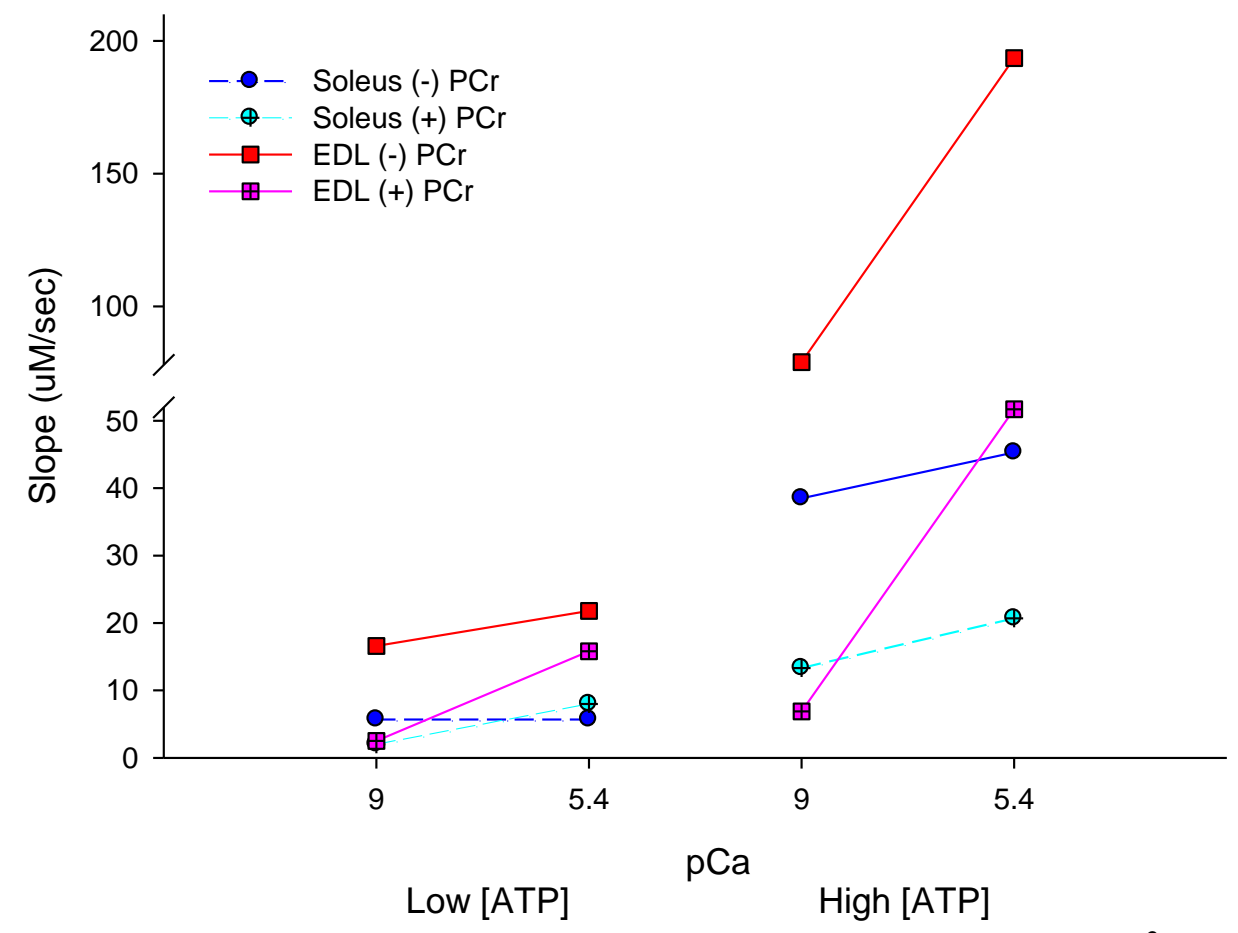

Figure 12. Change in NADH slope fluorescence decay at high and low $\mathrm{Ca}^{2+}$ in EDL and soleus muscle fibers. Values are slope in $\mu \mathrm{M} / \mathrm{sec}$. Low [ATP] indicates an [ATP] of 0.1 $\mathrm{mM}$ whereas high indicates $2 \mathrm{mM}$. (-) Without PCr, (+) With $\mathrm{PCr}(10 \mathrm{mM}$ concentration). 


\section{Experiment 3}

The effects of a change in [ATP] on the net rate of change of [ADP] are shown in Figure 13. Addition of PCr caused a reduction in the slope values compared to control conditions without PCr. Slope values also gradually declined in all conditions as [ATP] was reduced. These decreases in slope indicate two things: 1) decreased [ATP] lowers A.M.ATPase activity and 2) ADP accumulation is decreased in the presence of PCr.

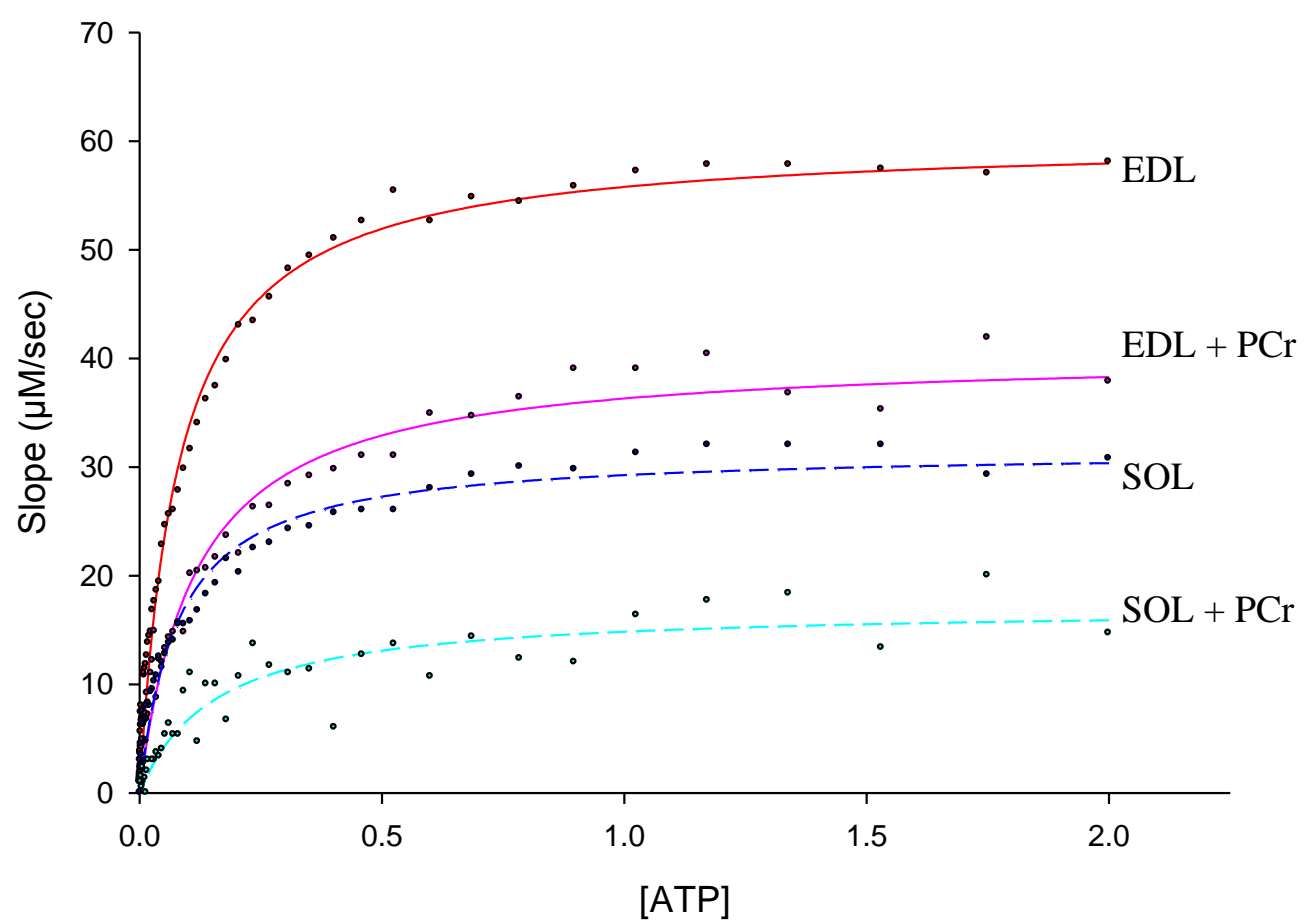

Figure 13. Slope change across an ATP gradient at high $\left[\mathrm{Ca}^{2+}\right]$. Values are slope in $\mu \mathrm{M} / \mathrm{sec}$. Lines labeled $+\mathrm{PCr}$ contain $10 \mathrm{mM}$ of PCr. Lines were constructed based on Michaelis-Menten kinetics. 


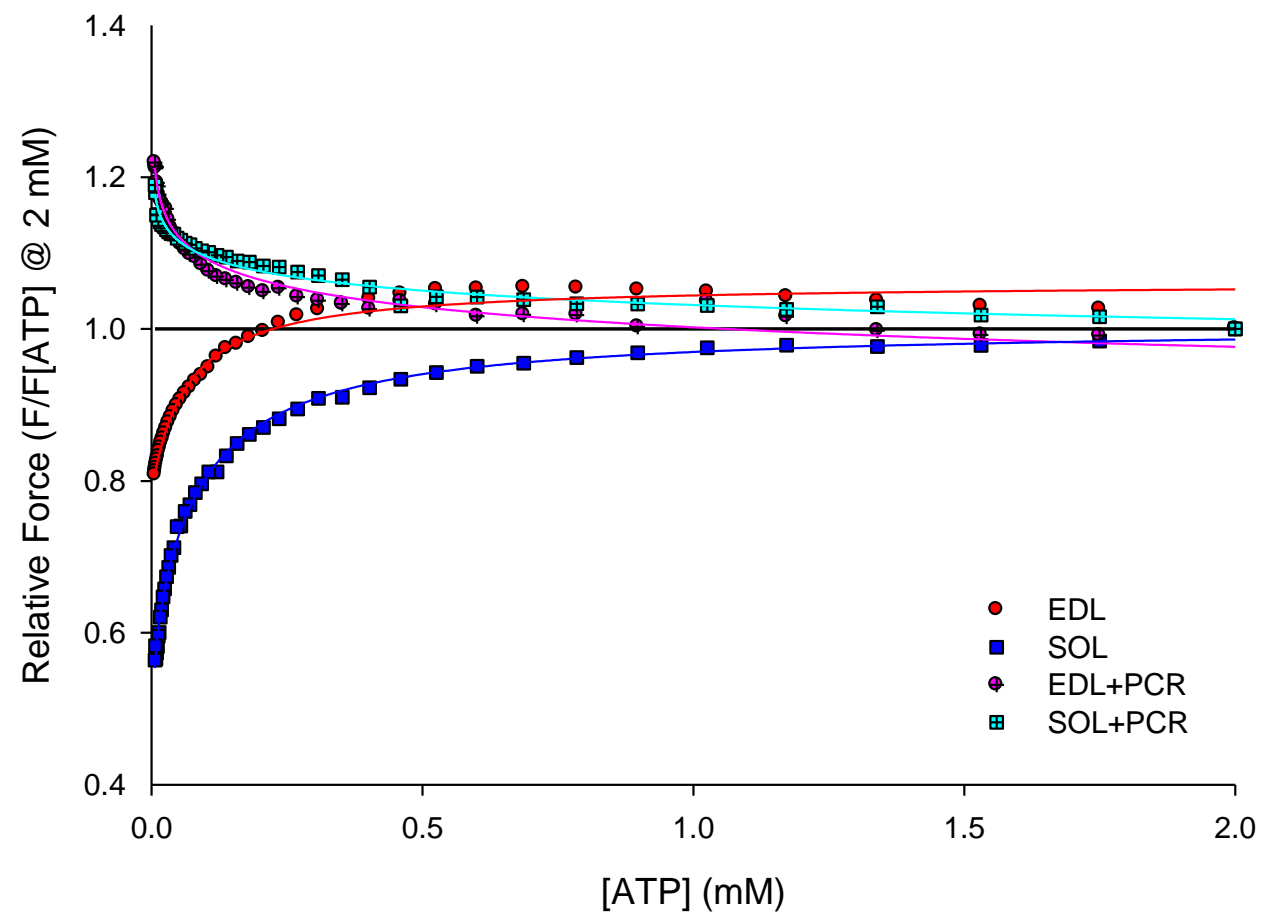

Figure 14. Force change across an $[A T P]$ gradient at high $\left[\mathrm{Ca}^{2+}\right]$. Fit lines for EDL and Soleus computed with the Michaelis-Menten equation.

The effects of changing [ATP] from 0 to $2 \mathrm{mM}$ on force are shown in Figure 14. Force values were adjusted by dividing all force values by force recorded at $2 \mathrm{mM}$ ATP. Fibers not supplied PCr showed an exponential increase in force as [ATP] increased (Km, 0.0025 for EDL and 0.1027 for soleus). When fibers were provided with $\mathrm{PCr}$ as [ATP] was decreased to low levels, force was approximately $15-20 \%$ larger than force values at 2 mM ATP.

\section{Experiment 4}

The [ADP] and [ATP] are reported as net rates of change in $\mu \mathrm{mol} / \mathrm{mg}$ wet weight/min in Table 5 and include both EDL and soleus muscles. Therefore changes are reflective of either net consumption or production. Analysis revealed a significant 
interaction between condition $\mathrm{X} \mathrm{Ca}^{2+}$ solution (Table 5, $\mathrm{P}<0.01$ ) for ADP rate only.

Further analysis revealed that the net change of [ADP] for the ADP+PCr condition was significantly higher in the high $\left[\mathrm{Ca}^{2+}\right]$ solution compared to the low $\left[\mathrm{Ca}^{2+}\right]$ solution.

Analysis of final concentrations of metabolites also revealed a significantly smaller $[\mathrm{ADP}]$ in high compared to low $\left[\mathrm{Ca}^{2+}\right](35.2 \pm 4.0$ vs. $52.8 \pm 4.0 \mu \mathrm{M} / \mathrm{mg}$ wet wt, $\mathrm{P}<$ 0.002). Net change rates did not differ between fiber types but there was a significant interaction between muscle type $\mathrm{X}$ condition for both [ATP] and [ADP] (Table 6, P < 0.03). Contrast testing revealed that [ATP] was significantly smaller in EDL bundles for conditions ATP and ATP+PCr when compared to soleus. Also [ADP] was significantly smaller in EDL than soleus for the ADP+PCr condition.

Table 5. Net Change in Metabolites at high and low $\left[\mathrm{Ca}^{2+}\right]$

$$
\text { High }\left[\mathrm{Ca}^{2+}\right]
$$

\section{Low $\left[\mathrm{Ca}^{2+}\right]$}

\begin{tabular}{ccccc} 
Condition & ATP & ADP & ATP & ADP \\
\hline ATP & $2.31 \pm 0.18$ & $0.45 \pm 0.11$ & $2.20 \pm 0.18$ & $0.42 \pm 0.11$ \\
ATP+PCr & $2.31 \pm 0.18$ & $0.06 \pm 0.11$ & $1.90 \pm 0.18$ & $0.06 \pm 0.11$ \\
ADP+PCr & $1.18 \pm 0.18$ & $2.01 \pm 0.11 *$ & $0.78 \pm 0.18$ & $1.43 \pm 0.11$ \\
\hline
\end{tabular}

Values are mean \pm SE and are reported in $\mu \mathrm{M} / \mathrm{mg}$ of wet weight / min. * Significantly different than low $\mathrm{Ca}^{2+}$. Net changes are computed after 30 minutes of activity in high (pCa 4.0) or low ( $\mathrm{pCa} 9.0$ ) $\mathrm{Ca}^{2+}$. Initial concentrations of ATP $=5 \mathrm{mM}, \mathrm{ADP}=2 \mathrm{mM}$, and $\mathrm{PCr}=10 \mathrm{mM}$. Number of skeletal muscle fiber bundles $(\mathrm{n}=10)$ for each condition. 
Table 6. Metabolite values in rat EDL and soleus bundles

EDL

SOL

\begin{tabular}{ccccl} 
Condition & ATP & ADP & ATP & \multicolumn{1}{c}{ ADP } \\
\hline ATP & $150.5 \pm 11.8 *$ & $13.2 \pm 4.0$ & $199.3 \pm 11.8$ & $12.7 \pm 4.0$ \\
ATP+PCr & $145.9 \pm 11.8 *$ & $1.5 \pm 4.0$ & $206.5 \pm 11.8$ & $2.0 \pm 4.0$ \\
ADP+PCr & $25.9 \pm 11.8$ & $34.8 \pm 4.0 *$ & $32.1 \pm 11.8$ & $53.2 \pm 4.0$ \\
\hline
\end{tabular}

Values are mean \pm SE and are reported in $\mu \mathrm{M}$ per mg of wet weight. * Significantly different than soleus. Number of skeletal muscle fiber bundles $(n=10)$ for each condition.

Overall, there was a treatment effect $(\mathrm{P}<0.0001)$ for both the net rate change of $[\mathrm{ATP}]$ and $[\mathrm{ADP}]$ as well as final concentrations of ATP and ADP (Table 7). Net rate change values for $[\mathrm{ADP}]$ indicate that addition of $\mathrm{PCr}$ to ATP decreases ADP production. Values for net rate change in the $\mathrm{ADP}+\mathrm{PCr}$ condition indicate ATP production is possible with endogenous $\mathrm{CK}$ in skinned fiber bundles. For reference, data for all conditions, muscle type, and $\left[\mathrm{Ca}^{2+}\right]$ are reported below in Table 8 for both final concentrations and net rate changes of ATP and ADP.

Table 7. Net rate change and metabolite values for the three conditions

Net Rate Change ( $\mu \mathrm{M} / \mathrm{mg}$ of wet weight / min)

Condition ATP ATP $\mathrm{ATP}+\mathrm{PCr}$ $2.25 \pm 0.13^{\mathrm{a}}$ $2.10 \pm 0.13^{\mathrm{a}}$ ADP+PCr $\quad 0.98 \pm 0.13^{\mathrm{b}}$ ADP
Concentration ( $\mu \mathrm{M} / \mathrm{mg}$ of wet weight) ATP ADP $174.9 \pm 8.3^{\mathrm{a}}$ $176.2 \pm 8.3^{\mathrm{a}}$ $13.0 \pm 2.8^{\mathrm{a}}$ $1.7 \pm 2.8^{\mathrm{b}}$

alues are mean \pm SE. Conditions with identical letters are not significantly different from one another. $\mathrm{N}=20$ for each condition. 
Table 8. Metabolite values in high and low $\left[\mathrm{Ca}^{2+}\right]$ of rat EDL and soleus bundles

Net Rate Change ( $\mu \mathrm{M} / \mathrm{mg}$ wet weight/min)

\begin{tabular}{cccccc}
${\left[\mathbf{C a}^{2+}\right]}_{\text {Low }}$ & & \multicolumn{2}{c}{ EDL } & \multicolumn{2}{c}{ SOL } \\
& Condition & ATP & ADP & ATP & ADP \\
& ATP & $2.10 \pm 0.27$ & $0.46 \pm 0.16$ & $2.31 \pm 0.26$ & $0.38 \pm 0.16$ \\
& ATP+PCr & $1.93 \pm 0.26$ & $0.05 \pm 0.16$ & $1.85 \pm 0.26$ & $0.07 \pm 0.16$ \\
& $\mathbf{A D P}+\mathbf{P C r}$ & $0.70 \pm 0.26$ & $1.35 \pm 0.16$ & $0.85 \pm 0.26$ & $1.50 \pm 0.16$ \\
$\mathbf{H i}$ & & & & & \\
\hline & $\mathbf{A T P}$ & $2.01 \pm 0.26$ & $0.43 \pm 0.16$ & $2.55 \pm 0.26$ & $0.47 \pm 0.16$ \\
& $\mathbf{A T P + P C r}$ & $2.10 \pm 0.26$ & $0.05 \pm 0.16$ & $2.52 \pm 0.26$ & $0.06 \pm 0.16$ \\
& $\mathbf{A D P + P C r}$ & $1.07 \pm 0.26$ & $1.85 \pm 0.16$ & $1.30 \pm 0.26$ & $2.21 \pm 0.16$ \\
\hline
\end{tabular}

Final Concentrations ( $\mu \mathrm{M} / \mathrm{mg}$ wet weight)

$$
\left[\mathrm{Ca}^{2+}\right]
$$

EDL

SOL

\begin{tabular}{cccccc} 
Low & Condition & ATP & ADP & ATP & ADP \\
\hline & ATP & $157.2 \pm 16.7$ & $13.7 \pm 5.6$ & $202.9 \pm 16.7$ & $11.4 \pm 5.6$ \\
& ATP+PCr & $148.6 \pm 16.7$ & $1.5 \pm 5.6$ & $216.5 \pm 16.7$ & $2.0 \pm 5.6$ \\
& ADP+PCr & $20.8 \pm 16.7$ & $41.7 \pm 5.6$ & $25.4 \pm 16.7$ & $63.8 \pm 5.6$
\end{tabular}

Hi

$\begin{array}{ccccc}\mathbf{A T P} & 143.8 \pm 16.7 & 12.7 \pm 5.6 & 195.7 \pm 16.7 & 14.0 \pm 5.6 \\ \mathbf{A T P}+\mathbf{P C r} & 143.0 \pm 16.7 & 1.4 \pm 5.6 & 196.5 \pm 16.7 & 1.9 \pm 5.6 \\ \mathbf{A D P}+\mathbf{P C r} & 31.1 \pm 16.7 & 27.9 \pm 5.6 & 38.9 \pm 16.7 & 42.5 \pm 5.6\end{array}$

Values are mean \pm SE. Number of skeletal muscle fiber bundles $(n=10)$ for each condition. 


\section{DISCUSSION}

The primary finding of this study is that endogenous CK can permit normal function of the contractile apparatus in glycerol skinned skeletal muscle fibers. Under limiting conditions of ATP substrate $(0.1 \mathrm{mM})$, added PCr allows normal isometric force generation across a range of $\left[\mathrm{Ca}^{2+}\right]$. Indirect evidence (reduced net ADP production as measured by NADH fluorescence) revealed that endogenous CK was able to convert ADP produced by A.M.ATPase to ATP in skeletal muscle across gradients of both $\mathrm{Ca}^{2+}$ and ATP. HPLC measurements of ATP and ADP directly confirmed that skinned skeletal muscle bundles have sufficient endogenous CK activity to produce ATP from substrates (ADP, PCr) and the ability to maintain low [ADP] in the presence of PCr. By showing how changing demands on skeletal muscle (through increased $\mathrm{Ca}^{2+}$ ) alters force production and calcium sensitivity, these findings lend support for the importance of the ATP regeneration system in skeletal muscle.

\section{Specific Aim 1}

The primary finding of experiment one is that skeletal muscle fibers supplied with 0.1 ATP and the metabolite(s) necessary to generate endogenous ATP, or only the metabolites of the CK reaction, generated force-pCa curves similar to the control condition of 2 mM ATP (see Figures 8 \& 9). The addition of metabolites (ADP and PCr) to fiber conditions where [ATP] was already sufficient (2 mM) (Figure 7), did not appear to cause any significant changes in either $\mathrm{pCa}_{50}$ or $n_{\mathrm{H}}$.

Investigations on the effects of $\mathrm{PCr}$ on contractile performance have shown that removal of PCr in skinned heart fibers with $3.2 \mathrm{mM}$ ATP induced a small leftward shift in the force/pCa curve, $\left(\mathrm{pCa}_{50}\right.$ increased from 5.7 to 5.9, $\left.\mathrm{P}<0.01\right)$ reflecting decreased 
$\mathrm{Ca}^{2+}$ sensitivity (Ventura-Clapier et al., 1987). In the current study, removal of $\mathrm{PCr}$ at high [ATP] $(2 \mathrm{mM})$ had minimal effects $\left(\mathrm{pCa}_{50}\right.$ decreased 6.2 to $\left.6.1, \mathrm{P}>0.05\right)$ which is possibly due to sufficient [ATP] whereby any further ATP generation did not noticeably alter contractile performance. It is possible that ADP production by A.M.ATPase from 2 mM ATP was not significant enough to impact $\mathrm{Ca}^{2+}$ sensitivity as the previously mentioned studied used [ATP] of $3.2 \mathrm{mM}$ and only assessed $\mathrm{Ca}^{2+}$ sensitivity of four fibers without PCr (Ventura-Clapier et al., 1987). However an increase in [ATP] from 2 to $3.2 \mathrm{mM}$ may not have much impact as the $\mathrm{K}_{\mathrm{mATP}}$ for A-M.ATPase is $0.2 \mathrm{mM}$. Despite no effect of PCr removal on contractile performance at $2 \mathrm{mM}$ ATP, removal of $\mathrm{PCr}$ from 0.1 ATP solutions did influence contractile performance.

Lowering [ATP] from 2 to $0.1 \mathrm{mM}$ caused a significant increase in $\mathrm{Ca}^{2+}$ sensitivity in both EDL and soleus fibers. One primary cause can be attributed to the rate of XBs transitioning between strong binding (SB) and weak binding (WB) states (Figure 5). Here, reduced availability of ATP decreases ATP binding to sites on myosin heads which prolongs XBs in the SB state (Figure 5). Therefore reduced [ATP] causes increased force below saturating conditions of $\mathrm{Ca}^{2+}$ resulting in increased $\mathrm{Ca}^{2+}$ sensitivity ( $\mathrm{pCa}_{50}, 7.1$ ). This finding can also be explained by a model developed by Brenner (1988) which describes isometric force $(\mathrm{F})$ utilizing rate constants of XBs transitioning from WB to SB $\left(\mathrm{f}_{a p p}\right)$ and SB to WB ( $\left.\mathrm{g}_{a p p}\right)$ states (see Figure 15), as well as the number of XBs actively participating in force generation (n), and average force per $\mathrm{XB}\left(\mathrm{F}_{\mathrm{av}}\right)$. Using these rate constants, Brenner developed an equation:

$$
\mathrm{F}=n * \mathrm{~F}_{\mathrm{av}} *\left[\mathrm{f}_{a p p} /\left(\mathrm{f}_{a p p}+\mathrm{g}_{a p p}\right)\right]
$$


Based on the above equation, a reduction in force in the 0.1 ATP condition may be due to a reduction in $g_{\text {app }}$ which would seem reasonable. The addition of $\mathrm{PCr}$ and/or ADP allowed for ATP regeneration in 0.1 ATP conditions, thus $\mathrm{pCa}_{50}$ returned to normal levels (5.9-6.2), hence, it can be assumed that $g_{\text {app }}$ was not impaired. Kerrick et al. (1991) showed a leftward shift in the force/pCa curve between 2 and $0.5 \mathrm{mM}$ ATP $\left(\mathrm{pCa}_{50} 5.4\right.$ and 5.6, respectively) whereas the current study found a greater leftward shift in the

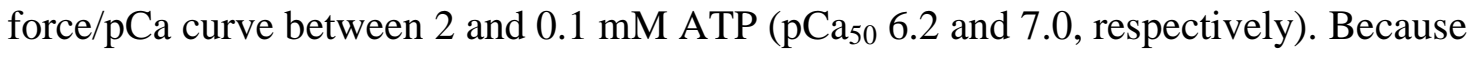
the $\mathrm{K}_{\mathrm{mATP}}$ for A-M-ATPase is $0.2 \mathrm{mM}$, the lower [ATP] of the current study compared to Kerrick et al. (1991) is likely responsible for the greater leftward shift of the force/pCa curve by placing greater demands on A-M.ATPase due to limited [ATP] availability.

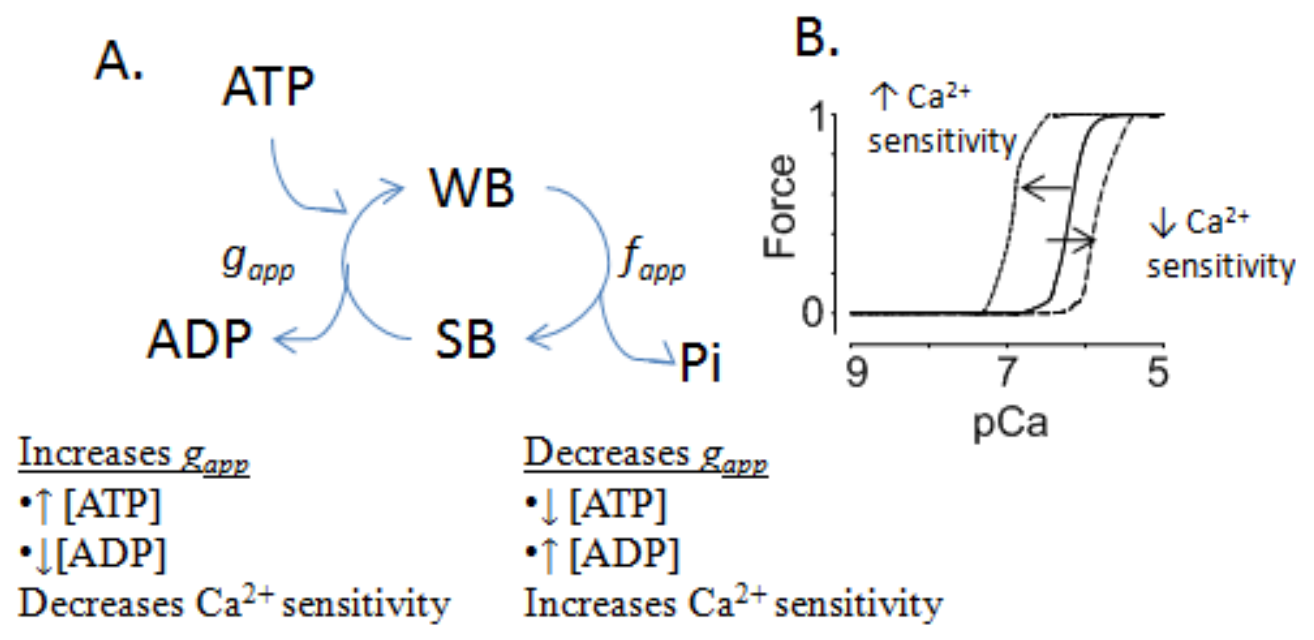

Figure 15. (A) Effects of ATP and ADP on $g_{a p p}$. WB = weak binding state, $\mathrm{SB}=$ strong binding state. (B) Force-pCa curves demonstrating shift from the solid line curve to the left and right indicating changes in $\mathrm{Ca}^{2+}$ sensitivity.

Previous studies have shown that increased [ADP] increases $\mathrm{F}_{\max }$ at saturating $\left[\mathrm{Ca}^{2+}\right]$ (pCa 4.5) (Cooke \& Pate, 1985; Metzger, 1996). These studies used concentrations of ADP on the order of 1-4 mM (Cooke \& Pate, 1985) and $5 \mathrm{mM}$ (Metzger, 1996). 
However other studies have shown that $[\mathrm{ADP}]$ in the physiological range $(10-300 \mu \mathrm{M})$ has little to no effect on maximal force generation (Chase \& Kushmerick, 1995). The results of the current study suggest that with sufficient $\mathrm{PCr}(10 \mathrm{mM})$, an [ADP] of $2 \mathrm{mM}$ has negligible effects on $\left[\mathrm{Ca}^{2+}\right]_{50}$ which may be due to endogenous $\mathrm{CK}$ lowering [ADP] and increasing [ATP] availability (see Specific Aim 2). Also the addition of ADP and/or $\mathrm{PCr}$ does not appear to significantly alter $\mathrm{pCa}_{50}$ values at high [ATP] $(2 \mathrm{mM})$ possibly because of saturating binding sites on A.M.ATPase. On the contrary at low $[\mathrm{ATP}]$ where $\mathrm{pCa}_{50}$ was significantly altered, addition of $\mathrm{PCr}$ returned $\mathrm{pCa}_{50}$ values similar to the 2 ATP condition. This is most likely due to CK being able to regenerate ATP to concentrations of $2 \mathrm{mM}$. Additional $\mathrm{ADP}$ with $\mathrm{PCr}$ at $0.1 \mathrm{ATP}$ resulted in reduced $\mathrm{Ca}^{2+}$ sensitivity as compared to the 2 ATP condition. The cause for this may be that due to additional ADP substrate, $[\mathrm{ATP}]$ was increased further which results in an increase in $\mathrm{g}_{a p p}$ (see Figure 15).

The steepness of the force/pCa curves were within a range of acceptable values as they can vary across experiments. Hill coefficients can be related to the four $\mathrm{Ca}^{2+}$ binding sites on troponin-C, of which two regulate the rate of ATP hydrolysis by A-M.ATPase (Potter \& Gergely, 1975; Kerrick et al., 1991). In EDL, slope values were larger than 4 suggesting that other components besides the four $\mathrm{Ca}^{2+}$ binding sites alter $n_{\mathrm{H}}$. While it is beyond the scope of this investigation to determine the specific mechanism, it is hypothesized that the rate at which the XBs cycle may influence $n_{\mathrm{H}}$. For example, low [ATP] caused a leftward shift in the force/pCa relationship which also lowered $n_{\mathrm{H}}$. Upon addition of PCr to the low [ATP], the effects on the force/pCa curve had a rightward shift and $n_{\mathrm{H}}$ increased to a value similar to high [ATP] in soleus fibers. 
Force values were variable across all conditions and ranged from 0.8 to 4.3 $\mathrm{kN} / \mathrm{m}^{2}$. The low $\left[\mathrm{ATP}\right.$ ] condition had significantly lower $\mathrm{F}_{\max }$ compared to the ADP+PCr condition $\left(0.80 \pm 0.69\right.$ vs. $\left.3.96 \pm 0.62 \mathrm{kN} / \mathrm{m}^{2}, \mathrm{P}<0.05\right)$. However one trend that can be noted is in EDL fibers, only the 0.1 ATP condition had impairments in maximal force generation. In other conditions where ATP was either adequate $(2 \mathrm{mM})$ or metabolites for the $\mathrm{PCr}$ system were present, $\mathrm{F}_{\max }$ was similar between conditions presumably due to the regeneration of ATP by CK.

A previous study using rat heart muscle reported that the addition of $\mathrm{PCr}(12 \mathrm{mM})$ to a $3.2 \mathrm{mM}$ ATP solution caused an $18 \%$ reduction in maximal force compared to a 12 mM solution of ATP (Ventura-Clapier et al., 1987). Therefore addition of PCr activates the endongenous $\mathrm{CK}$ enzyme and helps to maintain low [ADP] and theoretically reduces $\mathrm{F}_{\max }$. Increasing the supply of ATP may increase the amount of ADP present during active $\mathrm{XB}$ cycling which could increase force production. The data from Ventura-Clapier et al. (1987) coupled with the inconsistent results of [ADP] influencing tension levels in skinned skeletal muscle fibers (Cooke \& Pate, 1985; Chase \& Kushmerick, 1995; Metzger, 1996) warrants further study as findings presented here found no significant influence on $\mathrm{F}_{\max }$ with added ADP. However all conditions presented with increased ADP above physiological levels ( $10 \mu \mathrm{M}$ at rest to $300 \mu \mathrm{M}$ during exercise) was most likely minimized with $10 \mathrm{mM}$ PCr.

This study lends further support for the idea of functional coupling between CK and $\mathrm{A} \cdot \mathrm{M} \cdot \mathrm{ATPase}$ due to improvements in contractile performance when $[\mathrm{ATP}]$ was below the $\mathrm{K}_{\mathrm{mATP}}$ for A-M.ATPase. This is in spite of criticisms that the two enzymes $(\mathrm{CK}$ and $\mathrm{A} \cdot \mathrm{M} \cdot \mathrm{ATPase})$ are not coupled because of their distance $(>10 \mathrm{~nm})$ and that 
consumption of substrates by the enzymes is done at rates higher than their diffusion rates (Arrio-Dupont et al., 1992; Barros \& Martinez, 2007). The skinned fiber system used in the current study provided a way to assess whether endogenous CK present on the M-line of the sarcomere could sufficiently support contractile function. While diffusion measurements for ATP and PCr were not determined in this study, ${ }^{31} \mathrm{P}-\mathrm{NMR}$ studies have shown that diffusion of ATP and PCr are directionally dependent as opposed to being homogenous in all directions in cell cytosol (Kinsey et al., 1999; de Graaf et al., 2000). Also, a limitation with current ${ }^{31} \mathrm{P}-\mathrm{NMR}$ techniques is that it may be difficult to detect CK flux based on small microcompartments in vivo. A study performed on transgenic mice with graded expressions of MM-CK levels showed that in mice expressing only one-third the CK activity of wild-type controls had normal CK flux values (van Deursen et al., 1994). This indicates that ${ }^{31} \mathrm{P}-\mathrm{NMR}$ measurements may not be able to detect $\mathrm{CK}$ flux in microcompartments such as at the M-line in the sarcomere or near the sarcoplasmic reticulum. While this study presents an isolated microcompartment (the sarcomeres of a single skeletal muscle fiber), these results demonstrate that ATP produced by endogenous $\mathrm{CK}$ can be consumed by A-M.ATPase, suggesting the two enzymes are coupled.

With respect to diffusion distances of ATP reaching active sites on myosin heads, 0.1 ATP conditions with the ability to regenerate ATP did not appear to differ from conditions with adequate ATP $(2 \mathrm{mM})$, as both produced similar force/pCa curves. These data indicate that while contractile performance is impaired at low [ATP], additional metabolites of PCr with or without ADP restore function similar to conditions with $2 \mathrm{mM}$ ATP as well as conditions of ADP+PCr. Also, in the complete absence of ATP, skinned 
skeletal muscle fibers were able to generate normal force/pCa curves with only the substrates of the $\mathrm{CK}$ reaction (ADP, $\mathrm{PCr}$ ).

\section{Specific Aim 2}

The primary finding of the second experiment was that A.M.ATPase appears to use a combination of both exogenous ATP and endogenously generated ATP. In control conditions without $\mathrm{PCr}$, the large slope values for $\mathrm{NADH}$ fluorescence decay were indicative of ADP being shuttled through the PK/LDH pathway (see Figure 6, pg. 30). Addition of PCr to 2 or 0.1 ATP conditions caused a decrease in slope due to ADP being rephosphorylated to ATP by CK. This indirectly shows that CK was able to rephosphorylate ADP produced by A-M.ATPase. However, with added PCr, not all ADP was effectively recycled due to some detection of NADH fluorescence decay.

A similar finding was observed in rabbit heart myofibrils (Saks et al., 1984) where at least half of the ADP produced by A-M.ATPase was used by CK as opposed to PK, and this was with 50 times the amount of PK activity compared to CK activity. In the current study, exogenous PK activity was set at $25 \mathrm{U} / \mathrm{ml}$ whereas endogenous CK activity was not directly measured. After repeated washing of skinned fibers of chicken pectoralis muscle, CK activity was approximately 5-10\% of total cytosolic CK activity of an intact whole muscle (Wallimann et al., 1984; Gregor et al., 1999). Another author found that CK activity of glycerinated rabbit skeletal muscle was $1.8 \mu \mathrm{moles} / \mathrm{min} / \mathrm{mg}$ protein (Savabi et al., 1983) which was $26 \%$ of total cytosolic CK activity. This small activity of CK bound to the M-line in muscle fibers is remarkable in that it can generate sufficient ATP to meet the demands of A.M.ATPase despite making up a small portion of total MM-CK in skeletal muscle. 
Although CK activity was not measured, skinned fibers supplied with $0.1 \mathrm{mM}$ ATP and PCr from Experiment 1 were able to produce force-pCa curves similar to conditions with $2 \mathrm{mM}$ ATP (see Figure 7). This finding, coupled with reductions in NADH fluorescence decay with added PCr support the idea that endogenous CK rephosphorylates ADP produced by A-M.ATPase which can then be used to support XB cycling. One criticism of slope detection is that it relies on the PK reaction which produces ATP. While it is unlikely that the activity of PK was sufficient to impact findings on the importance of the $\mathrm{CK}$ regeneration system, force-pCa curves generated in experiment 1 did not contain added PK, therefore the influence of ATP production from that pathway was not possible. Despite the production of ATP through the PK reaction, a prior study in heart fibers found that even when PK activity was 100-times greater than $\mathrm{CK}$ activity, it was not enough to prevent creatine formation which suggests that ADP has preferential access to the CK reaction as opposed to PK (Saks et al., 1984). Therefore the decreased slope can be attributed to CK rephosphorylating ADP produced by A.M.ATPase to ATP.

Raising the [ATP] from 0.1 to $2 \mathrm{mM}$ resulted in increased slope values indicating an increase in ADP production by the A.M.ATPase reaction. This agrees with the findings of Saks et al. (1984) where the rate of ADP utilization was compared between 1 and $0.05 \mathrm{mM}$ ATP in skinned rat heart myofibrils. Slope measurements in conditions with PCr showed reduced slope values in both high and low [ATP] although much larger differences were found in high [ATP]. One exception occurred for soleus fibers in low [ATP] solution with and without PCr. Without PCr, slope values did not differ as $\left[\mathrm{Ca}^{2+}\right]$ increased $\left(5.7 \mu \mathrm{M} / \mathrm{sec}\right.$ for both low and high $\left.\mathrm{Ca}^{2+}\right)$ but did with $\mathrm{PCr}(2$ vs. $8 \mu \mathrm{M} / \mathrm{sec}$, low 
and high $\mathrm{Ca}^{2+}$, respectively). Slope values were already impeded due to the low [ATP] and with additional PCr, values were further reduced. Because A·M.ATPase activity is lower in soleus fibers compared to EDL, this may partly explain why soleus fibers did not differ at low [ATP] between high and low $\mathrm{Ca}^{2+}$. However in EDL fibers slopes did decline as they were slightly larger than soleus, but these declines were not significant. Therefore it may be that the low [ATP] limiting A-M.ATPase activity was more of a factor regardless of differences in maximal rates of A-M.ATPase. Based on data from experiment 1 where contractile performance was noticeably altered at low [ATP], improvements in contractile performance occurred upon addition of $\mathrm{PCr}$ whereas minimal changes occurred when $\mathrm{PCr}$ was added to high [ATP] conditions. This information coupled with slope data at low [ATP] indicates that PCr may be more important in situations where [ATP] is limited.

In summary, at least some of the ADP produced by A.M.ATPase appeared to be converted to ATP through the CK pathway and this conversion was limited when [ATP] was reduced to $0.1 \mathrm{mM}$. Due to similar $\mathrm{K}_{\mathrm{mADP}}$ values for CK and PK $(0.1 \mathrm{mM})$ (ArrioDupont et al., 1992; Krause \& Jacobus, 1992), with PK activity at $25 \mathrm{U} / \mathrm{ml}$, endogenous CK activity was sufficient to effectively compete with PK for ADP as evidenced by the reduced slope values compared to control conditions. However not all ADP was converted because slope values were still detected despite inclusion of PCr. This does indicate that $\mathrm{CK}$ is able to effectively utilize ADP produced by A.M.ATPase.

The third experiment was designed to determine the effects of $\mathrm{PCr}$ on the net rate of ADP utilization and $\mathrm{F}_{\max }$ across an $[\mathrm{ATP}]$ gradient at maximal $\left[\mathrm{Ca}^{2+}\right]$. The primary finding was that without PCr, $\mathrm{F}_{\max }$ declined as [ATP] declined. Limiting [ATP] may have 
resulted in increased formation of rigor bonds, thereby altering XB cycling rates causing a reduction in $\mathrm{F}_{\max }$. In control conditions without $\mathrm{PCr}$, slope values declined as [ATP] declined and this same pattern occurred in conditions with PCr. However, $\mathrm{F}_{\max }$ values increased as [ATP] was reduced with added PCr.

It is not entirely clear why force increased at low [ATP] with PCr. Slope values decreased in a similar fashion and were lower than control conditions at all [ATP], which indicated some ADP produced by A·M·ATPase is converted to ATP by endogenous CK. Thus at any given [ATP] where PCr was available, [ATP] was most likely increased above the given concentration. An interesting experiment by Sata et al. (1996) showed actin filament sliding velocity much higher when $\mathrm{CK}$ was present in their model $\left(\mathrm{K}_{\mathrm{mATP}}\right.$ $0.05 \mathrm{mM}$ with CK, $0.1 \mathrm{mM}$ without CK). Perhaps CK activity allowed greater velocity of shortening through some unknown mechanism because when the authors used the PEP/PK ATP regeneration system, $\mathrm{K}_{\mathrm{mATP}}$ was not reduced, despite lowering [ADP]. This lends further support that the location of endogenous CK near the active site of A.M.ATPase hydrolysis not only provides ATP, but alters enzyme kinetics resulting in favorable improvements, possibly maintained force at low [ATP].

Another factor may have been that the experiment was performed in high $\mathrm{Ca}^{2+}$ (pCa 4.0) conditions, as a similar experiment using skinned rat heart fibers by VenturaClapier \& Vassort (1985) was done without any added $\mathrm{Ca}^{2+}$. The authors demonstrated that rigor bonds form in low $\mathrm{Ca}^{2+}(\mathrm{pCa} 9.0)$ solution thereby increasing force as $[\mathrm{ATP}]$ is reduced. However in the current study at high $\mathrm{Ca}^{2+}(\mathrm{pCa} 4.0)$, as [ATP] was reduced without PCr, force declined which can be explained by rigor bonds forming and thus limiting the number of participating XBs to force generation. Furthermore, when cardiac 
fibers had a supply of PCr, force did not change at any [ATP] due to the regeneration potential of the $\mathrm{CK}$ reaction. It is likely that the high $\left[\mathrm{Ca}^{2+}\right]$ caused some contribution to increased force at low [ATP] in PCr conditions due to the ability of the system to recycle ATP, as it has been shown that CK can generate sufficient ATP to power XB cycling with very little ADP $(4 \mu \mathrm{M})$ when $[\mathrm{PCr}]$ is sufficient $(10 \mathrm{mM})$ (Savabi et al., 1983). Therefore perhaps at low [ATP], endogenous CK is able to produce ATP in close proximity to the A.M.ATPase sites which lend a small improvement (10-20\%) in force production.

The fourth experiment provided direct evidence that ADP (2 mM) and PCr (10 $\mathrm{mM}$ ) are sufficient to generate ATP within skinned skeletal muscle fibers without exogenous ATP. This is also supported by the ATP+PCr condition in which the [ADP] was extremely low $(0.06 \pm 0.08 \mu \mathrm{M} / \mathrm{mg}$ wet weight $)$. Conversely, [ADP] was significantly higher $(0.44 \pm 0.08 \mu \mathrm{M} / \mathrm{mg}$ wet weight $)$ in the ATP only condition due to the lack of PCr.

Despite an interaction between condition and $\left[\mathrm{Ca}^{2+}\right]$, only the ADP+PCr condition differed in $[A D P]$. Here, the $[A D P]$ was significantly less in the high $\mathrm{Ca}^{2+}$ solution compared to the low, which also led to a higher [ATP] (although not statistically significant). Net rate change of ADP consumption were $2.01 \pm 0.11$ vs. $1.43 \pm 0.11$ $\mu \mathrm{M} / \mathrm{mg}$ wet wt/min in high and low $\mathrm{Ca}^{2+}$, respectively. Although $\mathrm{CK}$ activity was not measured, based on the greater net rate and lower final concentration of ADP in high $\left[\mathrm{Ca}^{2+}\right]$ solution, it may be assumed that demands for ATP may have been greater. The summation of $[\mathrm{ATP}]$ and $[\mathrm{ADP}]$ values in high and low $\mathrm{Ca}^{2+}$ solutions yielded totals of 70.2 and $75.9 \mu$ moles/mg wet wt., respectively. These totals were similar, indicating that 
both conditions appeared to contain similar total concentration of metabolites despite differences in $\left[\mathrm{Ca}^{2+}\right]$. The only difference was that the high $\left[\mathrm{Ca}^{2+}\right]$ solution used more ADP and produced slightly more ATP. Increased $\left[\mathrm{Ca}^{2+}\right]$ should cause a rise in A.M.ATPase activity and change the energy requirements for the muscle. Because this only occurred in one of the three conditions, one explanation is that the skeletal muscle fiber bundles were not anchored and therefore were shortened. Shortened fibers can have decreased A·M·ATPase activity which would slow XB cycling.

Only one prior study assessed concentrations of the adenine nucleotides via HPLC with the intention of assessing the role of CK on A·M·ATPase (Sata et al., 1996). The investigators constructed a model of the contractile apparatus co-attaching myosin and CK from rabbit muscle on a glass coverslip with actin from rat heart. The authors found that at any initial $[\mathrm{ATP}](1,0.5,0.1$, or $0.05 \mathrm{mM})$, the $[\mathrm{ATP}] /[\mathrm{ADP}]$ ratio was very small in the presence of $\mathrm{CK}$ and in the absence of CK, the ratio increased. These findings were similar to the current study with the added benefit of being performed in skinned skeletal muscle fibers and not a constructed model. While not directly assessing metabolites with HPLC, one study by Wallimann et al. (1984) measured CK and A.M.ATPase activity in skinned chicken myofibrils and determined that the rate of ATP production by $\mathrm{CK}(0.8 \mu \mathrm{mol} \mathrm{PCr} / \mathrm{min} / \mathrm{mg}$ myofibrils $)$ was satisfactory to meet the demands of ATP hydrolysis by A·M·ATPase ( $0.4 \mu \mathrm{mol}$ ATP/min $/ \mathrm{mg}$ myofibrils). Therefore the finding that skinned rat skeletal muscle was able to produce ATP from $\mathrm{ADP}$ and $\mathrm{PCr}$ is indicative of the importance of bound $\mathrm{CK}$ to skeletal muscle fibers even after skinning by glycerol which removed cytosolic MM-CK and Mi-CK. 
Functional coupling between A.M.ATPase and CK has been demonstrated by measuring Michaelis-Menten kinetic curves with different ATP regeneration systems, showing improved kinetics (lower $\mathrm{K}_{\mathrm{mATP}}$ ) in an endogenous $\mathrm{CK}$ system compared to exogenous CK and the PK system in cardiac muscle (Krause \& Jacobus, 1992). It has also been shown that through indirect assessment of the pathway of ADP generated by $\mathrm{A} \cdot \mathrm{M} \cdot \mathrm{ATPase}$ in cardiac fibers, that some ADP is consumed by the CK system to produce ATP (Ventura-Clapier et al., 1987). The current findings confirm in skinned skeletal muscle that ADP produced by A.M.ATPase is converted to ATP by endogenous CK. This regeneration system is sufficient to restore function to the contractile apparatus when ATP is limited $(0.1 \mathrm{mM})$ or not available when provided with ADP and PCr. Direct assessment of metabolites in skinned skeletal muscle bundles via HPLC revealed that ADP and PCr produce ATP and that in conditions with ATP and PCr, [ADP] is kept low relative to conditions where the $\mathrm{CK}$ system is not active.

\section{Specific Aim 3}

Skeletal muscle fiber types vary in both mechanical and energetic properties. In

experiment one, slow twitch skeletal muscle fibers of the soleus had greater $\mathrm{Ca}^{2+}$ sensitivity (higher $\mathrm{pCa}_{50}$ ) than EDL fibers which has been shown in prior studies (Metzger \& Moss, 1990; Kandarian \& Williams, 1993; Ward et al., 2004). One reason for this is a two-fold difference in $\mathrm{g}_{a p p}$, the rate at which the XBs transition from the $\mathrm{SB}$ to WB state, between EDL and soleus muscles. Because soleus fibers have a smaller $g_{\text {app }}$, $\mathrm{XBs}$ are held in the SB transition state for a greater period of time, causing increased 
force at lower $\left[\mathrm{Ca}^{2+}\right]$ compared to EDL fibers. This causes a leftward shift in the force/pCa curve for soleus fibers.

Despite the smaller values for $\mathrm{pCa}_{50}$ in $\mathrm{EDL}$ fibers compared to soleus, none were significantly different but the $\mathrm{ADP}+\mathrm{PCr}$ condition. In this condition, endogenous $\mathrm{CK}$ was required to generate ATP and produce force. Because CK activity is greater in EDL fibers, more ATP would be generated than in soleus fibers, therefore with higher [ATP], $\mathrm{g}_{a p p}$ is increased leading to decreased $\mathrm{Ca}^{2+}$ sensitivity. This explains why $\mathrm{pCa}_{50}$ for EDL was 6.0, whereas for soleus fibers the value was 6.2 .

No statistically significant differences occurred in $\mathrm{F}_{\max }$ between the two fiber types within conditions. This was also found in skinned rat EDL and soleus muscle fibers by Ward et al. (2004). In human skeletal muscle fibers, differences in maximal force between fiber types are inconsistent. Typically when maximal force is normalized by CSA, differences between fiber types are removed (Malisoux et al., 2006), but some studies have shown greater force per CSA in type II compared to type I human fibers (Widrick et al., 1996; Widrick et al., 2002).

The hill coefficient $\left(n_{\mathrm{H}}\right)$ provides details on the steepness of the force/pCa relationship but cannot be completely indicative of $\mathrm{Ca}^{2+}$ binding to troponin- $\mathrm{C}$ (Brandt et al., 1980). Values for $n_{\mathrm{H}}$ were larger in EDL than soleus fibers for all conditions but three. Stephenson \& Williams (1981) reported larger $n_{\mathrm{H}}$ values for rat EDL compared to soleus (4 vs. 2 , respectively). One possible reason for this difference may be that the $\mathrm{Ca}^{2+}$ binding sites on troponin- $\mathrm{C}$ of fast-twitch fibers play a greater role on the rate of tension development than in slow twitch fibers. Brenner (1988) suggested that the ratio of $f_{\text {app }} / g_{\text {app }}$ may also influence the steepness $\left(n_{\mathrm{H}}\right)$ of force/pCa relationships which is a more 
plausible explanation due to the smaller values of $g_{\text {app }}$ for rat soleus fibers compared to EDL fibers (Ward et al., 2004).

In experiments two and four, assessing accumulation of [ADP] via NADH fluorescence decay, soleus fibers had lower values than the EDL both with and without PCr, but both fiber types showed reductions when PCr was added, indicating CK can use ADP from A-M.ATPase regardless of fiber type. In studies examining maximal A.M.ATPase activity, EDL fibers of the rat showed higher activity than slow fibers which are in agreement with previous studies (Wallimann et al., 1984; Bottinelli et al., 1994; Ward et al., 2004). Slope values were much larger in EDL than soleus (193.5 vs. $45.3 \mu \mathrm{M} / \mathrm{sec}$, at pCa 5.4, $2 \mathrm{mM}$ ATP) which can be indicative of greater A.M.ATPase activity. When comparing slope values in conditions with PCr, EDL and soleus fibers differed greatly (51.7 vs. $20.7 \mu \mathrm{M} / \mathrm{sec}$, at pCa 5.4 and $2 \mathrm{mM} \mathrm{ATP,} \mathrm{PCr).} \mathrm{Despite} \mathrm{soleus}$ having lower values with $\mathrm{PCr}$, it may be inferred that $\mathrm{CK}$ was more active in the soleus fibers. This is not true however because at high $\mathrm{Ca}^{2+}$ without $\mathrm{PCr}$, slope values were larger for EDL than soleus. Hence addition of PCr decreased slope values four-fold (193.5 to $51.7 \mu \mathrm{M} / \mathrm{sec}$ ), compared to a two-fold reduction in soleus fibers (45.3 to 20.7 $\mu \mathrm{M} / \mathrm{sec})$.

Based on these lower slope values, which can be indicative of A.M.ATPase rates of ATP hydrolysis, further support was generated by HPLC assessment of [ATP] and [ADP]. Greater activity of A·M·ATPase in EDL was likely responsible for the larger declines in [ATP] in EDL compared to soleus bundles as well as lower [ADP] due to the CK reaction consuming greater ADP (Table 6). One noteworthy study identified differences in fiber types based on content of PCr, Pi, and ATP (Kushmerick et al., 
1992). Although differences were detected, it is important to note that typically slow twitch fibers contain less PCr (32 vs. $16 \mathrm{mM} \mathrm{PCr).} \mathrm{Both} \mathrm{fiber} \mathrm{types} \mathrm{in} \mathrm{this} \mathrm{study} \mathrm{were}$ supplied with identical amounts of $\mathrm{PCr}(10 \mathrm{mM})$ and in spite of this [ADP]'s were still significantly less in EDL fibers compared to soleus.

In reference to experiment three, as [ATP] was lowered, both EDL and soleus $F_{\max }$ values declined with soleus values falling much sooner at higher [ATP] and to a greater extent than EDL. This may be related to A-M.ATPase rates which differ between fiber types as fast myosin heavy chain isoforms consume ATP at a higher rate than slow isoforms, thus XBs were cycling at a slower rate when faced with a reduced supply of ATP in soleus fibers. A secondary explanation may be that more XBs were in rigor bonds in soleus fibers compared to EDL, resulting in further reductions in force for the soleus fibers. Thus limiting the number of XBs seems more reasonable than transition rates of XBs between SB and WB states. This is because at high $\left[\mathrm{Ca}^{2+}\right]$, the rate at which XBs transition from SB to WB do not differ between fiber types (Ward et al., 2004), therefore $g_{\text {app }}$ should not be responsible for these differences in force.

There were some differences in EDL and soleus fibers for HPLC analysis of ATP and ADP. It would appear that A.M.ATPase rates were higher in EDL bundles based on the smaller [ATP] in EDL bundles in both the ATP $(150.5 \pm 11.8$ vs. $199.3 \pm 11.8$ $\mu \mathrm{mol} / \mathrm{mg}$ wet wt) and ATP+PCr conditions (145.9 \pm 11.8 vs. $206.5 \pm 11.8 \mu \mathrm{mol} / \mathrm{mg}$ wet wt). This is confirmed in the NADH slope measurements which were much higher in EDL fibers compared to soleus as well.

Fast and slow twitch fibers differ in enzyme activity rates for both A-M.ATPase and CK (Wallimann et al., 1984). Force when normalized by CSA did not differ between 
fiber types whereas $n_{\mathrm{H}}$ values were larger in fast twitch EDL fibers. Slope values representative of net ADP accumulation were also larger in EDL fast twitch fibers due to higher rates of A-M.ATPase and this also occurred in HPLC measurements of adenosine metabolites.

\section{Conclusions}

This study has shown that endogenous CK can permit normal function of the contractile apparatus in glycerol skinned skeletal muscle fibers. Specifically, under limiting conditions of ATP substrate $(0.1 \mathrm{mM}), \mathrm{PCr}$ allows normal isometric force generation across a range of $\left[\mathrm{Ca}^{2+}\right]$ and with only $\mathrm{CK}$ reaction substrates (ADP, $\mathrm{PCr}$ ) in the absence of ATP. Indirect evidence (reduced net ADP production as measured by NADH fluorescence) revealed endogenous $\mathrm{CK}$ was able to convert ADP produced by A·M.ATPase to ATP in skeletal muscle. This was confirmed directly through HPLC measurement of ATP and ADP that skinned skeletal muscle bundles have sufficient endogenous CK activity to produce ATP from substrates (ADP, PCr) and the ability to maintain low $[\mathrm{ADP}]$ in the presence of PCr.

Interestingly, when skinned skeletal muscle fibers were exposed to an [ATP] gradient at high $\left[\mathrm{Ca}^{2+}\right]$ with PCr, force was maintained and modestly increased. Removal of PCr resulted in a decline in force at low [ATP]. Production of ATP allowed XB cycling to occur sufficiently at low [ATP], maintaining force $15-20 \%$ above force values at high [ATP]. Whereas when endogenous CK was inactivated by removal of PCr, force dropped $20-40 \%$ at low [ATP] compared to force values at $2 \mathrm{mM}$ ATP. 
There were distinct differences between fast and slow twitch muscle fibers of the rat in both mechanical and energetic properties. Contractile performance variables were consistent with previous findings such that $n_{\mathrm{H}}$ values were greater in fast twitch fibers whereas $\mathrm{Ca}^{2+}$ sensitivity was greater in slow twitch fibers. No differences were found in $\mathrm{F}_{\max }$ values. Prior studies have shown greater activity of both A.M. ATPase and CK in fast twitch fibers (Wallimann et al., 1984). The present study confirmed this as indirect assessment of the route of ADP (as measured by a decline in NADH fluorescence) demonstrated a four-fold reduction in slope values of EDL fibers versus a two-fold reduction in soleus fibers. Data from the HPLC study revealed greater activity of $\mathrm{A} \cdot \mathrm{M} \cdot \mathrm{ATPase}$ in EDL fibers compared to soleus as evidenced by significantly smaller [ATP]. Differences between fiber types may be explained by differing rates of both $\mathrm{A} \cdot \mathrm{M} \cdot \mathrm{ATPase}$ and $\mathrm{CK}$ as well as rates of $\mathrm{XB}$ cycling.

This study adds to the evidence for specific compartmentation of CK near sites of ATP utilization and contributes to the body of knowledge on contractile performance in skinned skeletal muscle fibers. By showing how changing demands on skeletal muscle (through increased $\mathrm{Ca}^{2+}$ ) alters force production and $\mathrm{Ca}^{2+}$ sensitivity, these findings lend support for the importance of the ATP regeneration system in skeletal muscle. Based on these findings of the importance of PCr in low ATP $(0.1 \mathrm{mM})$ conditions, future studies should be conducted to examine how changes in PCr availability influence contractile performance and muscle energetics. 


\section{Recommendations for Future Research}

Skeletal muscle contraction requires a constant supply of ATP that must be replenished via ATP synthesis. Research has provided evidence for the importance of sites of ATP synthesis near sites of ATP utilization. Specifically, the location of MM-CK bound on the M-line of skeletal muscle is likely due to the need for maintained ATP homeostasis near the myosin XBs. These locations can be described as isolated microcompartments, which may contain differing $[\mathrm{ATP}]$ and $[\mathrm{ADP}]$ compared to the rest of the cellular environment. This study has shown the importance of endogenous CK in skinned skeletal muscle fibers and its relevance to preserving [ATP] for proper functioning of the contractile apparatus.

Relative to the assessment of contractile performance in skinned fibers, this study could be expanded upon by assessing fibers with varying degrees of CK activity. This could be done with a transgenic mouse model that expresses graded MM-CK levels (van Deursen et al., 1994). Assessment of these fibers may allow exploration of possible adaptations within the muscle. Further, adjustments could be made in the concentrations of PCr to account for the importance of this substrate in ATP regeneration as well as differences in enzyme activity between fast and slow twitch fiber types. It may be that fast and slow twitch fiber characteristics related to CK utilization may not differ in a skinned environment where in vivo PCr levels of fast twitch muscle are two-fold higher than slow twitch muscle (Kushmerick et al., 1992).

The functional coupling that occurs between CK and A-M.ATPase is only one of many coupled-enzyme systems linking energy production and energy consumption. Other enzymes have been linked to CK in the brain, liver, kidney, and cardiac and skeletal 
muscle cells. Specific enzymes include SERCA (Minajeva et al., 1996; Lees \& Williams, 2004), $\mathrm{Na}^{+} / \mathrm{K}^{+}$ATPase of the sarcolemma (Weng et al., 2002), and adenine nucleotide translocase (Lipskaya \& Savchenko, 2003). Basic understanding of these enzyme couplings related to energetic pathways of the cell has led to research in sarcomas (Patra et al., 2008) due to their ability to reduce CK content and activity in healthy tissue and brain cells (Burklen et al., 2006) as there is high energy consumption related to brain function processes. Just recently, it was discovered that PCr plays a role in developing myoblasts and is an important energy source for cell repair and growth (O'Connor et al., 2008).

The importance of understanding the complex organization of intracellular compartments are necessary in order to generate a clear picture of functional metabolic pathways. Evidence for microcompartments within the cell is growing (Saks et al., 2007), although not without controversy. Recent published work theorizing on the homogeneity of cell cytosolic contents conflict on whether or not diffusional differences exist throughout the aqueous cell medium (Barros \& Martinez, 2007; Selivanov et al., 2007). While the reductionist approach provided by skinned fiber studies allows specific examination of the contractile apparatus, in reference to interactions between $\mathrm{CK}$ and A·M·ATPase, the influence of other cell structures (e.g., sarcoplasmic reticulum, mitochondria) may play a role as barriers to diffusion and metabolite channeling. One of the next steps will be to measure local concentrations of metabolites near sites of utilization and production in intact biological systems as currently this is not possible.

Based on the wide application of enzymatic coupling of ATP consuming reactions versus ATP regenerating reactions, researchers are developing models that may be able to 
test these hypotheses (Long et al., 2005; Long et al., 2008). Current research on intact biological systems is performed typically with pulse-gradient ${ }^{31} \mathrm{P}-\mathrm{NMR}$, which allows assessment of intact skeletal muscle but not without some limitations. One such limitation was discovered when assessing the flux of CK in skeletal muscle with differing CK activity whereby mice expressing only one-third the CK activity of wild-type controls had normal CK flux values (van Deursen et al., 1994). This indicates that ${ }^{31} \mathrm{P}-\mathrm{NMR}$ measurements may not be able to detect CK flux in microcompartments such as at the Mline in the sarcomere or near the sarcoplasmic reticulum. Authors have attempted to circumvent this by assessing larger fibers of fish and observed that diffusion of ATP and PCr was ansitropic due to impairments by the sarcoplasmic reticulum and mitochondria (Kinsey et al., 1999).

While previous research has examined the role of functional coupling of enzymes through mathematical models (Selivanov et al., 2007), co-immobilizing enzymes to an artificial membrane (Arrio-Dupont et al., 1992), and through the use of skinned fibers (Wallimann et al., 1984; Ventura-Clapier et al., 1987), these studies have been isolated or reduced to a single system, demonstrating an isolated microcompartment. Because cells are complex structures filled with macrocompartments (mitochondria, lysosomes, sarcoplasmic reticulum) and microcompartments, future research must look to developing models and methods that test hypotheses in integrated biological systems. 


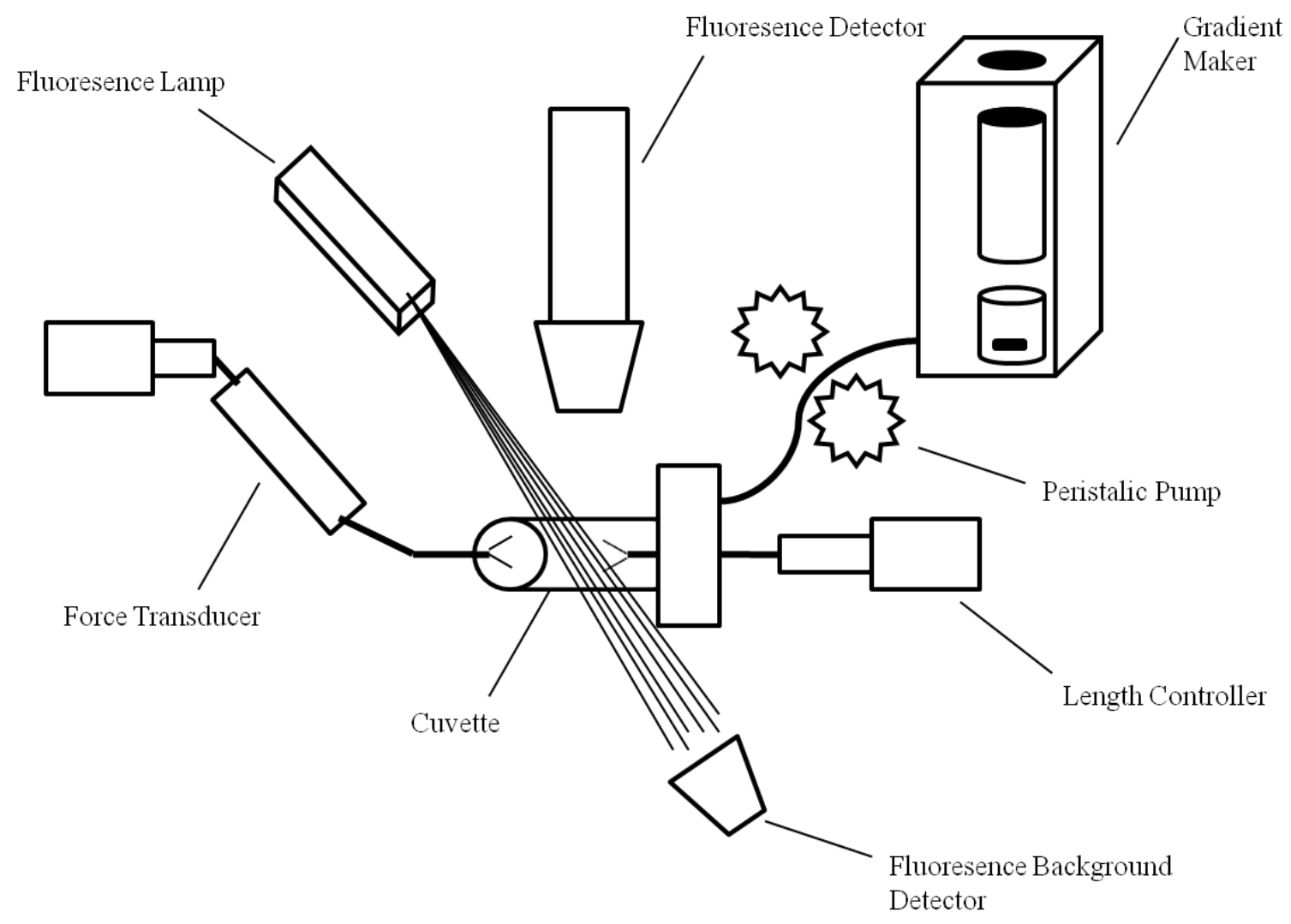

Figure 16. Schematic of the Güth Muscle Research System. 


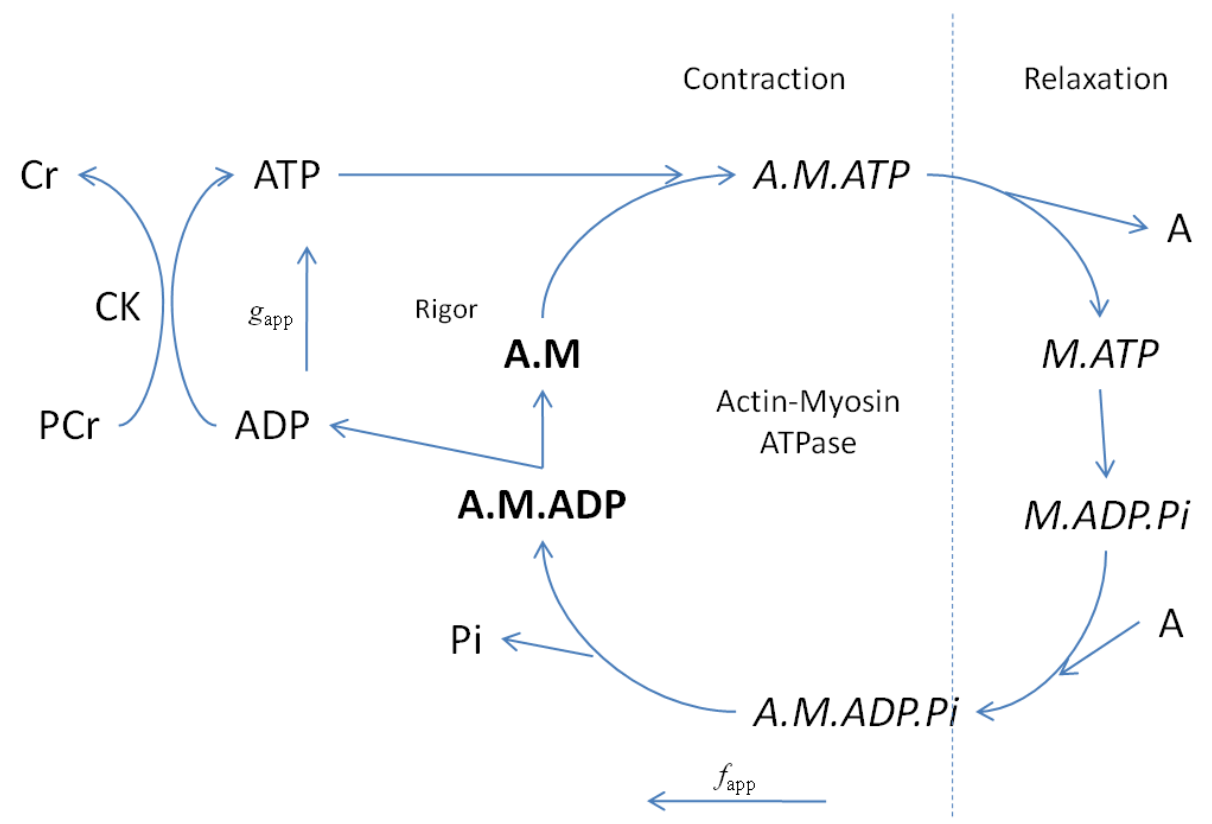

Figure 17. Cross bridge cycle and creatine kinase in skeletal muscle adapted from Ventura-Clapier et al. 1994. A=Actin. $\mathrm{M}=$ Myosin. $\mathrm{CK}=$ Creatine Kinase. $\mathrm{Cr}=$ Creatine. $\mathrm{PCr}=$ Phosphocreatine. A "." denotes a bound state. Bold indicates cross-bridge in strongly bound state. Italics indicates weakly bound state. 


\section{References}

Arrio-Dupont M. (1988). An example of substrate channeling between co-immobilized enzymes. Coupled activity of myosin ATPase and creatine kinase bound to frog heart myofilaments. FEBS Lett 240, 181-185.

Arrio-Dupont M, Bechet JJ \& d'Albis A. (1992). A model system of coupled activity of co-immobilized creatine kinase and myosin. Eur J Biochem 207, 951-955.

Barros LF \& Martinez C. (2007). An enquiry into metabolite domains. Biophys J 92, 3878-3884.

Bernocchi P, Ceconi C, Cargnoni A, Pedersini P, Curello S \& Ferrari R. (1994). Extraction and assay of creatine phosphate, purine, and pyridine nucleotides in cardiac tissue by reversed-phase high-performance liquid chromatography. Anal Biochem 222, 374-379.

Bessman SP \& Geiger PJ. (1981). Transport of energy in muscle: the phosphorylcreatine shuttle. Science 211, 448-452.

Bessman SP, Yang WC, Geiger PJ \& Erickson-Viitanen S. (1980). Intimate coupling of creatine phosphokinase and myofibrillar adenosinetriphosphatase. Biochem Biophys Res Commun 96, 1414-1420.

Bittl JA \& Ingwall JS. (1985). Reaction rates of creatine kinase and ATP synthesis in the isolated rat heart. A 31P NMR magnetization transfer study. J Biol Chem 260, 3512-3517.

Bottinelli R, Canepari M, Reggiani C \& Stienen GJ. (1994). Myofibrillar ATPase activity during isometric contraction and isomyosin composition in rat single skinned muscle fibres. J Physiol 481 ( Pt 3), 663-675.

Brandt PW, Cox RN \& Kawai M. (1980). Can the binding of $\mathrm{Ca}^{2+}$ to two regulatory sites on troponin $\mathrm{C}$ determine the steep pCa/tension relationship of skeletal muscle? Proc Natl Acad Sci U S A 77, 4717-4720.

Brenner B. (1988). Effect of $\mathrm{Ca}^{2+}$ on cross-bridge turnover kinetics in skinned single rabbit psoas fibers: implications for regulation of muscle contraction. Proc Natl Acad Sci U S A 85, 3265-3269.

Brenner B, Schoenberg M, Chalovich JM, Greene LE \& Eisenberg E. (1982). Evidence for cross-bridge attachment in relaxed muscle at low ionic strength. Proc Natl Acad Sci U S A 79, 7288-7291.

Brooks GA, Fahey, T.D., Baldwin, K.M. (2005). Exercise Physiology: Human Bioenergetics and Its Applications. McGraw-Hill, New York, NY. 
Burklen TS, Schlattner U, Homayouni R, Gough K, Rak M, Szeghalmi A \& Wallimann T. (2006). The Creatine Kinase/Creatine Connection to Alzheimer's Disease: CKInactivation, APP-CK Complexes and Focal Creatine Deposits. J Biomed Biotechnol 2006, 35936.

Chalovich JM \& Eisenberg E. (1982). Inhibition of actomyosin ATPase activity by troponin-tropomyosin without blocking the binding of myosin to actin. $J$ Biol Chem 257, 2432-2437.

Chase PB \& Kushmerick MJ. (1995). Effect of physiological ADP concentrations on contraction of single skinned fibers from rabbit fast and slow muscles. Am J Physiol 268, C480-489.

Cooke R. (2007). Modulation of the actomyosin interaction during fatigue of skeletal muscle. Muscle Nerve 36, 756-777.

Cooke R \& Pate E. (1985). The effects of ADP and phosphate on the contraction of muscle fibers. Biophys J 48, 789-798.

de Graaf RA, van Kranenburg A \& Nicolay K. (2000). In vivo (31)P-NMR diffusion spectroscopy of ATP and phosphocreatine in rat skeletal muscle. Biophys $\mathbf{J} \mathbf{7 8}$, 1657-1664.

Dowell RT \& Fu MC. (1992). Cardiac myofibrillar creatine kinase Km is not influenced by contractile protein binding. Life Sci 50, 1551-1559.

Ebashi S. (1963). Third Component Participating in the Superprecipitation of 'Natural Actomyosin'. Nature 200, 1010.

Ebashi S \& Ebashi F. (1964). A New Protein Component Participating in the Superprecipitation of Myosin B. J Biochem 55, 604-613.

Eggleton P \& Eggleton GP. (1928). Further observations on phosphagen. J Physiol 65, $15-24$.

Eisenberg E, Dobkin L \& Kielley WW. (1972). Heavy meromyosin: evidence for a refractory state unable to bind to actin in the presence of ATP. Proc Natl Acad Sci U S A 69, 667-671.

Eisenberg E \& Moos C. (1968). The adenosine triphosphatase activity of acto-heavy meromyosin. A kinetic analysis of actin activation. Biochemistry 7, 1486-1489.

Eisenberg E, Zobel CR \& Moos C. (1968). Subfragment 1 of myosin: adenosine triphophatase activation by actin. Biochemistry 7, 3186-3194. 
Franzini-Armstrong C. (1980). Structure of sarcoplasmic reticulum. Fed Proc 39, 24032409.

From AH, Zimmer SD, Michurski SP, Mohanakrishnan P, Ulstad VK, Thoma WJ \& Ugurbil K. (1990). Regulation of the oxidative phosphorylation rate in the intact cell. Biochemistry 29, 3731-3743.

Gillis JM \& O'Brien EJ. (1975). The effect of calcium ions on the structure of reconstituted muscle thin filaments. J Mol Biol 99, 445-459.

Godt RE \& Maughan DW. (1981). Influence of osmotic compression on calcium activation and tension in skinned muscle fibers of the rabbit. Pflugers Arch 391, 334-337.

Godt RE \& Nosek TM. (1989). Changes of intracellular milieu with fatigue or hypoxia depress contraction of skinned rabbit skeletal and cardiac muscle. J Physiol 412, $155-180$.

Greaser ML \& Gergely J. (1971). Reconstitution of troponin activity from three protein components. J Biol Chem 246, 4226-4233.

Gregor M, Janovska A, Stefl B, Zurmanova J \& Mejsnar J. (2003). Substrate channelling in a creatine kinase system of rat skeletal muscle under various $\mathrm{pH}$ conditions. Exp Physiol 88, 1-6.

Gregor M, Mejsnar J, Janovska A, Zurmanova J, Benada O \& Mejsnarova B. (1999). Creatine kinase reaction in skinned rat psoas muscle fibers and their myofibrils. Physiol Res 48, 27-35.

Güth K \& Wojciechowski R. (1986). Perfusion cuvette for the simultaneous measurement of mechanical, optical and energetic parameters of skinned muscle fibres. Pflugers Arch 407, 552-557.

Hancock CR, Brault JJ \& Terjung RL. (2006). Protecting the cellular energy state during contractions: role of AMP deaminase. J Physiol Pharmacol 57 Suppl 10, 17-29.

Hoar PE, Mahoney CW \& Kerrick WG. (1987). MgADP- increases maximum tension and $\mathrm{Ca}^{2+}$ sensitivity in skinned rabbit soleus fibers. Pflugers Arch 410, 30-36.

Huxley AF. (1957). Muscle structure and theories of contraction. Prog Biophys Biophys Chem 7, 255-318.

Huxley AF \& Niedergerke R. (1954). Structural changes in muscle during contraction; interference microscopy of living muscle fibres. Nature 173, 971-973. 
Huxley H \& Hanson J. (1954). Changes in the cross-striations of muscle during contraction and stretch and their structural interpretation. Nature 173, 973-976.

Huxley HE. (1953). Electron microscope studies of the organisation of the filaments in striated muscle. Biochim Biophys Acta 12, 387-394.

Huxley HE. (1969). The mechanism of muscular contraction. Science 164, 1356-1365.

Ingwall JS, Atkinson DE, Clarke K \& Fetters JK. (1990). Energetic correlates of cardiac failure: changes in the creatine kinase system in the failing myocardium. Eur Heart J 11 Suppl B, 108-115.

Iyengar MR. (1984). Creatine kinase as an intracellular regulator. J Muscle Res Cell Motil 5, 527-534.

Jacobs H, Heldt HW \& Klingenberg M. (1964). High activity of creatine kinase in mitochondria from muscle and brain and evidence for a separate mitochondrial isoenzyme of creatine kinase. Biochem Biophys Res Commun 16, 516-521.

Jorgensen AO, Shen AC, MacLennan DH \& Tokuyasu KT. (1982). Ultrastructural localization of the $\mathrm{Ca}^{2+}+\mathrm{Mg}^{2+}$-dependent ATPase of sarcoplasmic reticulum in rat skeletal muscle by immunoferritin labeling of ultrathin frozen sections. J Cell Biol 92, 409-416.

Kaasik A, Veksler V, Boehm E, Novotova M, Minajeva A \& Ventura-Clapier R. (2001). Energetic crosstalk between organelles: architectural integration of energy production and utilization. Circ Res 89, 153-159.

Kandarian SC \& Williams JH. (1993). Contractile properties of skinned fibers from hypertrophied skeletal muscle. Med Sci Sports Exerc 25, 999-1004.

Kerrick WG, Potter JD \& Hoar PE. (1991). The apparent rate constant for the dissociation of force generating myosin crossbridges from actin decreases during $\mathrm{Ca}^{2+}$ activation of skinned muscle fibres. J Muscle Res Cell Motil 12, 53-60.

Khan LA, Raj M \& Amin M. (1989). Coupling of the enzymic activities of myosin ATPase and creatine kinase and its role in muscular contraction. Indian $J$ Biochem Biophys 26, 148-152.

Kinsey ST, Locke BR, Penke B \& Moerland TS. (1999). Diffusional anisotropy is induced by subcellular barriers in skeletal muscle. NMR Biomed 12, 1-7.

Korge P, Byrd SK \& Campbell KB. (1993). Functional coupling between sarcoplasmicreticulum-bound creatine kinase and $\mathrm{Ca}(2+)$-ATPase. Eur J Biochem 213, 973 980. 
Korge P \& Campbell KB. (1994). Local ATP regeneration is important for sarcoplasmic reticulum $\mathrm{Ca}^{2+}$ pump function. Am J Physiol 267, C357-366.

Krause SM \& Jacobus WE. (1992). Specific enhancement of the cardiac myofibrillar ATPase by bound creatine kinase. J Biol Chem 267, 2480-2486.

Kushmerick MJ, Moerland TS \& Wiseman RW. (1992). Mammalian skeletal muscle fibers distinguished by contents of phosphocreatine, ATP, and Pi. Proc Natl Acad Sci U S A 89, 7521-7525.

Lees SJ \& Williams JH. (2004). Skeletal muscle sarcoplasmic reticulum glycogen status influences $\mathrm{Ca}^{2+}$ uptake supported by endogenously synthesized ATP. Am J Physiol Cell Physiol 286, C97-104.

Lipskaya TY \& Savchenko MS. (2003). Once again about the functional coupling between mitochondrial creatine kinase and adenine nucleotide translocase. Biochemistry (Mosc) 68, 68-79.

Long MS, Cans AS \& Keating CD. (2008). Budding and asymmetric protein microcompartmentation in giant vesicles containing two aqueous phases. $J \mathrm{Am}$ Chem Soc 130, 756-762.

Long MS, Jones CD, Helfrich MR, Mangeney-Slavin LK \& Keating CD. (2005). Dynamic microcompartmentation in synthetic cells. Proc Natl Acad Sci U S A 102, 5920-5925.

Lymn RW \& Taylor EW. (1971). Mechanism of adenosine triphosphate hydrolysis by actomyosin. Biochemistry 10, 4617-4624.

Macdonald WA \& Stephenson DG. (2006). Effect of ADP on slow-twitch muscle fibres of the rat: implications for muscle fatigue. J Physiol 573, 187-198.

Malisoux L, Francaux M, Nielens H \& Theisen D. (2006). Stretch-shortening cycle exercises: an effective training paradigm to enhance power output of human single muscle fibers. J Appl Physiol 100, 771-779.

Martonosi A, Gouvea MA \& Gergely J. (1960). Studies on actin. III. G-F transformation of actin and muscular contraction (experiments in vivo). J Biol Chem 235, 1707 1710.

McFarland EW, Kushmerick MJ \& Moerland TS. (1994). Activity of creatine kinase in a contracting mammalian muscle of uniform fiber type. Biophys $J$ 67, 1912-1924.

McLeish MJ \& Kenyon GL. (2005). Relating structure to mechanism in creatine kinase. Crit Rev Biochem Mol Biol 40, 1-20. 
Metzger JM. (1996). Effects of phosphate and ADP on shortening velocity during maximal and submaximal calcium activation of the thin filament in skeletal muscle fibers. Biophys $J$ 70, 409-417.

Metzger JM \& Moss RL. (1990). Calcium-sensitive cross-bridge transitions in mammalian fast and slow skeletal muscle fibers. Science 247, 1088-1090.

Minajeva A, Ventura-Clapier R \& Veksler V. (1996). $\mathrm{Ca}^{2+}$ uptake by cardiac sarcoplasmic reticulum ATPase in situ strongly depends on bound creatine kinase. Pflugers Arch 432, 904-912.

Myburgh KH. (2004). Can any metabolites partially alleviate fatigue manifestations at the cross-bridge? Med Sci Sports Exerc 36, 20-27.

O'Connor RS, Steeds CM, Wiseman RW \& Pavlath GK. (2008). Phosphocreatine as an energy source for actin cytoskeletal rearrangements during myoblast fusion. $J$ Physiol 586, 2841-2853.

Ohtsuki I. (1999). Calcium ion regulation of muscle contraction: the regulatory role of troponin T. Mol Cell Biochem 190, 33-38.

Patra S, Bera S, SinhaRoy S, Ghoshal S, Ray S, Basu A, Schlattner U, Wallimann T \& Ray M. (2008). Progressive decrease of phosphocreatine, creatine and creatine kinase in skeletal muscle upon transformation to sarcoma. FEBS J 275, 32363247.

Perry SV. (1954). Creatine phosphokinase and the enzymic and contractile properties of the isolated myofibril. Biochem J 57, 427-434.

Pette D \& Staron RS. (2000). Myosin isoforms, muscle fiber types, and transitions. Microsc Res Tech 50, 500-509.

Potter JD \& Gergely J. (1975). The calcium and magnesium binding sites on troponin and their role in the regulation of myofibrillar adenosine triphosphatase. J Biol Chem 250, 4628-4633.

Reedy MK, Holmes KC \& Tregear RT. (1965). Induced changes in orientation of the cross-bridges of glycerinated insect flight muscle. Nature 207, 1276-1280.

Rossi AM, Eppenberger HM, Volpe P, Cotrufo R \& Wallimann T. (1990). Muscle-type MM creatine kinase is specifically bound to sarcoplasmic reticulum and can support $\mathrm{Ca}^{2+}$ uptake and regulate local ATP/ADP ratios. J Biol Chem 265, 52585266.

Saks V, Monge C, Anmann T \& Dzeja P. (2007). Molecular System Bioenergetics: Energy for Life. Wiley, Weinheim. 
Saks VA, Chernousova GB, Vetter R, Smirnov VN \& Chazov EI. (1976). Kinetic properties and the functional role of particulate MM-isoenzyme of creatine phosphokinase bound to heart muscle myofibrils. FEBS Lett 62, 293-296.

Saks VA, Ventura-Clapier R, Huchua ZA, Preobrazhensky AN \& Emelin IV. (1984). Creatine kinase in regulation of heart function and metabolism. I. Further evidence for compartmentation of adenine nucleotides in cardiac myofibrillar and sarcolemmal coupled ATPase-creatine kinase systems. Biochim Biophys Acta 803, 254-264.

Sata M, Sugiura S, Yamashita H, Momomura S \& Serizawa T. (1996). Coupling between myosin ATPase cycle and creatinine kinase cycle facilitates cardiac actomyosin sliding in vitro. A clue to mechanical dysfunction during myocardial ischemia. Circulation 93, 310-317.

Savabi F, Geiger PJ \& Bessman SP. (1983). Kinetic properties and functional role of creatine phosphokinase in glycerinated muscle fibers--further evidence for compartmentation. Biochem Biophys Res Commun 114, 785-790.

Selivanov VA, Krause S, Roca J \& Cascante M. (2007). Modeling of spatial metabolite distributions in the cardiac sarcomere. Biophys J 92, 3492-3500.

Staron RS \& Johnson P. (1993). Myosin polymorphism and differential expression in adult human skeletal muscle. Comp Biochem Physiol B 106, 463-475.

Stein LA. (1995). Modeling of the actomyosin ATPase activity. Origin of the initial phosphate burst and implications of the phosphate release kinetics. Cell Biochem Biophys 27, 63-96.

Stein LA, Schwarz RP, Jr., Chock PB \& Eisenberg E. (1979). Mechanism of actomyosin adenosine triphosphatase. Evidence that adenosine 5'-triphosphate hydrolysis can occur without dissociation of the actomyosin complex. Biochemistry 18, 38953909.

Stephenson DG \& Williams DA. (1981). Calcium-activated force responses in fast- and slow-twitch skinned muscle fibres of the rat at different temperatures. $J$ Physiol 317, 281-302.

Sullivan MJ, Saltin B, Negro-Vilar R, Duscha BD \& Charles HC. (1994). Skeletal muscle $\mathrm{pH}$ assessed by biochemical and 31P-MRS methods during exercise and recovery in men. J Appl Physiol 77, 2194-2200.

Szent-Gyorgyi AG. (2004). The early history of the biochemistry of muscle contraction. $J$ Gen Physiol 123, 631-641. 
Turner DC, Wallimann T \& Eppenberger HM. (1973). A protein that binds specifically to the M-line of skeletal muscle is identified as the muscle form of creatine kinase. Proc Natl Acad Sci U S A 70, 702-705.

van Deursen J, Ruitenbeek W, Heerschap A, Jap P, ter Laak H \& Wieringa B. (1994). Creatine kinase (CK) in skeletal muscle energy metabolism: a study of mouse mutants with graded reduction in muscle CK expression. Proc Natl Acad Sci U S A 91, 9091-9095.

Ventura-Clapier R, Mekhfi H \& Vassort G. (1987). Role of creatine kinase in force development in chemically skinned rat cardiac muscle. J Gen Physiol 89, 815837.

Ventura-Clapier R \& Vassort G. (1985). Role of myofibrillar creatine kinase in the relaxation of rigor tension in skinned cardiac muscle. Pflugers Arch 404, 157-161.

Ventura-Clapier R, Veksler V \& Hoerter JA. (1994). Myofibrillar creatine kinase and cardiac contraction. Mol Cell Biochem 133-134, 125-144.

Wallimann T. (1996). 31P-NMR-measured creatine kinase reaction flux in muscle: a caveat! J Muscle Res Cell Motil 17, 177-181.

Wallimann T, Dolder M, Schlattner U, Eder M, Hornemann T, O'Gorman E, Ruck A \& Brdiczka D. (1998). Some new aspects of creatine kinase (CK): compartmentation, structure, function and regulation for cellular and mitochondrial bioenergetics and physiology. Biofactors 8, 229-234.

Wallimann T \& Eppenberger HM. (1985). Localization and function of M-line-bound creatine kinase. M-band model and creatine phosphate shuttle. Cell Muscle Motil 6, 239-285.

Wallimann T, Pelloni G, Turner DC \& Eppenberger HM. (1978). Monovalent antibodies against MM-creatine kinase remove the M line from myofibrils. Proc Natl Acad Sci U S A 75, 4296-4300.

Wallimann T, Schlosser T \& Eppenberger HM. (1984). Function of M-line-bound creatine kinase as intramyofibrillar ATP regenerator at the receiving end of the phosphorylcreatine shuttle in muscle. J Biol Chem 259, 5238-5246.

Wallimann T, Wyss M, Brdiczka D, Nicolay K \& Eppenberger HM. (1992). Intracellular compartmentation, structure and function of creatine kinase isoenzymes in tissues with high and fluctuating energy demands: the 'phosphocreatine circuit' for cellular energy homeostasis. Biochem J 281 ( Pt 1), 21-40. 
Ward CW, Kerrick GW \& Williams JH. (2004). Fiber Type Differences in the Ca2+ Acivation of Force and Actomyosin ATPase Activity. Basic Appl Myol 14, 285290.

Warrick HM \& Spudich JA. (1987). Myosin structure and function in cell motility. Annu Rev Cell Biol 3, 379-421.

Weng CF, Chiang CC, Gong HY, Chen MH, Lin CJ, Huang WT, Cheng CY, Hwang PP $\& \mathrm{Wu}$ JL. (2002). Acute changes in gill $\mathrm{Na}+\mathrm{K}+\mathrm{ATPase}$ and creatine kinase in response to salinity changes in the euryhaline teleost, tilapia (Oreochromis mossambicus). Physiol Biochem Zool 75, 29-36.

White HD \& Taylor EW. (1976). Energetics and mechanism of actomyosin adenosine triphosphatase. Biochemistry 15, 5818-5826.

Widrick JJ, Stelzer JE, Shoepe TC \& Garner DP. (2002). Functional properties of human muscle fibers after short-term resistance exercise training. Am J Physiol Regul Integr Comp Physiol 283, R408-416.

Widrick JJ, Trappe SW, Costill DL \& Fitts RH. (1996). Force-velocity and force-power properties of single muscle fibers from elite master runners and sedentary men. Am J Physiol 271, C676-683.

Williams JH, Vidt SE \& Rinehart J. (2008). Measurement of sarcoplasmic reticulum $\mathrm{Ca}^{2+}$ ATPase activity using high-performance liquid chromatography. Anal Biochem 372, 135-139.

Wiseman RW \& Kushmerick MJ. (1995). Creatine kinase equilibration follows solution thermodynamics in skeletal muscle. 31P NMR studies using creatine analogs. $J$ Biol Chem 270, 12428-12438.

Wyss M \& Kaddurah-Daouk R. (2000). Creatine and creatinine metabolism. Physiol Rev 80, $1107-1213$.

Yagi K \& Mase R. (1962). Coupled reaction of creatine kinase and myosin A-adenosine triphosphatase. J Biol Chem 237, 397-403.

Zurmanova J, Difato F, Malacova D, Mejsnar J, Stefl B \& Zahradnik I. (2007). Creatine kinase binds more firmly to the M-band of rabbit skeletal muscle myofibrils in the presence of its substrates. Mol Cell Biochem 305, 55-61. 


\section{APPENDIX I (Solutions)}

Table 9

2.0 mM ATP

pCa 9.0

\begin{tabular}{lrrrr}
\hline & Conc $(\mathbf{M})$ & FW & gm & ml HPr \\
\hline \hline $\mathrm{CaO}$ & 0.000 & 56.08 & 0.000 & 0.000 \\
$\mathrm{MgO}$ & 0.003 & 40.30 & 0.017 & 0.061 \\
$\mathrm{KOH}$ & 0.085 & 56.11 & 0.596 & 0.787 \\
EGTA & 0.007 & 380.40 & 0.333 & 0.000 \\
Imidazole & 0.132 & 68.08 & 1.126 & 0.000 \\
$\mathrm{HPr}$ & 0.07135 & 74.08 & 0.661 & 0.661 \\
\hline
\end{tabular}

Total HPr $\quad 1.509$

Water Added 123.491

pCa 4.0

\begin{tabular}{|c|c|c|c|c|}
\hline & Conc $(\mathrm{M})$ & FW & gm & ml HPr \\
\hline $\mathrm{CaO}$ & 0.007 & 56.08 & 0.050 & 0.132 \\
\hline $\mathrm{MgO}$ & 0.003 & 40.30 & 0.015 & 0.056 \\
\hline $\mathrm{KOH}$ & 0.085 & 56.11 & 0.596 & 0.787 \\
\hline EGTA & 0.007 & 380.40 & 0.333 & 0.000 \\
\hline Imidazole & 0.132 & 68.08 & 1.120 & 0.000 \\
\hline HPr & 0.05736 & 74.08 & 0.531 & 0.531 \\
\hline & & & $\begin{array}{r}\text { Total HPr } \\
\text { Water Added }\end{array}$ & $\begin{array}{r}1.506 \\
123.494\end{array}$ \\
\hline
\end{tabular}


Table 10

0.1 mM ATP

pCa 9.0

\begin{tabular}{lrrrr}
\hline & Conc (M) & FW & gm & ml HPr \\
\hline \hline $\mathrm{CaO}$ & 0.000 & 56.08 & 0.000 & 0.000 \\
$\mathrm{MgO}$ & 0.001 & 40.30 & 0.007 & 0.025 \\
$\mathrm{KOH}$ & 0.085 & 56.11 & 0.596 & 0.787 \\
EGTA & 0.007 & 380.40 & 0.333 & 0.000 \\
Imidazole & 0.136 & 68.08 & 1.156 & 0.000 \\
$\mathrm{HPr}$ & 0.07753 & 74.08 & 0.718 & 0.718 \\
\hline
\end{tabular}

Total HPr $\quad 1.531$

Water Added 123.469

pCa 4.0

\begin{tabular}{lrrrr}
\hline & Conc (M) & FW & gm & ml HPr \\
\hline \hline $\mathrm{CaO}$ & 0.007 & 56.08 & 0.049 & 0.130 \\
$\mathrm{MgO}$ & 0.001 & 40.30 & 0.006 & 0.020 \\
$\mathrm{KOH}$ & 0.085 & 56.11 & 0.596 & 0.787 \\
$\mathrm{EGTA}$ & 0.007 & 380.40 & 0.333 & 0.000 \\
Imidazole & 0.135 & 68.08 & 1.152 & 0.000 \\
$\mathrm{HPr}$ & 0.06378 & 74.08 & 0.591 & 0.591 \\
\hline
\end{tabular}

Total HPr $\quad 1.529$

Water Added 123.471 
Table 11

\section{0 mM ATP, 10.0 mM PCr}

\begin{tabular}{lrrrr} 
pCa 9.0 & & & & \\
\hline & Conc $(\mathbf{M})$ & FW & gm & ml HPr \\
\hline \hline $\mathrm{CaO}$ & 0.000 & 56.08 & 0.000 & 0.000 \\
$\mathrm{MgO}$ & 0.004 & 40.30 & 0.019 & 0.068 \\
$\mathrm{KOH}$ & 0.085 & 56.11 & 0.596 & 0.787 \\
EGTA & 0.007 & 380.40 & 0.333 & 0.000 \\
Imidazole & 0.116 & 68.08 & 0.984 & 0.000 \\
HPr & 0.06095 & 74.08 & 0.564 & 0.564 \\
\hline
\end{tabular}

Total HPr $\quad 1.420$

Water Added 123.580

pCa 4.0

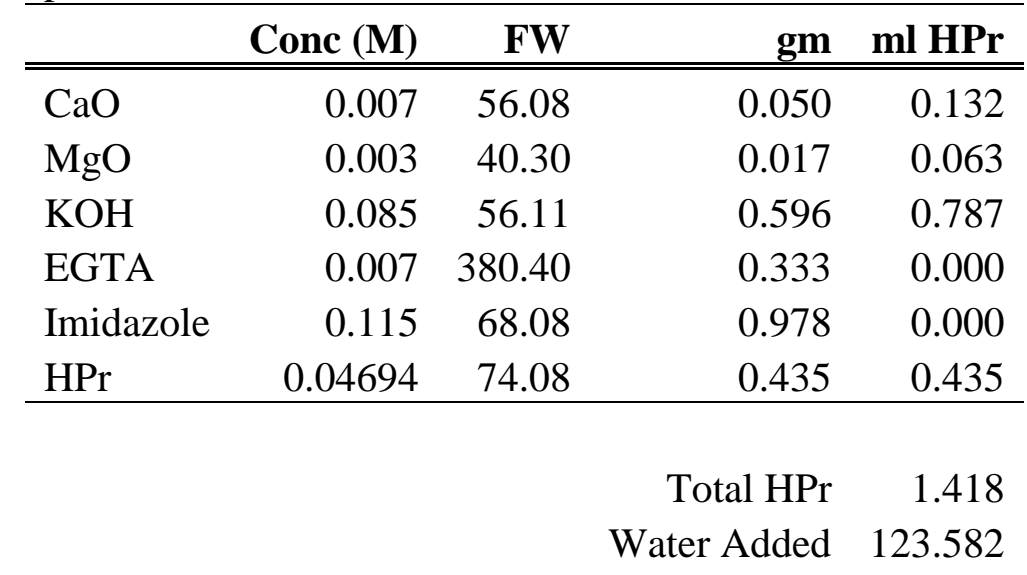


Table 12

\section{1 mM ATP, 10.0 mM PCr}

pCa 9.0

\begin{tabular}{lrrrr}
\hline & Conc (M) & FW & gm & ml HPr \\
\hline \hline $\mathrm{CaO}$ & 0.000 & 56.08 & 0.000 & 0.000 \\
$\mathrm{MgO}$ & 0.002 & 40.30 & 0.009 & 0.033 \\
$\mathrm{KOH}$ & 0.085 & 56.11 & 0.596 & 0.787 \\
EGTA & 0.007 & 380.40 & 0.333 & 0.000 \\
Imidazole & 0.119 & 68.08 & 1.014 & 0.000 \\
$\mathrm{HPr}$ & 0.06713 & 74.08 & 0.622 & 0.622 \\
\hline
\end{tabular}

Total HPr $\quad 1.442$

Water Added 123.558

pCa 4.0

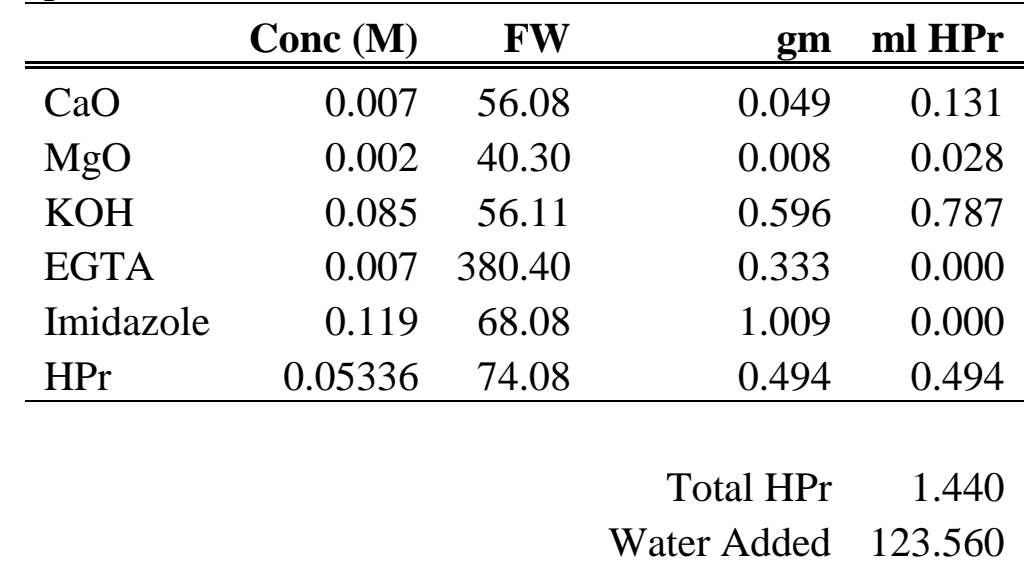


Table 13

2.0 mM ATP, 10.0 mM PCr, 2.0 mM ADP

pCa 9.0

\begin{tabular}{lrrrr}
\hline & Conc (M) & FW & gm & ml HPr \\
\hline \hline $\mathrm{CaO}$ & 0.000 & 56.08 & 0.000 & 0.000 \\
$\mathrm{MgO}$ & 0.006 & 40.30 & 0.029 & 0.106 \\
$\mathrm{KOH}$ & 0.085 & 56.11 & 0.597 & 0.788 \\
EGTA & 0.007 & 380.40 & 0.333 & 0.000 \\
Imidazole & 0.109 & 68.08 & 0.930 & 0.000 \\
$\mathrm{HPr}$ & 0.0566 & 74.08 & 0.524 & 0.524 \\
\hline
\end{tabular}

Total HPr $\quad 1.418$

Water Added 123.582

$\mathrm{pCa} 4.0$

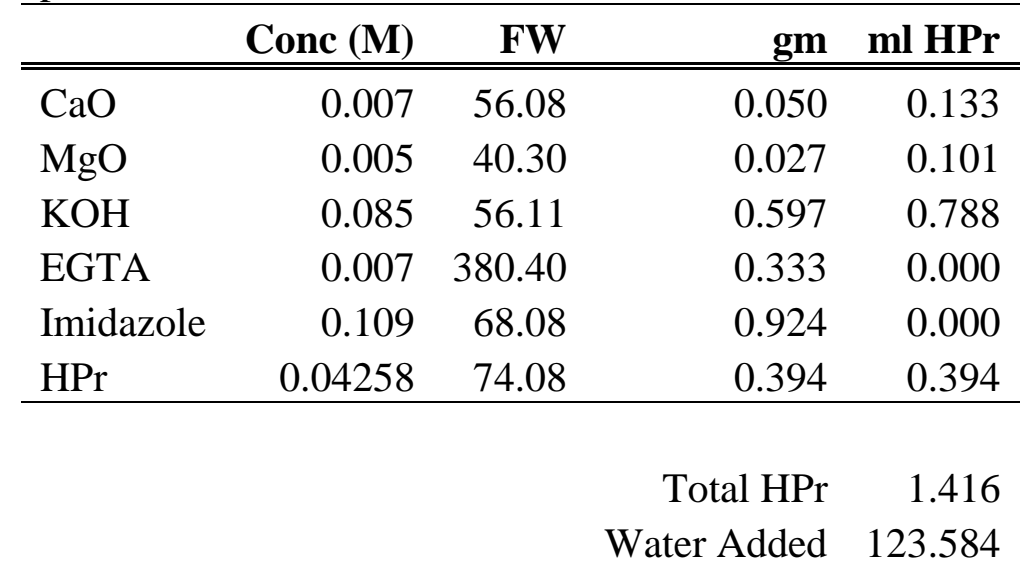


Table 14

0.1 mM ATP, 10 mM PCr, 2 mM ADP

pCa 9.0

\begin{tabular}{lrrrr}
\hline & Conc $(\mathbf{M})$ & FW & gm & ml HPr \\
\hline \hline $\mathrm{CaO}$ & 0.000 & 56.08 & 0.000 & 0.000 \\
$\mathrm{MgO}$ & 0.004 & 40.30 & 0.019 & 0.070 \\
$\mathrm{KOH}$ & 0.085 & 56.11 & 0.597 & 0.788 \\
EGTA & 0.007 & 380.40 & 0.333 & 0.000 \\
Imidazole & 0.113 & 68.08 & 0.960 & 0.000 \\
$\mathrm{HPr}$ & 0.06278 & 74.08 & 0.581 & 0.581 \\
\hline
\end{tabular}

Total HPr $\quad 1.440$

Water Added 123.560

pCa 4.0

\begin{tabular}{lrrrr}
\hline & Conc $(\mathbf{M})$ & FW & gm & ml HPr \\
\hline \hline $\mathrm{CaO}$ & 0.007 & 56.08 & 0.050 & 0.131 \\
$\mathrm{MgO}$ & 0.004 & 40.30 & 0.018 & 0.065 \\
$\mathrm{KOH}$ & 0.085 & 56.11 & 0.597 & 0.788 \\
EGTA & 0.007 & 380.40 & 0.333 & 0.000 \\
Imidazole & 0.112 & 68.08 & 0.955 & 0.000 \\
$\mathrm{HPr}$ & 0.04899 & 74.08 & 0.454 & 0.454 \\
\hline
\end{tabular}

Total HPr $\quad 1.438$

Water Added 123.562 
Table 15

10 mM PCr, 2 mM ADP

pCa 9.0

\begin{tabular}{lrrrr}
\hline & Conc (M) & FW & gm & ml HPr \\
\hline \hline $\mathrm{CaO}$ & 0.000 & 56.08 & 0.000 & 0.000 \\
$\mathrm{MgO}$ & 0.004 & 40.30 & 0.019 & 0.068 \\
$\mathrm{KOH}$ & 0.085 & 56.11 & 0.597 & 0.788 \\
EGTA & 0.007 & 380.40 & 0.333 & 0.000 \\
Imidazole & 0.113 & 68.08 & 0.962 & 0.000 \\
$\mathrm{HPr}$ & 0.0631 & 74.08 & 0.584 & 0.584 \\
\hline
\end{tabular}

Total HPr $\quad 1.441$

Water Added 123.559

pCa 4.0

\begin{tabular}{lrrrr}
\hline & Conc (M) & FW & gm & ml HPr \\
\hline \hline $\mathrm{CaO}$ & 0.007 & 56.08 & 0.050 & 0.131 \\
$\mathrm{MgO}$ & 0.003 & 40.30 & 0.017 & 0.063 \\
$\mathrm{KOH}$ & 0.085 & 56.11 & 0.597 & 0.788 \\
$\mathrm{EGTA}$ & 0.007 & 380.40 & 0.333 & 0.000 \\
Imidazole & 0.112 & 68.08 & 0.957 & 0.000 \\
$\mathrm{HPr}$ & 0.04933 & 74.08 & 0.457 & 0.457 \\
\hline
\end{tabular}

Total HPr $\quad 1.439$

Water Added 123.561 


\section{APPENDIX II (Gradient Calibration)}

Free $\mathrm{Ca}^{2+}$ concentrations will be periodically calibrated using fluorescent $\mathrm{Ca}^{2+}$

probe $\mathrm{Ca}^{2+}$ Green-2 (480 nm excitation, $515 \mathrm{~nm}$ emission). Fluorescence values will be converted to free- $\mathrm{Ca}^{2+}$ from the relationship:

$$
\text { Free }\left[\mathrm{Ca}^{2+}\right]=\mathrm{k}_{\mathrm{d}}\left(\mathrm{F}-\mathrm{F}_{\min }\right) /\left(\mathrm{F}_{\max }-\mathrm{F}\right)
$$

Where $\mathrm{F}_{\max }$ and $\mathrm{F}_{\min }$ are the maximal and minimal fluorescence values recorded in the presence of $1 \mathrm{mM}$ free $\mathrm{Ca}^{2+}$ and $7 \mathrm{mM}$ EGTA. The $\mathrm{k}_{\mathrm{d}}$ for $\mathrm{Ca}^{2+}$ Green-2 $\left(\mathrm{k}_{\mathrm{d}}=4.365 \mu \mathrm{M}\right)$ was provided by Dr. Glenn Kerrick. 

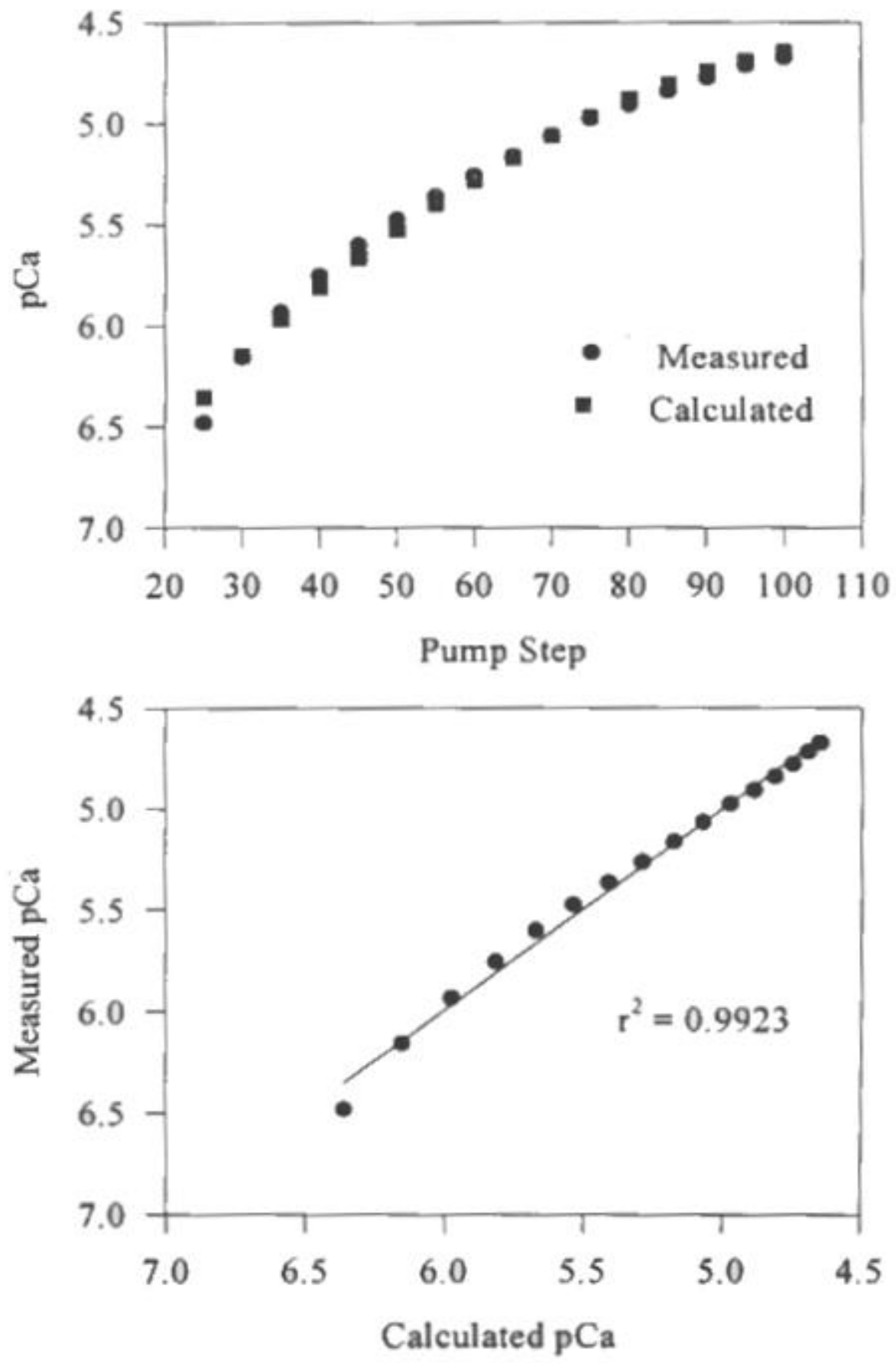

Figure 18. Calibration results. Measured and calculated pCa values vs. pump step (top). Measured pCa vs. calculated pCa (bottom). 


\section{APPENDIX III (Statistics)}

Table 16. Analysis of variance results. Comparison of $F_{\max }$ between conditions for EDL fibers

$\begin{array}{lrrrrr}\text { Source } & \text { DF } & \begin{array}{r}\text { Sum of } \\ \text { Squares }\end{array} & \text { Mean Square } & \text { F Ratio } & \text { Prob > F } \\ \text { Condition } & 6 & 54.53778 & 9.08963 & 2.3793 & 0.0438 \\ \text { Error } & 46 & 175.73190 & 3.82026 & & \\ \text { C. Total } & 52 & 230.26968 & & & \end{array}$

Table 17. Analysis of variance results. Comparison of $\mathrm{pCa}_{50}$ between conditions for EDL fibers

$\begin{array}{lrrrrr}\text { Source } & \text { DF } & \begin{array}{r}\text { Sum of } \\ \text { Squares }\end{array} & \text { Mean Square } & \text { F Ratio } & \text { Prob }>\text { F } \\ \text { Condition } & 6 & 6.5046915 & 1.08412 & 32.8694 & <.0001 \\ \text { Error } & 46 & 1.5171953 & 0.03298 & & \\ \text { C. Total } & 52 & 8.0218868 & & & \end{array}$

Table 18. Analysis of variance results. Comparison of $n_{\mathrm{H}}$ between conditions for EDL fibers

$\begin{array}{lrrrrr}\text { Source } & \text { DF } & \begin{array}{r}\text { Sum of } \\ \text { Squares }\end{array} & \text { Mean Square } & \text { F Ratio } & \text { Prob > F } \\ \text { Condition } & 6 & 67.34468 & 11.2241 & 0.9037 & 0.5006 \\ \text { Error } & 46 & 571.32082 & 12.4200 & & \\ \text { C. Total } & 52 & 638.66550 & & & \end{array}$


Table 19. Analysis of variance results. Comparison of $F_{\max }$ between conditions for soleus fibers

$\begin{array}{lrrrrr}\text { Source } & \text { DF } & \begin{array}{r}\text { Sum of } \\ \text { Squares }\end{array} & \text { Mean Square } & \text { F Ratio } & \text { Prob > F } \\ \text { Condition } & 6 & 47.06772 & 7.84462 & 1.8792 & 0.1048 \\ \text { Error } & 46 & 192.02615 & 4.17448 & & \\ \text { C. Total } & 52 & 239.09387 & & & \end{array}$

Table 20. Analysis of variance results. Comparison of $\mathrm{pCa}_{50}$ between conditions for soleus fibers

$\begin{array}{lrrrrr}\text { Source } & \text { DF } & \begin{array}{r}\text { Sum of } \\ \text { Squares }\end{array} & \text { Mean Square } & \text { F Ratio } & \text { Prob }>\text { F } \\ \text { Condition } & 6 & 8.181616 & 1.36360 & 33.7142 & <.0001 \\ \text { Error } & 46 & 1.860513 & 0.04045 & & \\ \text { C. Total } & 52 & 10.042128 & & & \end{array}$

Table 21. Analysis of variance results. Comparison of $n_{\mathrm{H}}$ between conditions for soleus fibers

$\begin{array}{lrrrrr}\text { Source } & \text { DF } & \begin{array}{r}\text { Sum of } \\ \text { Squares }\end{array} & \text { Mean Square } & \text { F Ratio } & \text { Prob > F } \\ \text { Condition } & 6 & 12.523489 & 2.08725 & 2.7366 & 0.0234 \\ \text { Error } & 46 & 35.084821 & 0.76271 & & \\ \text { C. Total } & 52 & 47.608311 & & & \end{array}$


Table 22. Type 3 Tests of Fixed Effects for [ATP] and [ADP], experiment 4

$\begin{array}{lrrrrl} & \text { Num } & \text { Den } & & \\ \text { Effect } & & & \text { F } & \\ & \text { DF } & \text { DF } & \text { Value } & \text { Pr }>\text { F } \\ \text { Solution } & 1 & 108 & 3.03 & 0.0846 \\ \text { Treatment } & 2 & 108 & 60.8 & <.0001 \\ \text { Muscle } & 1 & 108 & 3.58 & 0.0612 \\ \text { Treatment*Solution } & 2 & 108 & 3.39 & 0.0373 \\ \text { Solution*Muscle } & 1 & 108 & 0.04 & 0.8454 \\ \text { Treatment*Muscle } & 2 & 108 & 3.59 & 0.0311 \\ \text { Treatment*Solution*Muscle } & 2 & 108 & 0.26 & 0.7735\end{array}$

Treatment $=$ ATP or ATP $+\mathrm{PCr}$ or ADP $+\mathrm{PCr}$. Muscle $=\mathrm{EDL}$ or soleus, Solution $=$ High $\mathrm{Ca}^{2+}$ or Low $\mathrm{Ca}^{2+}$

Table 23. Type 3 Tests of Fixed Effects for net rate change of ATP, experiment 4

\begin{tabular}{|c|c|c|c|c|}
\hline \multirow[b]{2}{*}{ Effect } & Num & Den & \\
\hline & $\mathrm{DF}$ & $\mathrm{DF}$ & $\begin{array}{l}\mathrm{F} \\
\text { Value }\end{array}$ & $\operatorname{Pr}>\mathrm{F}$ \\
\hline Solution & 1 & 107 & 4.42 & 0.0378 \\
\hline Treatment & 2 & 107 & 29.51 & $<.0001$ \\
\hline Muscle & 1 & 107 & 2.55 & 0.1131 \\
\hline Treatment*Solution & 2 & 107 & 0.46 & 0.6341 \\
\hline Solution*Muscle & 1 & 107 & 0.89 & 0.3464 \\
\hline Treatment*Muscle & 2 & 107 & 0.14 & 0.8679 \\
\hline Treatment*Solution*Muscle & 2 & 107 & 0.17 & 0.8441 \\
\hline
\end{tabular}

Treatment $=$ ATP or ATP $+\mathrm{PCr}$ or ADP+PCr. Muscle $=$ EDL or soleus, Solution $=$ High $\mathrm{Ca}^{2+}$ or Low $\mathrm{Ca}^{2+}$ 
Table 24. Type 3 Tests of Fixed Effects for net rate change of ADP, experiment 4

\begin{tabular}{|c|c|c|c|c|}
\hline & Num & Den & $\mathrm{F}$ & \\
\hline Effect & $\mathrm{DF}$ & DF & Value & $\operatorname{Pr}>F$ \\
\hline Solution & 1 & 108 & 4.96 & 0.028 \\
\hline Treatment & 2 & 108 & 116.2 & $<.0001$ \\
\hline Muscle & 1 & 108 & 0.76 & 0.386 \\
\hline Treatment*Solution & 2 & 108 & 4.41 & 0.0145 \\
\hline Solution*Muscle & 1 & 108 & 0.35 & 0.5532 \\
\hline Treatment*Muscle & 2 & 108 & 0.88 & 0.418 \\
\hline Treatment*Solution*Muscl & 2 & 108 & 0.11 & 0.8953 \\
\hline
\end{tabular}




\section{APPENDIX IV (Experiment 4, Reliability)}

Table 25. Repeated measurements of [ATP] and [ADP] with HPLC

\begin{tabular}{ccccccccc}
$\begin{array}{c}\text { Sample \# } \\
\text { Trial \# }\end{array}$ & \multicolumn{2}{c}{$\mathbf{1}$} & \multicolumn{2}{c}{$\mathbf{2}$} & \multicolumn{2}{c}{$\mathbf{3}$} & $\mathbf{4}$ \\
[ATP] & [ADP] & [ATP] & [ADP] & [ATP] & [ADP] & [ATP] & [ADP] \\
\hline 1 & 3.838 & 0.206 & 3.187 & 0.363 & 3.395 & 0.380 & 3.914 & 0.200 \\
2 & 3.092 & 0.279 & 3.800 & 0.268 & 2.614 & 0.243 & 4.036 & 0.114 \\
3 & 3.388 & 0.248 & 3.660 & 0.216 & 3.514 & 0.282 & 3.979 & 0.180 \\
4 & - & - & - & - & - & - & 4.062 & 0.134 \\
5 & - & - & - & - & - & - & 4.003 & 0.156 \\
6 & - & - & - & - & - & - & 4.065 & 0.118 \\
\hline MEAN & 3.439 & 0.244 & 3.549 & 0.282 & 3.174 & 0.302 & 4.010 & 0.150 \\
St. Dev & 0.376 & 0.037 & 0.321 & 0.075 & 0.489 & 0.071 & 0.053 & 0.032 \\
CV (\%) & 10.9 & 15.0 & 9.1 & 26.4 & 15.4 & 23.4 & 1.3 & 21.1
\end{tabular}

MEAN CV $9.2 \quad$ ATP

MEAN CV 21.5 ADP 


\section{APPENDIX V (Raw Data)}

Experiment 1

2 ATP, EDL

\begin{tabular}{rccc}
\hline & Fmax $\left(\mathrm{kN} / \mathrm{m}^{2}\right)$ & $n_{\mathrm{H}}$ & $\mathrm{pCa} 50$ \\
\hline \hline 1 & 1.38 & 2.47 & 6.03 \\
2 & 5.25 & 2.64 & 6.18 \\
3 & 5.35 & 2.25 & 6.03 \\
4 & 2.77 & 4.74 & 6.29 \\
5 & 2.78 & 9.00 & 6.36 \\
6 & 3.17 & 3.62 & 6.35 \\
7 & 2.72 & 4.39 & 6.34 \\
\hline Mean & 3.35 & 4.16 & 6.23 \\
SEM & 0.55 & 0.89 & 0.06
\end{tabular}

\subsection{ATP, EDL}

\begin{tabular}{rccc} 
& Fmax $\left(\mathrm{kN} / \mathrm{m}^{2}\right)$ & $n_{\mathrm{H}}$ & $\mathrm{pCa}_{50}$ \\
\hline \hline 1 & 1.67 & 3.45 & 6.71 \\
2 & 1.16 & 4.48 & 7.16 \\
3 & 1.21 & 0.93 & 6.47 \\
4 & 0.34 & 1.51 & 7.28 \\
5 & 0.11 & 3.52 & 7.22 \\
6 & 0.04 & 8.03 & 7.16 \\
7 & 0.32 & 7.92 & 7.16 \\
8 & 1.52 & 5.42 & 7.11 \\
\hline Mean & 0.80 & 4.41 & 7.04 \\
SEM & 0.23 & 0.93 & 0.10
\end{tabular}

2 ATP, ADP, PCr, EDL

\begin{tabular}{rccc}
\hline & Fmax $\left(\mathrm{kN} / \mathrm{m}^{2}\right)$ & $n_{\mathrm{H}}$ & $\mathrm{pCa}{ }_{50}$ \\
\hline \hline 1 & 4.77 & 4.47 & 6.02 \\
2 & 7.30 & 6.62 & 6.09 \\
3 & 5.21 & 11.87 & 6.20 \\
4 & 1.23 & 7.28 & 6.15 \\
5 & 2.94 & 8.56 & 6.12 \\
6 & 1.50 & 3.19 & 5.96 \\
\hline Mean & 3.82 & 7.00 & 6.09 \\
SEM & 0.96 & 1.25 & 0.03
\end{tabular}


0.1 ATP, ADP, PCr, EDL

\begin{tabular}{rccc}
\hline & Fmax $\left(\mathrm{kN} / \mathrm{m}^{2}\right)$ & $n_{\mathrm{H}}$ & $\mathrm{pCa}_{50}$ \\
\hline 1 & 3.58 & 3.38 & 6.01 \\
2 & 0.79 & 3.24 & 5.52 \\
3 & 1.29 & 3.61 & 5.81 \\
4 & 5.39 & 10.30 & 6.04 \\
5 & 1.82 & 2.78 & 6.09 \\
\hline Mean & 2.58 & 4.66 & 5.89 \\
SEM & 0.85 & 1.42 & 0.11
\end{tabular}

ADP, PCr, EDL

\begin{tabular}{rccc}
\hline & Fmax $\left(\mathrm{kN} / \mathrm{m}^{2}\right)$ & $n_{\mathrm{H}}$ & $\mathrm{pCa}_{50}$ \\
\hline \hline 1 & 2.49 & 2.47 & 6.01 \\
2 & 3.33 & 15.63 & 6.13 \\
3 & 7.98 & 14.35 & 6.17 \\
4 & 6.77 & 7.67 & 6.04 \\
5 & 5.27 & 7.04 & 5.95 \\
6 & 5.38 & 5.39 & 5.76 \\
7 & 3.08 & 6.20 & 5.80 \\
8 & 1.92 & 3.65 & 6.01 \\
9 & 1.86 & 4.17 & 6.11 \\
10 & 1.51 & 2.33 & 5.98 \\
\hline Mean & 3.96 & 6.89 & 6.00 \\
SEM & 0.71 & 1.47 & 0.04
\end{tabular}

2 ATP, PCr, EDL

\begin{tabular}{rccc}
\hline & Fmax $\left(\mathrm{kN} / \mathrm{m}^{2}\right)$ & $n_{\mathrm{H}}$ & $\mathrm{pCa}_{50}$ \\
\hline \hline 1 & 5.54 & 5.47 & 6.28 \\
2 & 5.21 & 7.08 & 6.22 \\
3 & 7.29 & 7.92 & 6.19 \\
4 & 2.75 & 6.68 & 6.16 \\
5 & 1.78 & 5.92 & 6.06 \\
6 & 1.64 & 6.59 & 6.04 \\
7 & 1.43 & 4.83 & 6.08 \\
8 & 1.27 & 5.92 & 6.04 \\
\hline Mean & 3.36 & 6.30 & 6.13 \\
SEM & 0.82 & 0.34 & 0.03
\end{tabular}


0.1 ATP, PCr EDL

\begin{tabular}{rccc}
\hline & Fmax $\left(\mathrm{kN} / \mathrm{m}^{2}\right)$ & $n_{\mathrm{H}}$ & $\mathrm{pCa}_{50}$ \\
\hline \hline 1 & 3.19 & 10.13 & 6.54 \\
2 & 0.94 & 2.55 & 6.08 \\
3 & 2.88 & 2.75 & 6.00 \\
4 & 2.06 & 5.02 & 6.36 \\
5 & 6.89 & 4.18 & 6.17 \\
6 & 1.74 & 2.51 & 6.14 \\
7 & 2.40 & 13.52 & 6.10 \\
8 & 3.55 & 14.94 & 6.29 \\
9 & 4.02 & 2.59 & 5.84 \\
\hline Mean & 3.08 & 6.46 & 6.17 \\
SEM & 0.57 & 1.68 & 0.07
\end{tabular}

2 ATP, Soleus

\begin{tabular}{cccc}
\hline & Fmax $\left(\mathrm{kN} / \mathrm{m}^{2}\right)$ & $n_{\mathrm{H}}$ & $\mathrm{pCa} 50$ \\
\hline \hline 1 & 6.13 & 2.69 & 6.34 \\
2 & 2.65 & 4.42 & 6.19 \\
3 & 5.34 & 2.17 & 6.41 \\
4 & 3.43 & 2.94 & 6.74 \\
5 & 2.19 & 1.41 & 5.99 \\
6 & 0.77 & 2.03 & 6.06 \\
7 & 1.47 & 5.28 & 6.46 \\
8 & 2.08 & 1.95 & 5.91 \\
\hline Mean & 3.01 & 2.86 & 6.26 \\
SEM & 0.66 & 0.47 & 0.10
\end{tabular}

\subsection{ATP, Soleus}

\begin{tabular}{cccc}
\hline & Fmax $\left(\mathrm{kN} / \mathrm{m}^{2}\right)$ & $n_{\mathrm{H}}$ & $\mathrm{pCa}_{50}$ \\
\hline \hline 1 & 1.24 & 1.26 & 7.08 \\
2 & 4.77 & 1.72 & 6.85 \\
3 & 0.15 & 1.78 & 6.97 \\
4 & 0.33 & 1.85 & 7.39 \\
5 & 0.24 & 2.04 & 7.17 \\
6 & 1.74 & 1.15 & 7.24 \\
\hline Mean & 1.41 & 1.63 & 7.12 \\
SEM & 0.72 & 0.14 & 0.08
\end{tabular}


2 ATP, ADP, PCr, Soleus

\begin{tabular}{cccc}
\hline & Fmax $\left(\mathrm{kN} / \mathrm{m}^{2}\right)$ & $n_{\mathrm{H}}$ & $\mathrm{pCa}_{50}$ \\
\hline \hline 1 & 6.64 & 3.68 & 6.11 \\
2 & 1.29 & 3.77 & 6.00 \\
3 & 5.20 & 2.32 & 6.25 \\
4 & 3.43 & 4.12 & 6.18 \\
5 & 9.08 & 2.12 & 6.09 \\
6 & 1.69 & 2.14 & 6.07 \\
7 & 3.11 & 2.51 & 6.13 \\
8 & 3.93 & 1.45 & 5.92 \\
9 & 3.91 & 2.58 & 6.11 \\
\hline Mean & 4.25 & 2.74 & 6.09 \\
SEM & 0.81 & 0.30 & 0.03
\end{tabular}

0.1 ATP, ADP, PCr, Soleus

\begin{tabular}{cccc}
\hline & Fmax $\left(\mathrm{kN} / \mathrm{m}^{2}\right)$ & $n_{\mathrm{H}}$ & $\mathrm{pCa}_{50}$ \\
\hline \hline 1 & 0.67 & 1.92 & 5.82 \\
2 & 0.74 & 3.16 & 6.03 \\
3 & 3.37 & 2.35 & 6.13 \\
4 & 2.92 & 1.65 & 5.85 \\
5 & 1.90 & 1.59 & 5.70 \\
6 & 1.11 & 2.57 & 6.15 \\
7 & 0.58 & 2.61 & 6.05 \\
\hline Mean & 1.61 & 2.27 & 5.96 \\
SEM & 0.43 & 0.22 & 0.06
\end{tabular}

\section{ADP, PCr, Soleus}

\begin{tabular}{cccc}
\hline & Fmax $\left(\mathrm{kN} / \mathrm{m}^{2}\right)$ & $n_{\mathrm{H}}$ & $\mathrm{pCa}_{50}$ \\
\hline \hline 1 & 4.50 & 2.16 & 6.17 \\
2 & 2.95 & 2.44 & 6.25 \\
3 & 4.38 & 1.89 & 6.25 \\
4 & 2.39 & 2.55 & 6.36 \\
5 & 2.01 & 3.25 & 6.23 \\
6 & 2.16 & 1.97 & 6.02 \\
7 & 4.61 & 1.61 & 6.07 \\
8 & 1.84 & 2.46 & 6.17 \\
\hline Mean & 3.10 & 2.29 & 6.19 \\
SEM & 0.42 & 0.18 & 0.04
\end{tabular}


2 ATP, PCr, Soleus

\begin{tabular}{cccc}
\hline & Fmax $\left(\mathrm{kN} / \mathrm{m}^{2}\right)$ & $n_{\mathrm{H}}$ & $\mathrm{pCa}_{50}$ \\
\hline \hline 1 & 6.94 & 3.41 & 6.24 \\
2 & 1.94 & 1.77 & 5.82 \\
3 & 0.56 & 1.34 & 5.91 \\
4 & 0.09 & 2.15 & 6.14 \\
5 & 2.88 & 2.82 & 6.30 \\
6 & 2.34 & 2.91 & 6.26 \\
7 & 3.72 & 2.90 & 6.13 \\
\hline Mean & 2.64 & 2.47 & 6.11 \\
SEM & 0.86 & 0.28 & 0.07
\end{tabular}

\subsection{ATP, PCr Soleus}

\begin{tabular}{cccc}
\hline & Fmax $\left(\mathrm{kN} / \mathrm{m}^{2}\right)$ & $n_{\mathrm{H}}$ & $\mathrm{pCa}_{50}$ \\
\hline \hline 1 & 1.10 & 3.92 & 6.32 \\
2 & 7.51 & 3.27 & 6.62 \\
3 & 6.40 & 3.34 & 6.54 \\
4 & 0.91 & 4.37 & 6.28 \\
5 & 5.95 & 1.22 & 5.91 \\
6 & 1.70 & 1.90 & 6.17 \\
\hline Mean & 3.93 & 3.00 & 6.31 \\
SEM & 1.23 & 0.49 & 0.10
\end{tabular}


Experiment 2

2 ATP, EDL

\begin{tabular}{rcccc}
\hline \multicolumn{5}{c}{ Slope $(\boldsymbol{\mu M} / \mathbf{s e c})$} \\
\hline \multicolumn{1}{c}{$\mathbf{- P C a}$} & $\mathbf{9}$ & $\mathbf{5 . 4}$ & $\mathbf{9}$ & $\mathbf{5 . 4}$ \\
\hline \hline 1 & 93 & 307 & 20 & 69 \\
2 & 141 & 346 & 3 & 30 \\
3 & 37 & 67 & 3 & 85 \\
4 & 45 & 54 & 3 & 32 \\
5 & - & - & 18 & 29 \\
6 & - & - & 1 & 87 \\
$\mathbf{7}$ & - & - & 0 & 30 \\
Mean & 79 & 194 & 7 & 52 \\
SEM & 24 & 77 & 3 & 10
\end{tabular}

0.1 ATP, EDL

\begin{tabular}{ccccc}
\hline \multicolumn{5}{c}{ Slope $(\boldsymbol{\mu M} / \mathbf{s e c})$} \\
\hline pCa & $\mathbf{9}$ & $\mathbf{5 . 4}$ & $\mathbf{9}$ & $\mathbf{5 . 4}$ \\
\hline \hline 1 & 84 & 104 & 5 & 11 \\
2 & 4 & 7 & 0 & 8 \\
3 & 2 & 9 & 2 & 13 \\
4 & 15 & 13 & 0 & 8 \\
5 & 17 & 26 & 5 & 19 \\
6 & 8 & 9 & 3 & 36 \\
7 & 2 & 3 & - & - \\
8 & 8 & 11 & - & - \\
9 & 9 & 14 & - & - \\
Mean & 17 & 22 & 3 & 16 \\
SEM & 9 & 10 & 1 & 4
\end{tabular}

2 ATP, Soleus

\begin{tabular}{rcccc}
\hline \multicolumn{5}{c}{ Slope $(\boldsymbol{\mu M} / \mathbf{s e c})$} \\
\hline pCa & $\mathbf{9}$ & $\mathbf{5 . 4}$ & $\mathbf{9}$ & $\mathbf{5 . 4}$ \\
\hline \hline 1 & 31 & 45 & 19 & 35 \\
2 & 50 & 57 & 16 & 18 \\
3 & 32 & 29 & 14 & 19 \\
4 & 41 & 50 & 4 & 11 \\
5 & - & - & 8 & 13 \\
6 & - & - & 24 & 27 \\
7 & - & - & 8 & 22 \\
\hline Mean & 39 & 45 & 13 & 21 \\
SEM & 4 & 6 & 3 & 3
\end{tabular}

\subsection{ATP, Soleus}

\begin{tabular}{rcccc}
\hline \multicolumn{5}{c}{ Slope $(\boldsymbol{\mu M} / \mathbf{s e c})$} \\
\hline pCa & $\mathbf{9}$ & $\mathbf{5 . 4}$ & $\mathbf{9}$ & $\mathbf{+ P . 4}$ \\
\hline \hline 1 & 5 & 11 & 4 & 7 \\
2 & 9 & 8 & 1 & 3 \\
3 & 4 & 4 & 2 & 16 \\
4 & 3 & 2 & 1 & 6 \\
5 & 7 & 3 & - & - \\
6 & 6 & 6 & - & - \\
Mean & 6 & 6 & 2 & 8 \\
SEM & 1 & 1 & 1 & 3
\end{tabular}




\section{Experiment 3}

EDL

\begin{tabular}{|c|c|c|c|c|c|c|c|c|c|}
\hline \multirow{3}{*}{ [ATP] } & \multicolumn{5}{|c|}{$-\mathrm{PCr}$} & \multicolumn{4}{|c|}{$+\mathrm{PCr}$} \\
\hline & \multicolumn{5}{|c|}{$\mathbf{F} / \mathbf{F}_{(2 \mathrm{mMATP})}$} & \multicolumn{4}{|c|}{$\mathbf{F} / \mathbf{F}_{(2 \mathrm{mM} \mathrm{ATP})}$} \\
\hline & 1 & 2 & 3 & 4 & 5 & 1 & 2 & 3 & 4 \\
\hline 2.000 & 1.00 & 1.00 & 1.00 & 1.00 & 1.00 & 1.00 & 1.00 & 1.00 & 1.00 \\
\hline 1.750 & 1.03 & 1.00 & 1.02 & 1.06 & 1.03 & 0.99 & 0.97 & 1.00 & 1.00 \\
\hline 1.531 & 1.02 & 0.99 & 1.02 & 1.07 & 1.04 & 1.00 & 0.98 & 1.00 & 0.99 \\
\hline 1.340 & 1.03 & 0.99 & 1.03 & 1.09 & 1.05 & 1.00 & 1.00 & 1.01 & 0.99 \\
\hline 1.172 & 1.02 & 0.99 & 1.04 & 1.11 & 1.06 & & 1.06 & 1.01 & 1.00 \\
\hline 1.026 & 1.02 & 0.99 & 1.05 & 1.12 & 1.07 & 1.01 & 1.12 & 1.02 & 1.00 \\
\hline 0.897 & 1.02 & 0.98 & 1.05 & 1.13 & 1.07 & 1.00 & 0.99 & 1.03 & 1.00 \\
\hline 0.785 & 1.01 & 0.98 & 1.06 & 1.14 & 1.08 & 1.00 & 1.04 & 1.04 & 1.00 \\
\hline 0.687 & 1.01 & 0.98 & 1.07 & 1.15 & 1.07 & 1.05 & 0.99 & 1.04 & 1.00 \\
\hline 0.601 & 1.00 & 0.97 & 1.07 & 1.16 & 1.07 & 1.01 & 1.00 & 1.05 & 1.00 \\
\hline 0.526 & 0.99 & 0.96 & 1.08 & 1.16 & 1.07 & 1.01 & 1.05 & 1.06 & 1.01 \\
\hline 0.460 & 0.99 & 0.95 & 1.07 & 1.16 & 1.06 & 1.01 & 1.06 & 1.06 & 1.01 \\
\hline 0.403 & 0.98 & 0.94 & 1.07 & 1.16 & 1.05 & 1.01 & 1.01 & 1.07 & 1.01 \\
\hline 0.352 & 0.97 & 0.93 & 1.06 & 1.16 & 1.0 & 1.02 & 1.03 & 1.08 & 1.01 \\
\hline 0.308 & 0.96 & 0.92 & 1.06 & 1.15 & 1.04 & 1.02 & 1.03 & 1.09 & 1.01 \\
\hline 0.270 & 0.96 & 0.91 & 1.05 & 1.14 & 1.0 & 1.02 & 1.04 & 1.10 & 1.01 \\
\hline 0.236 & 0.95 & 0.90 & 1.05 & 1.14 & $1 .($ & 1.08 & 1.02 & 1.10 & 1.01 \\
\hline 0.206 & 0.94 & 0.89 & 1.04 & 1.13 & 0. & 1.02 & 1.05 & 1.11 & 1.02 \\
\hline 0.181 & 0.94 & 0.87 & 1.03 & 1.12 & 0.99 & 1.03 & 1.05 & 1.12 & 1.02 \\
\hline 0.158 & 0.93 & 0.86 & 1.02 & 1.11 & 0.98 & 1.03 & 1.06 & 1.13 & 1.03 \\
\hline 0.138 & 0.92 & 0.85 & 1.03 & 1.10 & & & 1.07 & 1.14 & 1.03 \\
\hline 0.121 & 0.91 & 0.84 & 1.01 & & & 1 & 1.07 & 1.14 & 1.03 \\
\hline 0.106 & 0.90 & 0.83 & 1.00 & 1.08 & 0.93 & 1.03 & 1.08 & 1.16 & 1.03 \\
\hline 0.093 & 0.90 & 0.82 & 0.99 & 1.07 & 0.91 & 1.03 & 1.10 & 1.18 & 1.04 \\
\hline 0.081 & 0.89 & 0.82 & 0.98 & 1.06 & 0.91 & 1.03 & 1.11 & 1.19 & 1.05 \\
\hline 0.071 & 0.88 & 0.81 & 0.98 & 1.05 & 0.90 & 1.04 & 1.12 & 1.20 & 1.04 \\
\hline 0.062 & 0.88 & 0.80 & 0.97 & & & & 1.13 & 1.21 & 1.04 \\
\hline 0.054 & 0.87 & 0.79 & 0.96 & 1.03 & 0.8 & 1.04 & 1.14 & 1.21 & 1.05 \\
\hline 0.048 & 0.86 & 0.78 & 0.95 & 1.02 & 0.88 & 1.05 & 1.15 & 1.22 & 1.05 \\
\hline 0.042 & 0.86 & 0.77 & 0.94 & 1.02 & 0.87 & 1.05 & 1.16 & 1.23 & 1.06 \\
\hline 0.036 & 0.85 & 0.77 & 0.93 & 1.01 & 0.86 & 1.06 & 1.17 & 1.24 & 1.06 \\
\hline 0.032 & 0.84 & 0.76 & 0.93 & & & 1.06 & 1.20 & 1.25 & 1.07 \\
\hline & 0.84 & 0.75 & 0.92 & & & & 1.23 & 1.27 & 1.07 \\
\hline 0.024 & 0.83 & 0.75 & 0.91 & 0.98 & 0.84 & 1.07 & 1.20 & 1.27 & 1.08 \\
\hline 0.021 & 0.83 & 0.74 & 0.90 & 0.98 & 0.84 & 1.07 & 1.22 & 1.29 & 1.08 \\
\hline 0.019 & 0.82 & 0.73 & 0.90 & 0.97 & 0.83 & 1.07 & 1.23 & 1.29 & 1.08 \\
\hline 0.016 & 0.81 & 0.73 & 0.89 & 0.96 & 0.83 & 1.07 & 1.24 & 1.29 & 1.08 \\
\hline 0.014 & 0.81 & 0.72 & 0.89 & & 0.82 & 1.08 & 1.25 & 1.29 & 1.09 \\
\hline 0.012 & 0.80 & 0.72 & 0.88 & 0.95 & 0.81 & 1.09 & 1.27 & 1.30 & 1.09 \\
\hline 0.011 & 0.80 & 0.71 & 0.88 & 0.94 & 0.81 & 1.09 & 1.27 & 1.32 & 1.10 \\
\hline 0.010 & 0.80 & 0.70 & 0.87 & 0.94 & 0.80 & 1.13 & 1.28 & 1.34 & 1.10 \\
\hline 0.008 & 0.80 & 0.70 & 0.86 & 0.93 & 0.79 & 1.09 & 1.29 & 1.36 & 1.11 \\
\hline 0.007 & 0.79 & 0.70 & 0.86 & 0.93 & 0.79 & 1.10 & 1.29 & 1.36 & 1.11 \\
\hline
\end{tabular}


EDL

\begin{tabular}{ccccccccc}
\hline & \multicolumn{3}{c}{$\mathbf{- P C r}$} & \multicolumn{5}{c}{$+\mathbf{P C r}$} \\
\hline [ATP] & \multicolumn{3}{c}{ Slope } & $(\boldsymbol{\mu} \mathbf{M} / \mathbf{s e c})$ & \multicolumn{5}{c}{ Slope $(\boldsymbol{\mu M} / \mathbf{s e c})$} \\
\hline \hline & $\mathbf{1}$ & $\mathbf{2}$ & $\mathbf{3}$ & $\mathbf{4}$ & $\mathbf{1}$ & $\mathbf{2}$ & $\mathbf{3}$ & $\mathbf{4}$ \\
2.000 & 21 & 44 & 44 & 58 & 20 & 18 & 21 & 50 \\
1.750 & 18 & 43 & 43 & 59 & 18 & 15 & 38 & 48 \\
1.531 & 22 & 44 & 44 & 58 & 22 & 17 & 35 & 48 \\
1.340 & 21 & 43 & 43 & 59 & 21 & 18 & 34 & 40 \\
1.172 & 21 & 41 & 41 & 59 & 21 & 18 & 36 & 46 \\
1.026 & 21 & 45 & 45 & 57 & 21 & 23 & 36 & 41 \\
0.897 & 19 & 41 & 41 & 58 & 19 & 17 & 33 & 40 \\
0.785 & 19 & 40 & 40 & 56 & 19 & 16 & 37 & 47 \\
0.687 & 20 & 41 & 41 & 54 & 20 & 11 & 32 & 37 \\
0.601 & 18 & 41 & 41 & 53 & 18 & 9 & 32 & 40 \\
0.526 & 18 & 46 & 46 & 52 & 18 & 9 & 32 & 38 \\
0.460 & 17 & 43 & 43 & 49 & 17 & 4 & 28 & 36 \\
0.403 & 17 & 43 & 43 & 45 & 17 & 7 & 30 & 23 \\
0.352 & 16 & 40 & 40 & 46 & 16 & 14 & 27 & 32 \\
0.308 & 16 & 40 & 40 & 44 & 16 & 12 & 25 & 28 \\
0.270 & 14 & 37 & 37 & 40 & 14 & 10 & 16 & 35 \\
0.236 & 14 & 35 & 35 & 39 & 14 & 11 & 16 & 31 \\
0.206 & 14 & 34 & 34 & 38 & 14 & 4 & 14 & 32 \\
0.181 & 11 & 34 & 34 & 34 & 11 & 9 & 12 & 30 \\
0.158 & 12 & 30 & 30 & 33 & 12 & 16 & 12 & 23 \\
0.138 & 9 & 29 & 29 & 31 & 9 & 8 & 11 & 26 \\
0.121 & 9 & 28 & 28 & 30 & 9 & 8 & 7 & 28 \\
0.106 & 10 & 24 & 24 & 28 & 10 & 5 & 10 & 25 \\
0.093 & 9 & 23 & 23 & 25 & 9 & 7 & 7 & 12 \\
0.081 & 8 & 21 & 21 & 24 & 8 & 1 & 9 & 24 \\
0.071 & 7 & 19 & 19 & 22 & 7 & 3 & 6 & 19 \\
0.062 & 6 & 22 & 22 & 21 & 6 & 6 & 4 & 17 \\
0.054 & 6 & 20 & 20 & 20 & 6 & 5 & 4 & 18 \\
0.048 & 6 & 20 & 20 & 16 & 6 & 3 & 3 & 13 \\
0.042 & 5 & 15 & 15 & 16 & 5 & 5 & 6 & 13 \\
0.036 & 5 & 15 & 15 & 14 & 5 & 2 & 3 & 16 \\
0.032 & 4 & 13 & 13 & 15 & 4 & 0 & 5 & 17 \\
0.028 & 4 & 13 & 13 & 12 & 4 & 2 & 5 & 13 \\
0.024 & 3 & 11 & 11 & 12 & 3 & - & 5 & 15 \\
0.021 & 3 & 11 & 11 & 11 & 3 & - & 4 & 9 \\
0.019 & 3 & 11 & 11 & 9 & 3 & 3 & 4 & - \\
0.016 & 1 & 10 & 10 & 11 & 1 & - & 2 & 7 \\
0.014 & 2 & 8 & 8 & 9 & 2 & - & 3 & 6 \\
0.012 & 2 & 8 & 8 & 7 & 2 & - & 2 & 10 \\
0.011 & 2 & 8 & 8 & 6 & 2 & - & 0 & 10 \\
0.010 & 2 & 10 & 10 & 7 & 2 & - & 2 & 5 \\
0.008 & 1 & 7 & 7 & 4 & 1 & - & - & 4 \\
0.007 & 0 & 5 & 5 & 5 & 0 & - & 3 & 5 \\
\hline & & & & & & & &
\end{tabular}


Soleus

\begin{tabular}{|c|c|c|c|c|c|c|c|c|}
\hline & \multicolumn{4}{|c|}{$-\mathrm{PCr}$} & \multicolumn{4}{|c|}{$+\mathrm{PCr}$} \\
\hline \multirow[t]{2}{*}{ [ATP] } & \multicolumn{4}{|c|}{$\mathbf{F} / \mathbf{F}_{(2 \mathrm{mM} \mathrm{ATP})}$} & \multicolumn{4}{|c|}{$\mathbf{F} / \mathbf{F}_{(2 \mathrm{mM} \mathrm{ATP})}$} \\
\hline & 1 & 2 & 3 & 4 & 1 & 2 & 3 & 4 \\
\hline 2.000 & 1.00 & 1.00 & 1.00 & 1.00 & 1.00 & 1.00 & 1.00 & 1.00 \\
\hline 1.750 & 0.96 & 0.98 & 1.00 & 1.00 & 1.00 & 1.01 & 1.00 & 1.05 \\
\hline 1.531 & 0.94 & 0.98 & 0.99 & 1.00 & 1.01 & 1.01 & 0.99 & 1.06 \\
\hline 1.340 & 0.93 & 0.99 & 0.99 & 1.00 & 1.01 & 1.04 & 1.00 & 1.08 \\
\hline 1.172 & 0.94 & 0.99 & 1.00 & 1.00 & 1.01 & 1.02 & 0.99 & 1.08 \\
\hline 1.026 & 0.92 & 1.00 & 1.00 & 0.98 & 1.01 & 1.03 & 0.99 & 1.09 \\
\hline 0.897 & 0.92 & 1.00 & 0.99 & 0.97 & 1.01 & 1.02 & 0.99 & 1.10 \\
\hline 0.785 & 0.91 & 1.00 & 0.99 & 0.96 & 1.02 & 1.01 & 0.99 & 1.11 \\
\hline 0.687 & 0.90 & 0.99 & 0.98 & 0.95 & 1.03 & 1.02 & 0.99 & 1.12 \\
\hline 0.601 & 0.90 & 1.00 & 0.98 & 0.93 & 1.03 & 1.02 & 0.99 & 1.13 \\
\hline 0.526 & 0.88 & 1.00 & 0.97 & 0.92 & 1.03 & 1.00 & 1.00 & 1.14 \\
\hline 0.460 & 0.86 & 1.00 & 0.96 & 0.91 & 1.03 & 0.94 & 0.99 & 1.16 \\
\hline 0.403 & 0.85 & 0.98 & 0.96 & 0.90 & 1.03 & 1.03 & 1.00 & 1.16 \\
\hline 0.352 & 0.84 & 0.96 & 0.95 & 0.90 & 1.04 & 1.06 & 1.00 & 1.17 \\
\hline 0.308 & 0.82 & 0.98 & 0.95 & 0.88 & 1.04 & 1.06 & 1.00 & 1.18 \\
\hline 0.270 & 0.81 & 0.96 & 0.94 & 0.87 & 1.04 & 1.07 & 1.00 & 1.19 \\
\hline 0.236 & 0.79 & 0.95 & 0.94 & 0.86 & 1.04 & 1.08 & 1.00 & 1.20 \\
\hline 0.206 & 0.78 & 0.93 & 0.93 & 0.85 & 1.04 & 1.09 & 1.00 & 1.20 \\
\hline 0.181 & 0.75 & 0.93 & 0.92 & 0.84 & 1.05 & 1.09 & 1.00 & 1.21 \\
\hline 0.158 & 0.74 & 0.91 & 0.92 & 0.82 & 1.05 & 1.10 & 1.00 & 1.22 \\
\hline 0.138 & 0.72 & 0.89 & 0.91 & 0.81 & 1.05 & 1.11 & 1.00 & 1.22 \\
\hline 0.121 & 0.70 & 0.84 & 0.90 & 0.80 & 1.05 & 1.11 & 1.00 & 1.22 \\
\hline 0.106 & 0.69 & 0.87 & 0.90 & 0.79 & 1.05 & 1.12 & 1.01 & 1.23 \\
\hline 0.093 & 0.67 & 0.84 & 0.90 & 0.78 & 1.06 & 1.12 & 1.00 & 1.23 \\
\hline 0.081 & 0.65 & 0.82 & 0.90 & 0.77 & 1.06 & 1.13 & 1.00 & 1.24 \\
\hline 0.071 & 0.63 & 0.80 & 0.88 & 0.76 & 1.06 & 1.14 & 1.01 & 1.24 \\
\hline 0.062 & 0.62 & 0.79 & 0.88 & 0.75 & 1.06 & 1.14 & 1.00 & 1.25 \\
\hline 0.054 & 0.60 & 0.75 & 0.87 & 0.74 & 1.06 & 1.15 & 1.00 & 1.25 \\
\hline 0.048 & 0.59 & 0.73 & 0.92 & 0.73 & 1.06 & 1.16 & 1.00 & 1.26 \\
\hline 0.042 & 0.57 & 0.70 & 0.86 & 0.72 & 1.07 & 1.17 & 1.01 & 1.26 \\
\hline 0.036 & 0.55 & 0.68 & 0.86 & 0.72 & 1.07 & 1.17 & 1.00 & 1.27 \\
\hline 0.032 & 0.54 & 0.65 & 0.85 & 0.71 & 1.07 & 1.17 & 1.01 & 1.27 \\
\hline 0.028 & 0.52 & 0.63 & 0.85 & 0.70 & 1.07 & 1.19 & 1.00 & 1.27 \\
\hline 0.024 & 0.51 & 0.59 & 0.84 & 0.69 & 1.08 & 1.19 & 1.00 & 1.27 \\
\hline 0.021 & 0.49 & 0.58 & 0.84 & 0.68 & 1.08 & 1.19 & 1.01 & 1.27 \\
\hline 0.019 & 0.48 & 0.54 & 0.83 & 0.67 & 1.08 & 1.20 & 1.00 & 1.28 \\
\hline 0.016 & 0.46 & 0.50 & 0.85 & 0.67 & 1.08 & 1.21 & 1.00 & 1.27 \\
\hline 0.014 & 0.45 & 0.48 & 0.81 & 0.66 & 1.08 & 1.23 & 1.00 & 1.27 \\
\hline 0.012 & 0.44 & 0.48 & 0.81 & 0.65 & 1.09 & 1.22 & 1.00 & 1.27 \\
\hline 0.011 & 0.43 & 0.45 & 0.81 & 0.65 & 1.09 & 1.23 & 1.01 & 1.27 \\
\hline 0.010 & 0.41 & 0.44 & 0.80 & 0.64 & 1.09 & 1.23 & 1.00 & 1.28 \\
\hline 0.008 & 0.41 & 0.43 & 0.80 & 0.63 & 1.10 & 1.37 & 1.00 & 1.28 \\
\hline 0.007 & 0.40 & 0.42 & 0.88 & 0.64 & 1.10 & 1.33 & 1.01 & 1.29 \\
\hline
\end{tabular}


Soleus

\begin{tabular}{cccccccc}
\hline & \multicolumn{4}{c}{$\mathbf{c}$-PCr } & \multicolumn{3}{c}{$+\mathbf{P C r}$} \\
\hline [ATP] & \multicolumn{3}{c}{ Slope $(\boldsymbol{\mu M} / \mathbf{s e c})$} & \multicolumn{3}{c}{ Slope $(\boldsymbol{\mu M} / \mathbf{s e c})$} \\
\hline \hline & $\mathbf{1}$ & $\mathbf{2}$ & $\mathbf{3}$ & $\mathbf{4}$ & $\mathbf{1}$ & $\mathbf{2}$ & $\mathbf{3}$ \\
2.000 & 19 & 29 & 46 & 20 & 18 & 11 & 19 \\
1.750 & 28 & 29 & 45 & 21 & 16 & 10 & 18 \\
1.531 & 24 & 28 & 45 & 20 & 16 & 13 & 31 \\
1.340 & 33 & 29 & 44 & 22 & 16 & 11 & 13 \\
1.172 & 35 & 26 & 46 & 21 & 17 & 13 & 25 \\
1.026 & 33 & 30 & 44 & 21 & 16 & 11 & 26 \\
0.897 & 35 & 27 & 43 & 20 & 15 & 12 & 22 \\
0.785 & 31 & 26 & 42 & 20 & 14 & 11 & 11 \\
0.687 & 32 & 26 & 44 & 18 & 13 & 12 & 12 \\
0.601 & 34 & 24 & 39 & 20 & 13 & 11 & 19 \\
0.526 & 31 & 25 & 38 & 18 & 12 & 11 & 9 \\
0.460 & 30 & 21 & 37 & 16 & 10 & 10 & 21 \\
0.403 & 31 & 21 & 35 & 17 & 11 & 9 & 18 \\
0.352 & 29 & 20 & 33 & 21 & 10 & 7 & 1 \\
0.308 & 27 & 20 & 30 & 21 & 8 & 8 & 18 \\
0.270 & 26 & 19 & 31 & 21 & 8 & 9 & 16 \\
0.236 & 26 & 16 & 31 & 19 & 8 & 6 & 21 \\
0.206 & 27 & 15 & 29 & 19 & 8 & 6 & 27 \\
0.181 & 22 & 14 & 27 & 18 & 7 & 7 & 18 \\
0.158 & 27 & 14 & 27 & 18 & 7 & 6 & 7 \\
0.138 & 22 & 11 & 27 & 17 & 4 & 6 & 20 \\
0.121 & 21 & 13 & 23 & 16 & 5 & 5 & 20 \\
0.106 & 22 & 9 & 21 & 15 & 5 & 4 & 5 \\
0.093 & 21 & 8 & 19 & 15 & 4 & 5 & 24 \\
0.081 & 16 & 9 & 21 & 16 & 5 & 6 & 17 \\
0.071 & 18 & 10 & 19 & 15 & 3 & 4 & 9 \\
0.062 & 19 & 6 & 17 & 14 & 4 & 4 & 8 \\
0.054 & 18 & 8 & 16 & 13 & 3 & 4 & 12 \\
0.048 & 17 & 7 & 14 & 13 & 2 & 4 & 10 \\
0.042 & 15 & 7 & 14 & 12 & 3 & 2 & 7 \\
0.036 & 16 & 4 & 16 & 14 & 3 & 2 & 5 \\
0.032 & 15 & 5 & 11 & 12 & 2 & 2 & 7 \\
0.028 & 14 & 5 & 10 & 12 & 2 & 3 & 4 \\
0.024 & 12 & 4 & 11 & 11 & 1 & 3 & 5 \\
0.021 & 14 & 3 & 10 & 10 & 2 & 4 & 0 \\
0.019 & 9 & 3 & 9 & 11 & 3 & 2 & 0 \\
0.016 & 13 & 2 & 8 & 10 & 2 & 2 & 5 \\
0.014 & 11 & 0 & 6 & 10 & 2 & 3 & 1 \\
0.012 & 13 & 2 & 7 & 10 & 0 & 1 & 0 \\
0.011 & 10 & 2 & 4 & 11 & 1 & 1 & 2 \\
0.010 & 10 & 2 & 5 & 9 & 1 & 1 & 0 \\
0.008 & 11 & 2 & 3 & 9 & 2 & 0 & 0 \\
0.007 & 12 & 0 & 1 & 13 & 1 & 1 & 1 \\
\hline & & & & & & & \\
\hline
\end{tabular}


Experiment 4

ATP. EDL

\begin{tabular}{rcccccccc}
\hline \multicolumn{1}{c}{$\mathbf{p C a} 9.0$} \\
\hline & $\begin{array}{r}\text { [ATP] } \\
(\mathbf{m M})\end{array}$ & $\begin{array}{c}\text { [ADP] } \\
\text { [ATP] } \\
(\boldsymbol{\mu M} / \mathbf{m g} \text { wet weight })\end{array}$ & $\begin{array}{c}\text { [ADP] } \\
\text { [ATP] } \\
(\mathbf{m M})\end{array}$ & $\begin{array}{c}\text { [ADP] } \\
\text { [ATP] } \\
(\boldsymbol{\mu M} / \mathbf{m g} \text { wet weight })\end{array}$ \\
\hline \hline 1 & 6.62 & 0.82 & 344.9 & 42.9 & 3.53 & 0.23 & 184.0 & 11.9 \\
2 & 3.44 & 0.44 & 111.4 & 14.2 & 3.60 & 0.28 & 116.3 & 9.0 \\
3 & 0.13 & 0.01 & 5.0 & 0.5 & 3.39 & 0.28 & 131.6 & 10.9 \\
4 & 3.96 & 0.14 & 115.1 & 4.1 & 3.59 & 0.32 & 104.5 & 9.2 \\
5 & 3.76 & 0.53 & 175.1 & 24.8 & 3.43 & 0.39 & 159.4 & 18.1 \\
6 & 4.14 & 0.19 & 265.1 & 12.4 & 3.79 & 0.18 & 242.9 & 11.8 \\
7 & 3.94 & 0.18 & 152.0 & 7.0 & 3.33 & 0.33 & 128.5 & 12.6 \\
8 & 3.38 & 0.47 & 95.7 & 13.3 & 3.78 & 0.20 & 107.2 & 5.5 \\
9 & 4.03 & 0.16 & 202.6 & 8.2 & 3.09 & 0.61 & 155.1 & 30.4 \\
10 & 3.79 & 0.36 & 105.5 & 10.0 & 3.89 & 0.26 & 108.3 & 7.3 \\
\hline Mean & 3.72 & 0.33 & 157.2 & 13.7 & 3.54 & 0.31 & 143.8 & 12.7 \\
SEM & 0.49 & 0.08 & 30.3 & 3.9 & 0.08 & 0.04 & 13.8 & 2.2
\end{tabular}

ATP, PCr. EDL

\begin{tabular}{|c|c|c|c|c|c|c|c|c|}
\hline & \multicolumn{4}{|c|}{ pCa 9.0 } & \multicolumn{4}{|c|}{ pCa 4.0} \\
\hline & [ATP] & [ADP] & [ATP] & [ADP] & [ATP] & [ADP] & [ATP] & [ADP] \\
\hline & \multicolumn{2}{|c|}{$(\mathbf{m M})$} & \multicolumn{2}{|c|}{$(\mu \mathrm{M} / \mathrm{mg}$ wet weight $)$} & \multicolumn{2}{|c|}{$(\mathrm{mM})$} & \multicolumn{2}{|c|}{ ( $\mu \mathrm{M} / \mathrm{mg}$ wet weight) } \\
\hline 1 & 3.38 & 0.03 & 175.9 & 1.6 & 3.71 & 0.04 & 193.2 & 1.9 \\
\hline 2 & 3.71 & 0.05 & 120.0 & 1.5 & 3.47 & 0.01 & 112.3 & 0.4 \\
\hline 3 & 3.46 & 0.04 & 134.3 & 1.6 & 3.34 & 0.04 & 129.6 & 1.7 \\
\hline 4 & 3.64 & 0.04 & 105.7 & 1.2 & 3.38 & 0.06 & 98.4 & 1.8 \\
\hline 5 & 4.25 & 0.05 & 197.5 & 2.2 & 3.63 & 0.03 & 168.9 & 1.2 \\
\hline 6 & 3.89 & 0.04 & 249.1 & 2.8 & 3.49 & 0.04 & 223.8 & 2.4 \\
\hline 7 & 2.87 & 0.03 & 110.9 & 1.0 & 3.42 & 0.04 & 132.0 & 1.5 \\
\hline 8 & 4.48 & 0.06 & 126.8 & 1.6 & 3.65 & 0.02 & 103.5 & 0.5 \\
\hline 9 & 3.21 & 0.01 & 161.5 & 0.5 & 3.31 & 0.04 & 166.2 & 2.0 \\
\hline 10 & 3.76 & 0.05 & 104.8 & 1.4 & 3.68 & 0.03 & 102.6 & 0.8 \\
\hline Mean & 3.66 & 0.04 & 148.6 & 1.5 & 0.78 & 0.65 & 31.1 & 27.9 \\
\hline SEM & 0.15 & 0.00 & 14.9 & 0.2 & 0.13 & 0.17 & 5.5 & 8.9 \\
\hline
\end{tabular}


ADP, PCr. EDL

pCa 9.0

pCa 4.0

\begin{tabular}{|c|c|c|c|c|c|c|c|c|}
\hline & [ATP] & [ADP] & [ATP] & [ADP] & [ATP] & [ADP] & [ATP] & [ADP] \\
\hline & \multicolumn{2}{|c|}{$(\mathbf{m M})$} & \multicolumn{2}{|c|}{ ( $\mu \mathrm{M} / \mathrm{mg}$ wet weight) } & \multicolumn{2}{|c|}{$(\mathbf{m M})$} & \multicolumn{2}{|c|}{ ( $\mu \mathrm{M} /$ mg wet weight) } \\
\hline 1 & 0.36 & 1.23 & 18.6 & 63.9 & 0.68 & 0.64 & 35.4 & 33.4 \\
\hline 2 & 0.58 & 0.78 & 18.7 & 25.2 & 0.60 & 0.47 & 19.4 & 15.2 \\
\hline 3 & 0.72 & 0.63 & 27.9 & 24.3 & 0.44 & 1.07 & 17.1 & 41.4 \\
\hline 4 & 0.51 & 1.02 & 14.8 & 29.8 & 0.70 & 0.54 & 20.4 & 15.7 \\
\hline 5 & 0.33 & 1.52 & 15.5 & 70.8 & 1.12 & 0.23 & 52.0 & 10.5 \\
\hline 6 & 0.69 & 0.63 & 44.0 & 40.4 & 0.27 & 1.51 & 17.2 & 96.9 \\
\hline 7 & 0.33 & 1.40 & 12.6 & 54.0 & 0.87 & 0.55 & 33.6 & 21.1 \\
\hline 8 & 0.74 & 0.64 & 21.0 & 18.0 & 0.36 & 1.42 & 10.2 & 40.3 \\
\hline 9 & 0.27 & 1.41 & 13.5 & 71.0 & 1.27 & 0.08 & 63.9 & 4.2 \\
\hline 10 & 0.75 & 0.70 & 21.0 & 19.5 & 1.52 & 0.00 & 42.3 & 0.0 \\
\hline Mean & 0.53 & 1.00 & 20.8 & 41.7 & 3.51 & 0.03 & 143.0 & 1.4 \\
\hline SEM & 0.06 & 0.12 & 2.9 & 6.8 & 0.05 & 0.004 & 13.6 & 0.2 \\
\hline
\end{tabular}


ATP. Soleus

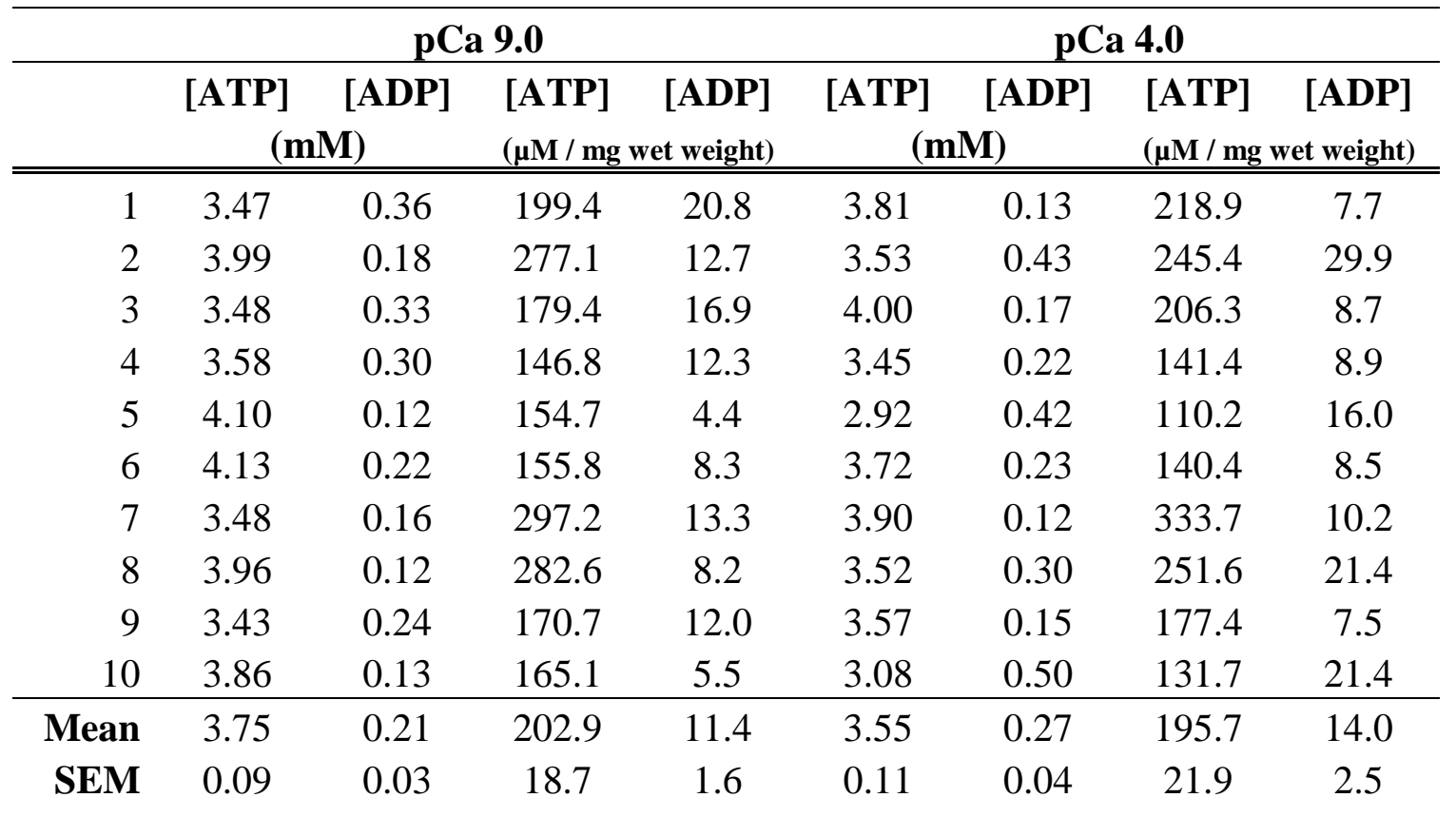

ATP, PCr. Soleus

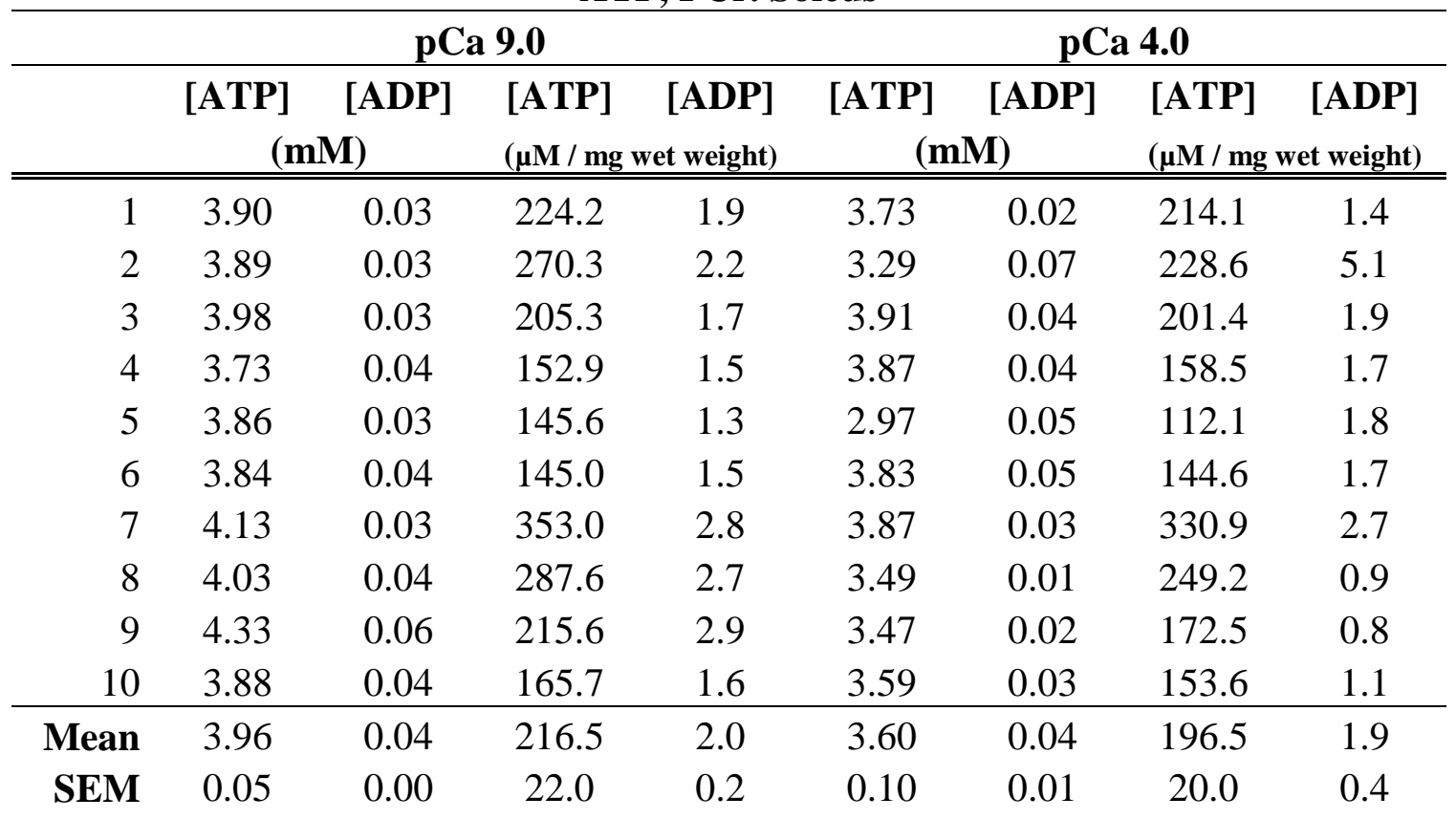


ADP, PCr. Soleus

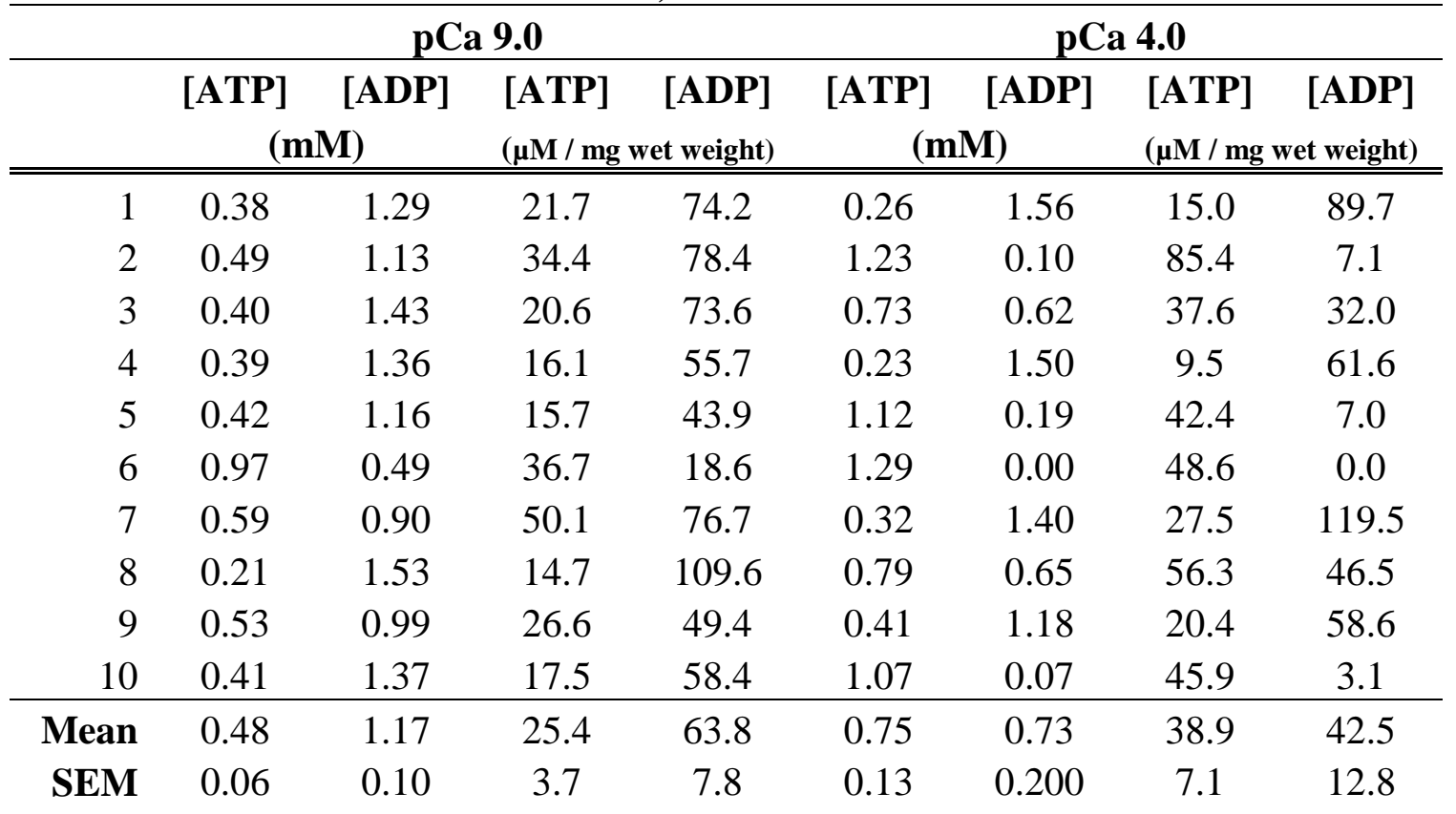

